\author{
UNIVERSIDADE DE SÃO PAULO \\ FACULDADE DE CIÊNCIAS FARMACÊUTICAS DE RIBEIRÃO PRETO
}

Administração de dehidroepiandrosterona (DHEA) como mediador da resposta imune em ratos Wistar infectados com Trypanosoma cruzi submetidos ao estresse repetitivo. 


\author{
UNIVERSIDADE DE SÃO PAULO \\ FACULDADE DE CIÊNCIAS FARMACÊUTICAS DE RIBEIRÃO PRETO
}

\title{
Administração de dehidroepiandrosterona (DHEA) como mediador da resposta imune em ratos Wistar infectados com \\ Trypanosoma cruzi submetidos ao estresse repetitivo.
}

Tese de Doutorado apresentada ao Programa de Pós-Graduação em Biociências Aplicadas à

Farmácia para obtenção do Título de Doutor em Biociências Aplicadas Á Farmácia

Área de Concentração: Biociências Aplicadas à Farmácia.

Orientada: Leony Cristina Caetano

Orientador: Prof. Dr. José Clóvis do Prado Júnior

Ribeirão Preto 
AUTORIZO A REPRODUÇÃO E DIVULGAÇÃO TOTAL OU PARCIAL DESTE TRABALHO, POR QUALQUER MEIO CONVENCIONAL OU ELETRÔNICO, PARA FINS DE ESTUDO E PESQUISA, DESDE QUE CITADA A FONTE.

FICHA CATALOGRÁFICA

Caetano, Leony Cristina

Administração de Dehidroepiandrosterona (DHEA) como mediador da resposta imune em ratos Wistar infectados com Trypanosoma cruzi submetidos ao estresse repetitivo. Ribeirão Preto, 2009.

109p.: il.; $30 \mathrm{~cm}$.

Tese de Doutorado, apresentada à Faculdade de Ciências Farmacêuticas de Ribeirão Preto/USP- Área de concentração: Biociências Aplicadas à Farmácia.

Orientador: do Prado Júnior, José Clóvis.

1. Trypanosoma cruzi. 2. Dehidroepiandrosterona. 3. Estresse repetitivo. 


\section{FOLHA DE APROVAÇÃO}

Autor: Leony Cristina Caetano

Título: Administração de dehidroepiandrosterona (DHEA) como mediador da resposta imune em ratos Wistar infectados com Trypanosoma cruzi submetidos ao estresse repetitivo.

Tese de Doutorado apresentada ao Programa de PósGraduação em Biociências Aplicadas à Farmácia para obtenção do Título de Doutor em Biociências Aplicadas à Farmácia

Área de Concentração: Biociências Aplicadas à Farmácia.

Orientador: Prof. Dr. José Clóvis do prado Júnior.

Aprovado em:______

Banca Examinadora

Prof.(a) Dr.(a).

Instituição:

Assinatura:

Prof.(a) Dr.(a).

Instituição:

Assinatura:

Prof.(a) Dr.(a).

Instituição:

Assinatura:

Prof.(a) Dr.(a).

Instituição:

Assinatura:

Prof.(a) Dr.(a).

Instituição: Assinatura: 


\section{OP ODeus...}

"Passo todas as coisas naquele que me fortalece (Filipenses 4.13)

\section{OAos meus Opais}

A quem deva a minha vida, exemplos de dignidade, respeito, perseveransa, amor e carinho.

\section{Mos meus irmãos}

Qluana e Fair pelas alegrias, incentivo, carinho e amor.

A minha cunhada Pusana e minha sobrinha Yelena pela incentiva.

Ha meu Cespasa

Quiz. Henrique pela sua compreensão, cumplicidade, paciência e dedicas̃ão. 


\section{AGRADECIMENTOS}

Ao Prof. Dr. José Clóvis do Prado Júnior pela oportunidade e confiança a mim depositada. Sua alegria e incentivo foram fundamentais no desenvolvimento deste trabalho...

Muito obrigada!

Aos funcionários do laboratório: Miriam Paula Alonso Toldo, Maria Antônia (Toninha) e Georgius pela ajuda oferecida.

Às amigas, Fabricia Helena Santello, Marina Del Vecchio Filipin e Vânia Brazão, pósgraduandas do laboratório de parasitologia, colaboradoras deste trabalho, cuja competência, sabedoria, incentivo e carinho foram imprescindíveis.

À Luana Naiara Caetano pela disposição sempre demonstrada em colaborar com os experimentos.

Aos docentes de Parasitologia da FCFRP-USP pela constante colaboração durante a realização deste trabalho.

Aos técnicos do laboratório de Parasitologia, Maria Antônia (Toninha) e Georgius pela ajuda oferecida.

À Miriam Paula Alonso Toldo, técnica do laboratório de parasitologia, pela amizade e colaboração. 
Ao docente e suas técnicas do laboratório de Patologia da FMRP-USP, pela grande colaboração na confecção das lâminas histológicas.

Às funcionárias da FCFRP-USP: Aline Carolina Lemos, Maraísa Palhão Vérri, Stella Felippe de Freitas, Regina de Albuquerque, Vânia Claúdia de Albuquerque e Wânia Maria Tavares da Silva.

Aos colegas do laboratório de Parasitologia da FCFRP-USP, agradeço a todos sem exceção.

Aos Funcionários do serviço de pós-graduação, agradeço a todos pela colaboração.

Aos animais utilizados nos experimentos cuja colaboração involuntária foi essencial.

À CAPES pela concessão de bolsa de doutorado e a Faculdade de Ciências Farmacêuticas de Ribeirão Preto-USP pela oportunidade de realização do curso de doutorado.

À FAPESP pela concessão do projeto de pesquisa, para que o mesmo pudesse ser realizado.

Meus sinceros agradecimentos a todos que colaboraram direta ou indiretamente para a realização deste trabalho. 


\section{SUMÁRIO}

Resumo

Abstract

Lista de Figuras

Lista de Tabelas

Lista de Abreviaturas

1.

1.1

INTRODUÇÃO-

i

1.2

Doença de Chagas e resposta imune---------------------------------- 1

1.3

1.4

1.5

Patologia dos Megas-

Dehidroepiandrosterona (DHEA)

2.

Estresse-

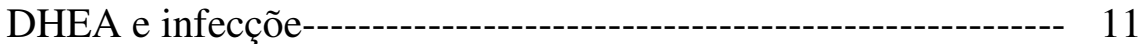

3.

JUSTIFICATIVA -

OBJETIVOS

4.

4.1 .

4.2.

MATERIAL

Animais------------------------------------------------------------------ 16

4.3 .

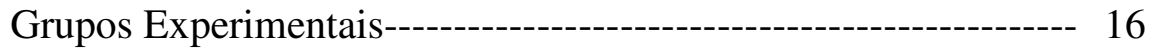

4.4 .

Parasitas---------------------------------------------------------------------- 17

4.5 .

4.6.

4.7 .

Infecção-

Suplementação com DHEA ------------------------------------ 18

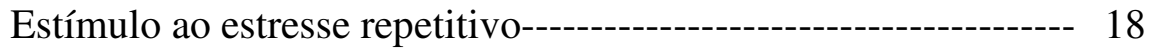

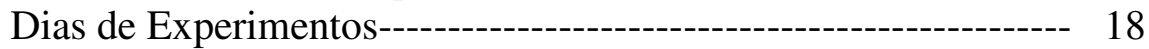

4.8 .

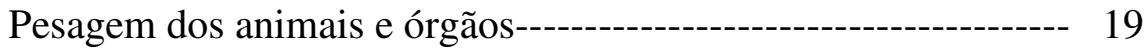

4.9 .

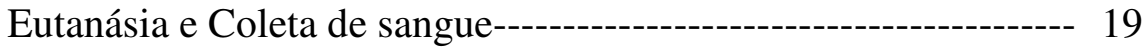

4.10.

Contagem de macrófagos peritoniais

Preparação da suspensão de células peritoneais e dosagem de 20

4.12 . Óxido Nítrico

4.13 .

Linfoproliferação

Técnica histológica----------------------------------------------------- 22

4.14 .

Intensidade do parasitismo tecidual-

4.15 .

4.16 .

Determinação da concentração das citocinas - IL-2, IL-4, Il-10, 22

TNF- $\alpha$, e IFN- $\gamma$ -

4.17 .

Corticosterona-

Quantificação de neurônios------------------------------------------- 24

4.18 .

4.19 .

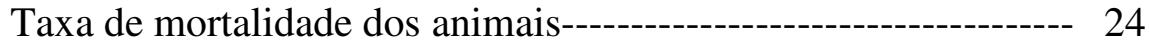

5.

Análises Estatísticas------------------------------------------------------ 24

5.1.

5.2 .

RESULTADOS-

Taxa de mortalidade dos animais ---------------------------------- 26

5.3 .

Peso Corpóreo

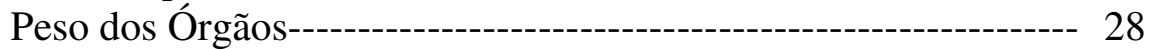

5.4 .

Parasitemia-

5.5 .

Contagem Global de macrófagos peritoniais-

Linfoproliferação

5.7.

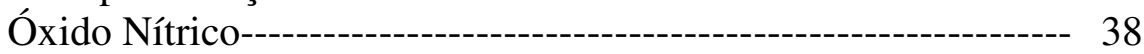

5.8 .

Dosagem de IL-2 
5.10 .

5.11 .

5.12 .

5.13 .

5.14 .

5.15 .

5.16 .

5.17 .

5.18 .

5.19 .

6.

7.

8.

ANEXOS ANEXO A ANEXO B

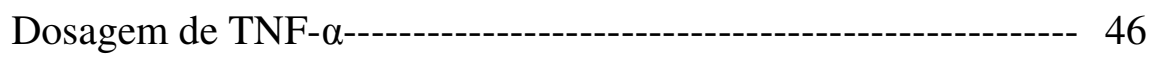

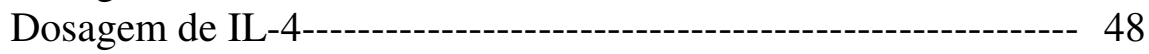

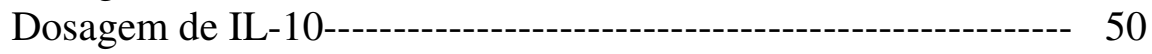

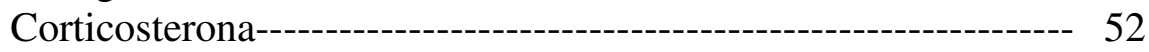

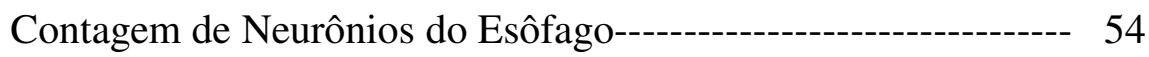

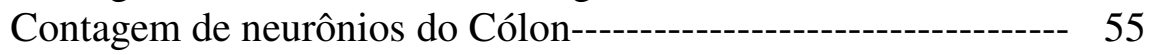

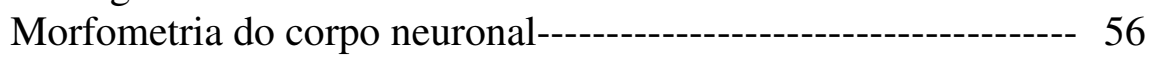

Parasitismo Tecidual do Coração---------------------------------- 64

Análise Cariométrica----o----- 65

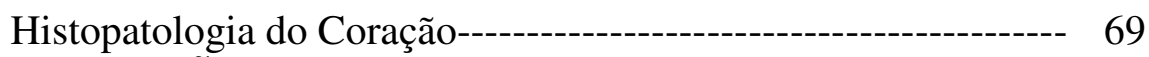

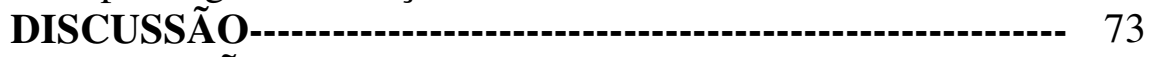

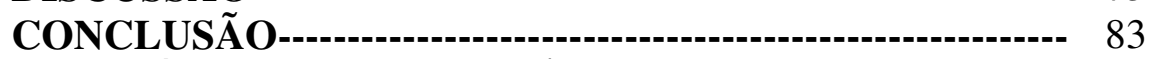

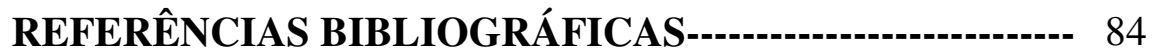




\section{RESUMO}

CAETANO, LEONY CRISTINA. Administração de deidroepiandrosterona (DHEA) como mediador da resposta imune em ratos jovens e senis infectados com Trypanosoma cruzi submetidos ao estresse repetitivo. 2009. Faculdade de Ciências Farmacêuticas de Ribeirão Preto, Universidade de São Paulo, Ribeirão Preto.

A doença de Chagas representa um importante problema para a Saúde Publica na América Latina, onde o tratamento é limitado principalmente na fase crônica. Mesmo controlando a replicação parasitária, a completa eliminação do parasita e a cura da doença não são observadas de forma consistente. A ativação do eixo adrenal-hipotálamo-hipófise possui um papel importante na supressão do sistema imune. Neste trabalho foram observados os efeitos do estresse repetitivo em ratos Wistar infectados com a cepa Y de Trypanosoma cruzi durante as fases aguda e crônica da doença experimental, através da exposição dos animais a vapores de éter por um minuto duas vezes ao dia. O estresse repetitivo provocou aumento do número de parasitas e a administração de DHEA reduziu significantemente a parasitemia durante a fase aguda. A resposta TH-1 foi mais vigorosa em animais submetidos à terapia com DHEA mesmo quando submetidos ao estresse repetitivo. Assim TNF- $\alpha$, IFN- $\gamma$, IL-2, NO e linfoproliferação mostraram concentrações mais elevadas quando comparadas aos animais não submetidos à terapia. A resposta TH-2 nos grupos sem suplementação com DHEA, IL-4 e IL-10 apresentaram valores reduzidos nos animais infectados e estressados submetidos à terapia com DHEA. A concentração de corticosterona mostrou-se elevada para animais estressados e infectados em relação aos animais submetidos a terapia com DHEA. A histopatologia apresentou redução no número de neurônios nas fases aguda e crônica para os animais estressados e infectados, os mesmos apresentaram desorganização tecidual cardíaca com aumento do número de ninhos de amastigotas e moderado processo inflamatório por células mononucleares. Estes resultados sugerem que o estresse repetitivo pode ser considerado como 
fator importante durante o desenvolvimento da doença de Chagas experimental, aumentando sua patogênese através de distúrbios do sistema imune do hospedeiro.

Palavras Chaves: Trypanosoma cruzi, DHEA, estresse repetitivo, resposta imune, ratos. 


\begin{abstract}
CAETANO, LEONY CRISTINA. Administration of the dehidroepiandrosterone (DHEA) as mediador of the immune response in Young and ageing rats infected with Trypanosoma cruzi submitted to repetitive stress. 2009. Faculdade de Ciências Farmacêuticas de Ribeirão Preto, Universidade de São Paulo, Ribeirão Preto.
\end{abstract}

Chagas' disease represents an important public health problem in Latin American, where the treatment is limited especially to chronic phase, besides the harmful side effects. Although controlling the parasite replication, the complete elimination of the etiologic agent still was not observed. Activation of the hypothalamus-pituitary-adrenal axis plays a major role in the suppression of the immune system. We have investigated the effects of repetitive stress on Wistar rats infected with the Y strain of Trypanosoma cruzi during the acute and chronic phases of the experimental disease by the exposure to ether vapor for one minute twice a day. Repetitive stress resulted in an elevated number of circulating parasites and DHEA administration reduced significantly blood parasites during the acute phase. Several immunological parameters were evaluated. TH-1 response was more vigorous in animals submitted to DHEA therapy even those which underwent repetitive stress. So, TNF- $\alpha$, IFN- $\gamma$, IL-2, NO and lymphoproliferation displayed enhanced concentrations as compared to unsupplied animals. The TH-2 immune response in groups without DHEA supplementation, showed reduce values for IL-4 and IL-10 in groups infected and stressed submitted to DHEA therapy. Enhanced corticosterone concentration was a observed for infected and stressed animals. DHEA triggered reduced levels of corticosterone. The histopathology revealed that stressed animals showed a reduction in the number of neurons. Histological sections of heart smears from infected and stressed animals displayed deep tissue disorganization, increased parasite burdens and moderate diffused mononuclear inflammatory process. These results suggest that repetitive stress could be considered an 
important factor during development of experimental Chagas' disease, enhancing pathogenesis through disturbance of the host's immune system.

Key words: Trypanosoma cruzi, DHEA, repetitive stress, immune response, rats. 


\section{LISTA DE FIGURAS}

Figura 1. Peso corpóreo de ratos Wistar machos controles no $7^{\circ}, 14^{\circ}, 21^{\circ}$ e $180^{\circ}$ dias, dos seguintes grupos: Controle (C); Controle tratado com DHEA (D); Controle submetido ao estresse (E); Controle submetido ao estresse e tratado com DHEA (ED)...................................................26

Figure 2. Peso corpóreo de ratos Wistar machos infectados com a cepa Y de $T$. cruzi, no $7^{\circ}, 14^{\circ}$, $21^{\circ}$ e $180^{\circ}$ dias após a infecção, dos seguintes grupos: Infectado (I); Infectado tratado com DHEA (ID); Infectado submetido ao estresse (IE); Infectado submetido ao estresse e tratado com DHEA (IED) .27

Figure 3. Peso do coração de ratos Wistar machos controle, no $7^{\circ}, 14^{\circ}, 21^{\circ}$ e $180^{\circ}$ dias, dos seguintes grupos: Controle (C), Controle tratado com DHEA (D), Controle Estressado (E), Controle Estressado e tratado com DHEA (ED). .28

Figura 4. Peso do coração de ratos Wistar machos infectados com a cepa Y de $T$. cruzi, no $7^{\circ}, 14^{\circ}$, $21^{\circ}$ e $180^{\circ}$ dias após a infecção, dos seguintes grupos: Infectado (I), Infectado tratado com DHEA (ID), Infectado Estressado (IE) e Infectado Estressado e tratado com DHEA (IED). .29

Figura 5. Evolução da parasitemia em ratos Wistar machos infectados com a cepa Y de T. cruzi durante os $7^{\circ}, 14^{\circ}, 21^{\circ}$ dias após a infecção, dos seguintes grupos: Infectado (I), Infectado tratado com DHEA (ID), Infectado estressado (IE) e Infectado estressado tratado com DHEA (IED)..........30

Figura 6. Proliferação de esplenócitos induzidos por ConA $(1 \mu \mathrm{g} / \mathrm{mL})$ de ratos Wistar machos controles durante a fase aguda $\left(7^{\circ}, 14^{\circ}\right.$ e $21^{\circ}$ dia após infecção) e crônica ( $180^{\circ}$ dias após infecção), 
dos seguintes grupos: Controle (C); Controle tratado com DHEA (D); Controle submetido ao estresse (E); Controle submetido ao estresse e tratado com DHEA (ED)....

Figura 7. Proliferação de esplenócitos induzidos por ConA $(1 \mu \mathrm{g} / \mathrm{mL})$ de ratos Wistar machos infectados com $1 \times 10^{5}$ formas tripomastigotas sangüícolas da cepa Y de Trypanosoma cruzi durante a fase aguda $\left(7^{\circ}, 14^{\circ}\right.$ e $21^{\circ}$ dia após infecção) e crônica $\left(180^{\circ}\right.$ dias após infecção), dos seguintes grupos: Infected (I); Infectado tratado com DHEA (ID); Infectado submetido ao estresse (IE) e Infectado submetido ao estresse e tratado com DHEA (IED). .34

Figura 8. Proliferação de timócitos induzidos por $\operatorname{ConA}(1 \mu \mathrm{g} / \mathrm{mL})$ de ratos Wistar machos durante a fase aguda $\left(7^{\circ}, 14^{\circ}\right.$ e $21^{\circ}$ dia após infecção) e crônica (180 dias após infecção), dos seguintes grupos: Controle (C); Controle tratado com DHEA (D); Controle submetido ao estresse (E); Controle submetido ao estressse e tratado com DHEA (ED). .36

Figura 9. Proliferação de timócitos induzidos por $\operatorname{ConA}(1 \mu \mathrm{g} / \mathrm{mL})$ de ratos Wistar machos infectados com $1 \times 10^{5}$ formas tripomastigotas sangüícolas da cepa Y de Trypanosoma cruzi durante a fase aguda $\left(7^{\circ}, 14^{\circ}\right.$ e $21^{\circ}$ dia após infecção) e crônica $\left(180^{\circ}\right.$ dias após infecção), dos seguintes grupos: Infectado (I); Infectado tratado com DHEA (ID); Infectado submetido ao estresse (IE) e Infectado submetido ao estresse e tratado com DHEA (IED)

Figura 10. Produção de óxido nítrico expresso em $\mu \mathrm{M}$ de macrófagos peritoneais de ratos Wistar machos controles durante a fase aguda $\left(7^{\circ}, 14^{\circ}\right.$ e $21^{\circ}$ dia após infecção) e crônica $\left(180^{\circ}\right.$ dias após infecção) estimulados e não estimulados por LPS, dos seguintes grupos: Controle (C); Controle tratado com DHEA (D); Controle submetido ao estresse (E); Controle submetido ao estresse e tratado com DHEA (ED). 
Figura 11. Produção de óxido nítrico expresso em $\mu \mathrm{M}$ em ratos Wistar machos infectados e infectados com a cepa Y de $T$. cruzi durante a fase aguda $\left(7^{\circ}, 14^{\circ}\right.$ e $21^{\circ}$ dia após infecção) e crônica (180 dias após infecção) estimuladas e não estimuladas por LPS. Nos seguintes grupos: Infectado (I); Infectado tratado com DHEA (ID); Infectado submetido ao estresse (IE) e Infectado submetido ao estresse e tratado com DHEA (IED)

Figura 12. Concentrações de IL-2 (pg/mL) determinadas no soro de ratos Wistar machos controles durante os $7^{\circ}, 14^{\circ}, 21^{\circ}$ e $180^{\circ}$ dias de experimentos, nos seguintes grupos: Controle (C); Controle tratado com DHEA (D); Controle submetido ao estresse (E); Controle submetido ao estresse e tratado com DHEA (ED).......

Figura 13. Concentrações de IL-2 (pg/mL) determinadas no soro de ratos Wistar machos infectados com a cepa Y de $T$. cruzi durante os $7^{\circ}, 14^{\circ}, 21^{\circ}$ e $180^{\circ}$ dias de experimentos, nos seguintes grupos: Nos seguintes grupos: Infectado (I); Infectado tratado com DHEA (ID); Infectado submetido ao estresse (IE) e Infectado submetido ao estresse e tratado com DHEA (IED). .43

Figura 14. Concentrações de IFN- $\gamma(\mathrm{pg} / \mathrm{mL})$ determinadas no soro de ratos Wistar machos controles durante os $7^{\circ}, 14^{\circ}, 21^{\circ}$ e $180^{\circ}$ dias de experimentos, nos seguintes grupos: Controle $(\mathrm{C})$; Controle tratado com DHEA (D); Controle submetido ao estresse (E); Controle submetido ao estressse e tratado com DHEA (ED) .44

Figura 15. Concentrações de IFN- $\gamma(\mathrm{pg} / \mathrm{mL})$ determinadas no soro de ratos Wistar machos infectados com a cepa $\mathrm{Y}$ de $T$. cruzi durante os $7^{\circ}, 14^{\circ}, 21^{\circ}$ e $180^{\circ}$ dias de experimentos, nos seguintes grupos: Infectado (I); Infectado tratado com DHEA (ID); Infectado submetido ao estresse (IE) e Infectado submetido ao estresse e tratado com DHEA (IED). 
Figura 16. Concentrações de TNF- $\alpha(\mathrm{pg} / \mathrm{mL})$ determinadas no soro de ratos Wistar machos controles durante os $7^{\circ}, 14^{\circ}, 21^{\circ}$ e $180^{\circ}$ dias de experimentos, nos seguintes grupos: Controle (C); Controle tratado com DHEA (D); Controle submetido ao estresse (E); Controle submetido ao

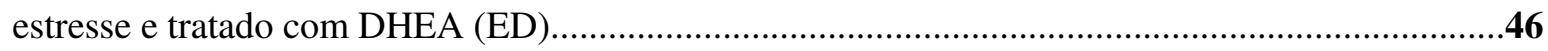

Figura 17. Concentrações de TNF- $\alpha(\mathrm{pg} / \mathrm{mL})$ determinadas no soro de ratos Wistar machos infectados com a cepa $\mathrm{Y}$ de $T$. cruzi durante os $7^{\circ}, 14^{\circ}, 21^{\circ}$ e $180^{\circ}$ dias de experimentos, nos seguintes grupos: Infectado (I); Infectado tratado com DHEA (ID); Infectado submetido ao estresse (IE) e Infectado submetido ao estresse e tratado com DHEA (IED). .47

Figura 18. Concentrações de IL-4 (pg/mL) determinadas no soro de ratos Wistar machos controles durante os $7^{\circ}, 14^{\circ}, 21^{\circ}$ e $180^{\circ}$ dias de experimentos, nos seguintes grupos: Controle (C); Controle tratado com DHEA (D); Controle submetido ao estresse (E); Controle submetido ao estresse e tratado com DHEA (ED).

Figura 19. Concentrações de IL-4 (pg/mL) determinadas no soro de ratos Wistar machos infectados com a cepa Y de $T$. cruzi durante os $7^{\circ}, 14^{\circ}, 21^{\circ}$ e $180^{\circ}$ dias de experimentos, nos seguintes grupos: Infectado (I); Infectado tratado com DHEA (ID); Infectado submetido ao estresse (IE) e Infectado submetido ao estresse e tratado com DHEA (IED)

Figura 20. Concentrações de IL-10 (pg/mL) determinadas no soro de ratos Wistar machos controles durante os $7^{\circ}, 14^{\circ}, 21^{\circ}$ e $180^{\circ}$ dias de experimentos, nos seguintes grupos: Controle (C); Controle tratado com DHEA (D); Controle submetido ao estresse (E); Controle submetido ao estresse e tratado com DHEA (ED). 
Figura 21. Concentrações de IL-10 (pg/mL) determinadas no soro de ratos Wistar machos controles durante os $7^{\circ}, 14^{\circ}, 21^{\circ}$ e $180^{\circ}$ dias de experimentos, nos seguintes grupos: Nos seguintes grupos: Infectados (I); Infectado tratado com DHEA (ID); Infectado submetido ao estresse (IE); Infectado submetido ao estresse e tratado com DHEA (IED). .51

Figura 22. Concentrações de corticosterona $(\mathrm{pg} / \mathrm{mL})$ determinadas no soro de ratos Wistar machos controles durante os $7^{\circ}, 14^{\circ}, 21^{\circ}$ e $180^{\circ}$ dias de experimentos, nos seguintes grupos: Controles (C); Controles tratado com DHEA (D); Controles submetido ao estresse (E); Controles submetido ao estresse e tratado com DHEA (ED) .52

Figura 23. Concentrações de corticosterona $(\mathrm{pg} / \mathrm{mL})$ determinadas no soro de ratos Wistar machos controles durante os $7^{\circ}, 14^{\circ}, 21^{\circ}$ e $180^{\circ}$ dias de experimentos, nos seguintes grupos: Infectados (I); Infectado tratado com DHEA (ID); Infectado submetido ao estresse (IE); Infectado submetido ao estresse e tratado com DHEA (IED). .53

Figura 24. Quantificação de neurônios no esôfago de ratos Wistar machos controles e infectados com a cepa Y de $T$. cruzi durante a fase aguda da infecção (pico de parasitemia $7^{\circ}$ dia após infecção) e durante a fase crônica da infecção (180 dias após infecção), nos seguintes grupos: Infectados (I); Infectado tratado com DHEA (ID); Infectado submetido ao estresse (IE); Infectado submetido ao estresse e tratado com DHEA (IED) .54

Figura 25. Quantificação de neurônios no cólon de ratos Wistar machos controles e infectados com a cepa Y de $T$. cruzi durante a fase aguda da infecção (pico de parasitemia $7^{\circ}$ dia após infecção) e durante a fase crônica da infecção (180 dias após infecção), nos seguintes grupos: Infectados (I); Infectado tratado com DHEA (ID); Infectado submetido ao estresse (IE); Infectado submetido ao estresse e tratado com DHEA (IED). .55 
Figura 26. Cortes histológicos $(6 \mu \mathrm{m})$ de corações de ratos Wistar machos não infectados (controles) colhidos no $14^{\circ}$ dia de experimento, nos seguintes grupos: A: grupo Controle, B: Controle tratado com DHEA, C: Controle estressado, D: Controle submetido ao estresse e tratado com DHEA

Figura 27. Cortes histológicos $(6 \mu \mathrm{m})$ de corações de ratos Wistar machos não infectados (controles) colhidos no $180^{\circ}$ dia de experimento, nos seguintes grupos: A: grupo Controle, B: Controle tratado com DHEA, C: Controle estressado, D: Controle submetido ao estresse e tratado

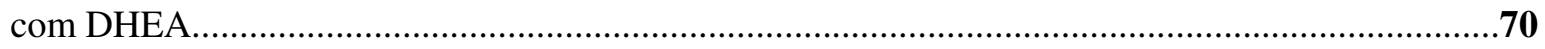

Figura 28. Cortes histológicos $(6 \mu \mathrm{m})$ de corações de ratos Wistar machos infectados i.p. com 100.000 formas tripomastigotas sangüícolas da cepa Y de Trypanosoma cruzi colhidos no $14^{\circ}$ dia de experimento, nos seguintes grupos: A: grupo Infectado, B: Infectado tratado com DHEA, C: Infectado estressado, D: Infectado submetido ao estresse e tratado com DHEA............................71

Figura 29. Cortes histológicos $(6 \mu \mathrm{m})$ de corações de ratos Wistar machos infectados i.p. com 100.000 formas tripomastigotas sangüícolas da cepa Y de Trypanosoma cruzi colhidos no $180^{\circ}$ dia de experimento, nos seguintes grupos: A: grupo Infectado, B: Infectado tratado com DHEA, C: Infectado estressado, D: Infectado submetido ao estresse e tratado com DHEA.............................72 


\section{LISTA DE TABELAS}

Tabela 1. Contagem global de macrófagos peritoniais em ratos Wistar machos controles (não infectados) e infectados com a cepa Y de $T$. cruzi durante os $7^{\circ}, 14^{\circ}, 21^{\circ}$ e $180^{\circ}$ dias de experimento. 31

Tabela 2. Os parâmetros resultantes do estudo morfométrico do corpo neuronal do esôfago de ratos Wistar machos dos grupos estudados durante o pico da infecção ( $7^{\circ}$ dia após infecção). Foi realizada a comparação entre os grupos Controle (C) e Infectado (I), Controle tratado com DHEA (D) e Infectado tratado com DHEA (ID) .56

Tabela 3. Os parâmetros resultantes do estudo morfométrico do corpo neuronal do esôfago de ratos Wistar machos dos grupos estudados durante o pico da infecção ( $7^{\circ}$ dia após infecção). Foi realizada a comparação entre os grupos Controle Estressado (E) e Infectado submetido ao estresse (IE), Controle estressado e tratado com DHEA (ED) e Infectado submetido ao estresse e tratado com DHEA (IED)

Tabela 4. Os parâmetros resultantes do estudo morfométrico do corpo neuronal do esôfago de ratos Wistar machos dos grupos estudados durante o pico da infecção $180^{\circ}$ dia após infecção. Foi realizada a comparação entre os grupos Controle (C) e Infectado (I), Controle tratado com DHEA (D) e Infectado tratado com DHEA (ID). .58 
Tabela 5. Os parâmetros resultantes do estudo morfométrico do corpo neuronal do esôfago de ratos Wistar machos dos grupos estudados durante o pico da infecção $180^{\circ}$ dia após infecção. Foi realizada a comparação entre os grupos Controle Estressado (E) e Infectado submetido ao estresse (IE), Controle estressado e tratado com DHEA (ED) e Infectado submetido ao estresse e tratado com DHEA (IED).

Tabela 6. Os parâmetros resultantes do estudo morfométrico do corpo neuronal do cólon de ratos Wistar machos dos grupos estudados durante o pico da infecção $7^{\circ}$ dia após infecção. Foi realizada a comparação entre os grupos Controle (C) e Infectado (I), Controle tratado com DHEA (D) e Infectado tratado com DHEA (ID) .60

Tabela 7. Os parâmetros resultantes do estudo morfométrico do corpo neuronal do cólon de ratos Wistar machos dos grupos estudados durante o pico da infecção $7^{\circ}$ dia após infecção. Foi realizada a comparação entre os grupos Controle Estressado (E) e Infectado submetido ao estresse (IE), Controle estressado e tratado com DHEA (ED) e Infectado submetido ao estresse e tratado com DHEA (IED) .61

Tabela 8. Os parâmetros resultantes do estudo morfométrico do corpo neuronal do cólon de ratos Wistar machos dos grupos estudados durante o pico da infecção $180^{\circ}$ dia após infecção. Foi realizada a comparação entre os grupos Controle (C) e Infectado (I), Controle tratado com DHEA (D) e Infectado tratado com DHEA (ID). .62 
Tabela 9. Os parâmetros resultantes do estudo morfométrico do corpo neuronal do cólon de ratos Wistar machos dos grupos estudados durante o pico da infecção $180^{\circ}$ dia após infecção. Foi realizada a comparação entre os grupos Controle Estressado (E) e Infectado submetido ao estresse (IE), Controle estressado tratado com DHEA (ED) e Infectado submetido ao estresse e tratado com DHEA (IED).

Tabela 10. Análise quantitativa dos ninhos de amastigotas no coração de ratos Wistar machos infectados com a cepa $\mathrm{Y}$ de $T$. cruzi, nos animais infectados (I), infectados tratados com DHEA (ID), infectados estressados (IE) e infectados estressados e tratado com DHEA (IED) em todos os dias de experimentos.

Tabela 11. Valores médios dos parâmetros nucleares do coração de ratos Wistar machos dos grupos: Controle (C) e Infectado (I), Controle tratado com DHEA (D) e Infectado tratado com DHEA (ID) durante a fase aguda (pico de parasitemia $7^{\circ}$ dia após infecção)..65

Tabela 12. Valores médios dos parâmetros nucleares do coração de ratos Wistar machos dos grupos: Estressado (E) e Infectado submetido ao estresse (IE), Controle estressado e tratado com DHEA (ED) e Infectado submetido ao estresse e tratado com DHEA (IED) durante a fase aguda (pico de parasitemia $7^{\circ}$ dia após infecção). .66

Tabela 13. Valores médios dos parâmetros nucleares do coração de ratos Wistar machos dos grupos: Controle (C) e Infectado (I), Controle tratado com DHEA (D) e Infectado tratado com DHEA (ID) durante a fase crônica ( $180^{\circ}$ dia após infecção) .67 
Tabela 14. Valores médios dos parâmetros nucleares do coração de ratos Wistar machos dos grupos: Estressado (E) e Infectado submetido ao estresse (IE), Controle estressado e tratado com DHEA (ED) e Infectado submetido ao estresse e tratado com DHEA (IED)

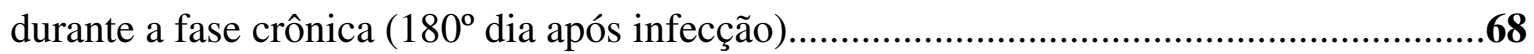




\section{LISTA DE ABREVIATURAS}

C- Controle

D- Dehidroepiandrosterona

DHEA- Dehidroepiandrosterona

E- Estresse

ED- Estressado tratado com DHEA

HPA- Eixo Hipófise-Hipotálamo-Adrenal

I- Infectado

ID- Infectado tratado com DHEA

IE- Infectado submetidos ao estresse

IED- Infectado submetidos ao estresse e tratado com DHEA

IFN- $\boldsymbol{\gamma}$ - Interferon Gama

IL-2- Interleucina 2

IL-4- Interleucina 4

IL-10- Interleucina 10

LPS- Lipopolissacarídeos

MHC- Complexo principal de histocompatibilidade

NK- Células natural Killer

NO- Nitric Oxide (Óxido Nítrico)

RPMI- Meio de cultura (Roswell Park Memorial Institute)

Th- T Helper

TNF- $\boldsymbol{\alpha}$ - Fator de Necrose Tumoral Alfa 


\section{INTRODUÇÃO:}

\subsection{Doença de Chagas e resposta imune}

A doença de Chagas descrita por Carlos Ribeiro Justiniano das Chagas em 1909 ou tripanossomíase americana tem por agente etiológico o flagelado digenético Trypanosoma cruzi. A maior parte dos casos de infecção em seres humanos, ou em outros vertebrados é transmitida pelo contato da pele ou mucosas com fezes ou urina de insetos hematófagos da família Reduviidae contaminados por T. cruzi (CHAGAS, 1909). Segundo a organização mundial de saúde existem cerca de 18 milhões de pessoas infectadas na América Latina (WHO, 2003). A maioria dos indivíduos infectados sobrevive à fase aguda da doença permanecendo aparentemente assintomáticos por um longo período ou durante toda a sua vida. Estudos epidemiológicos mostram que de 30 a $40 \%$ dos indivíduos portadores de tripanossomíase americana desenvolvem a forma clinica mais severa da doença, apresentando um quadro inflamatório que comumente resulta em cardiomiopatia e/ou disfunção do trato gastro-intestinal (KÖBERLE, 1968; ANDRADE et al., 1970; BRENER et al., 2000). A razão pelas quais alguns indivíduos desenvolvem a forma mais severa da doença é por que as manifestações clínicas são altamente heterogêneas, são em parte, ainda desconhecidas e representam grande desafio nesse campo da ciência.

A infecção por T. cruzi sensibiliza diferentes compartimentos do sistema imune, levando ao aparecimento de respostas humorais e celulares específicas contra o parasita. A mobilização do sistema imune é importante na redução da carga parasitária, mas, por outro lado, pode contribuir para o aparecimento das manifestações crônicas da doença, que podem ser bastante danosas ao paciente (BRENER \& GAZZINELLI, 1997). Na fase crônica da infecção humana por $T$. cruzi, o diagnóstico laboratorial é alcançado preferencialmente por reações sorológicas como: detecção de IgG (MONCAYO \& 
YANINE, 2006), hemaglutinação indireta, imunofluorescência, exames de isolamento do parasita tais como xenodiagnóstico, hemocultura e mais recentemente a Reação em Cadeia da Polimerase (PCR) (RUSSOMANDO et al., 1998; GALVÃO et al., 2003).

Estudos experimentais com T. cruzi demostram dramática mudança na população de células do sistema imune e órgãos linfóides, que incluem esplenomegalia, atrofia tímica e ativação policlonal de células T e B associada com hipergamaglobulinemia (LEITE-DEMORAES et al., 1992). Em humanos e roedores infiltrados inflamatórios compostos principalmente por células $\mathrm{T} \mathrm{CD}^{+}$são observados em vários tecidos incluindo o coração (SANTOS et al., 2001), esôfago e cólon (SUN \& TARLETON, 1993). Diferentes modelos experimentais mostram que a carga parasitária, a taxa de mortalidade e reposta inflamatória são dependentes da atividade das células T (GONÇALVES-DA-COSTA et al., 1984; TARLETON et al., 1992). De fato, células $\mathrm{T} \mathrm{CD}^{+}$e $\mathrm{CD}^{+}$são requeridas para reduzir a parasitemia, prevenir a morte do animal e estabelecer uma memória imunológica contra o parasita (ROTTENBERG et al., 1993; TARLETON et al., 1996). Citocinas secretadas pelas células $\mathrm{T}$ exercem papel central na resposta imune do hospedeiro regulando a habilidade dos macrófagos infectados em eliminar o parasita (HUNTER et al., 1997; TARLETON et al., 2000). Uma variedade de modelos experimentais demonstra que, uma superprodução de citocinas do tipo-2 ou bloqueio da produção das do tipo-1, estão relacionadas com maior vulnerabilidade do hospedeiro e a forma letal da infecção (HOFT et al., 1993; ROTTENBERG et al., 1995; HUNTER et al., 1996; ABRAHAMSOHN \& COFFMAN, 1996). Animais resistentes à infecção exibem padrão combinado da produção de citocinas do tipo 1 e 2 nos compartimentos linfóides e órgãos que são alvos da infecção parasitária (ZHANG \& TARLETON, 1996, ZHANG \& TARLETON, 1996a), sugerindo a possibilidade de um balanço entre citocinas do tipo-1 e 2 pode ser benéfico ao hospedeiro. 
A invasão de diversas células do sistema imunológico, em especial de macrófagos por T. cruzi inicia uma série de interações moleculares que mobilizam a resposta imune inata do hospedeiro (REED, 1995; ALIBERTI et al., 1996).

Tipicamente ocorre em macrófagos a secreção da interleucina 12 (IL-12) que ativa as células natural killer (NK) a produzirem interferon gama (IFN- $\gamma$ ), atuando diretamente sobre os macrófagos, ativando-os para atividade microbicida (GAZZINELLI et al., 1992; REED, 1995; ALIBERTI et al., 1996). A citocina pró-inflamatória fator de necrose tumoral alfa (TNF- $\alpha$ ), produzida por macrófagos durante a infecção por $T$. cruzi, participa dessa interação de forma sinérgica tanto como IL-12 e IFN- $\gamma$ (OSWALD et al., 1992).

Os macrófagos desempenham importante função contra a infecção por $T$. cruzi via peroxidase, óxido nítrico (NO) e produção de peroxinitrito, demonstrando alto poder citotóxico contra as formas epimastigotas desse parasita (THOMSON et al., 1999). Os macrófagos quando ativados liberam NO que está envolvido em uma variedade de funções biológicas, como a vasodilatação sangüínea, agregação plaquetária e neuro-transmissão (MONCADA et al., 1991). O NO tem importante papel no controle de muitas infecções, apresentando atividade antibacteriana, antiparasitária e antiviral (FLORA FILHO \& ZILBERSTEIN, 2000) sendo considerado molécula efetora microbicida em macrófagos contra patógenos como T. cruzi (GAZZINELLI et al., 1992).

O NO é gerado por uma família de isoenzimas expressas em grande variedade de células de mamíferos, através da catálise enzimática do aminoácido essencial L-arginina (MONCADA et al., 1991). A catálise enzimática da reação do aminoácido L-arginina e oxigênio resultam na formação de L-citrulina e óxido nítrico e é feita por enzimas que são constitutivas ou induzidas.

A comunicação dos sistemas endócrino e imune é de grande importância para a 
manutenção da homeostase tanto em humanos como em roedores, e a magnitude da resposta imune é amplamente influenciada por diferentes hormônios. Contudo, essa relação não tem sido explorada sistematicamente e alguns dos novos conceitos que surgem, são baseados em hipóteses e/ou especulações que necessitam de maiores evidencias que os comprovem. Roedores representam bons modelos para estudo da resposta imune, especialmente para imunidade inata, pois esta se mantém conservada em diferentes espécies, ao contrário da resposta imune específica (RAMIREZ et al., 2000).

O controle da fase aguda da infecção é dependente da ativação de várias células do sistema imune, tais como a Natural Killer (NK), T CD4+, T CD8+ e linfócitos B responsáveis pela produção de anticorpos (KRETTLI \& BRENER, 1976; ROTTENBERG et al., 1993). Diferentes estudos indicam participação fundamental do interferon gama (IFN- $\gamma)$, do fator de necrose tumoral alfa (TNF- $\alpha$ ), da interleucina-2 (IL-2), interleucina-12 (IL-12) e do óxido nítrico (NO) na resistência do hospedeiro, à infecção por T. cruzi (SANTOS et al., 2001). Por outro lado, a interleucina-4 (IL-4) e interleucina-10 (IL-10) parecem aumentar a suscetibilidade do hospedeiro à infecção (ABRAHAMSOHN \& COFFMAN, 1996).

A interação entre os sistemas endócrino e imunológico influencia a resposta imune celular (OBERBECK et al., 2001). O DHEA, que está entre os mais abundantes esteróides secretados pelo córtex da glândula adrenal (EBELING \& KOIVISTO, 1994) é reconhecido por aumentar as defesas do hospedeiro estimulando o sistema imune (OBERBECK et al., 2001). Trabalhos realizados em roedores mostram a ação protetora do DHEA contra diversas infecções letais causadas por vírus, bactérias e parasitas (MORFIN et al., 2000; MORALES-MONTOR et al., 2001). Progressivas disfunções dos sistemas imune e 
endócrino durante o envelhecimento são corrigidas após tratamento com DHEA (KROBOTH et al., 1999; MARTINEZ-TABOADA et al., 2002; SACCO et al., 2002). A presença de receptor específico para DHEA foi demonstrada em células do sistema imune (OKABE et al., 1995). Tratamento com DHEA-S elimina a expressão constitutiva de IL-10 reduz a produção da sua forma induzível (SPENCER et al., 1996) e a concentração de IL-4 (REGELSON et al., 1994). Suplementação diária com DHEA aumenta o número de monócitos, de células $\mathrm{B}$, $\mathrm{T}$ e $\mathrm{NK}$, como também o número de receptores para IL-2 (KHORRAM et al., 1997). Além disso, DHEA mantém a produção de INF- $\gamma$ durante o processo infeccioso (REGELSON et al., 1994).

\subsection{Patologia dos Megas}

Na fase aguda da infecção, muitos neurônios periféricos são destruídos (KÖBERLE, 1968), contribuindo para a patogenia da cardiopatia crônica, megaesôfago e megacólon (KÖBERLE, 1968; OLIVEIRA, 1985; ROSSI \& BESTETTI, 1995).

Durante a fase crônica, cinco formas clínicas podem ser apresentadas: indeterminada, cardíaca, digestiva, mista (cardíaca e digestiva) e formas nervosas (ANDRADE et al., 1970). As manifestações da doença de Chagas na forma digestiva são atribuidas a destruição de nervos do plexo mientérico, no qual conduz a desordenação dos movimentos peristálticos, hipertrofia e dilatação do músculo (TOSTES et al., 1994).

A forma digestiva da doença de Chagas é caracterizada por efeitos no esôfago e cólon, onde ocorre hipertrofia e dilatação muscular do esôfago ou cólon como resultado de denervação do plexo mientérico, com conseqüentes alterações na secreção e diminuição da 
coordenação desses órgãos (COSTA, 1969; KÖBERLE, 1963; REZENDE E MOREIRA, 2000).

Os efeitos da denervação mientérica do jejuno proximal e a população de células endócrinas, cinco meses após o tratamento com cloreto de benzalcônio, em ratos machos albinos Wistar, foi observada por SANTOS e colaboradores (2000). Os autores verificaram redução significativa no número de neurônios do plexo mientérico jejunal dos animais tratados, sendo a população de células endócrinas significantemente aumentadas no segmento do intestino, concluindo que a denervação mientérica intestinal causada pelo tratamento com cloreto de benzalcônio, talvez induza a hiperplasia de células endócrinas.

O envolvimento digestivo está relacionado à virulência da cepa estudada que pode levar a complicações do megaesôfago e megacólon, podendo não somente estar associado à doença de Chagas crônica (PRATA, 1994). A fase crônica é indicada por distúrbios do sistema nervoso entérico, importante fator da patogenia do megaesôfago e megacólon (PRATA, 1994, 2004). É de conhecimento que a denervação leva a hiperplasia do cólon descendente (ZUCOLOTO et al., 1988), aumenta a espessura da mucosa intestinal (ZUCOLOTO et al., 1988, 1997), e estase do conteúdo do lúmem com importante distenção das vísceras (SOBREIRA et al., 2001).

Alguns autores têm demonstrado que a infecção por T. cruzi causa distúrbios na atividade de vários neurotransmissores (MAIFRINO et al., 1999). Os neurotransmissores possuem ação excitatória e inibitória, e estas ações estão balanceadas.

De modo geral, a denervação intestinal pode ser induzida cirurgicamente (LACHAT \& GONÇALVES, 1978; HADZIJAHIC et al., 1993), pela infecção com T. cruzi (FERNANDES et al., 1991) e pela extirpação química de neurônios mientéricos com aplicação de cloreto de benzalcônio no cólon (SATO et al., 1978; SAKATA et al., 1979; 
ZUCOLOTO et al., 1988, 1997; OLIVEIRA et al., 1990).

Nos últimos anos, ainda que a maioria dos trabalhos relativos à resposta inflamatória na doença de Chagas continuasse a se preocupar basicamente com a miocardite, desenvolveram-se alguns estudos sistematizados, sobre a resposta inflamatória no tubo digestivo de chagásicos crônicos (ADAD et al., 1991; CAMARGOS et al., 2000).

Em recentes trabalhos publicados, CAETANO et al, (2006); CAETANO et al, (2008a e 2008b) descreveram a ação protetora da ciclofosfamida sobre os neurônios mientéricos do esôfago e cólon, em C. callosus senis infectados com a cepa MORC -1 de T. cruzi.

\subsection{Dehidroepiandrosterona (DHEA)}

O DHEA é um esteróide sintetizado principalmente no córtex das glândulas adrenais a partir do colesterol em quatro passos distintos na via esteroidogênica. Primeiro, o colesterol necessita ser captado pela mitocôndria, processo que conta com ajuda da proteína de regulação aguda da esteroidogênese (StAR). Então, é convertido para pregnenolona (PREG) pela enzima de clivagem da cadeia lateral do colesterol (P450scc). A seguir, a PREG sofre 17-alfa-hidroxilação por ação da P450c17. Logo após, a 17-OH-PREG é convertida para DHEA por ação da atividade de lise da enzima P450c17 (MILLER, 2005).

O DHEA diferentemente de outros hormônios secretados pelo córtex da adrenal (aldosterona e cortisol) (SALEK et al., 2002), apresenta redução na sua secreção durante o processo natural de envelhecimento (ARLT \& HEWISON, 2002) e está associada com muitas doenças presentes na fase avançada da vida (DEBONNEUIL et al., 2006; LABRIE et al., 2007), como por exemplo, doenças cardiovasculares (WU et al., 2007), osteoporose, depressão (LAMBERTS et al., 1997; HINSON \& RAVEN, 1999) e síndrome de Alzheimer (SUNDERLAND et al., 1989). Além disso, baixos níveis de DHEA também estão 
associados com câncer (SCHWARTZ et al., 1986), obesidade (SANTORO et al., 2005) e alterações na função imune (CASSON et al., 1993).

Embora o DHEA seja secretado em quantidades significantes nas adrenais de humanos e primatas superiores, encontra-se praticamente ausente em roedores (MILLER, 2002). Considerado o hormônio esteróide androgênio mais importante (NESTLER et al., 1992), possui efeitos imuno-estimulatório em animais (BLAUER et al., 1991) e humanos (CASSON et al., 1993). Embora suas ações biológicas não tenham sido bem definidas, esse esteróide parece ter impacto positivo sobre o bem estar (ARIT et al.,1999) e apresenta potente ação moduladora da resposta imune, melhorando as defesas do hospedeiro através da restauração das funções celulares, revertendo a suscetibilidade do hospedeiro à infecções (OBERBECK et al., 2001). Experimentalmente, sua administração aumenta a resistência a patógenos bacterianos, virais (DANENBERG et al, 1997; BEN NATHAN et al., 1999), protozoários (RASMUSSEN et al, 1995) e Schistosoma mansoni (FALLON et al, 1998). DHEA restabelece a proliferação de esplenócitos e a secreção de IL-2, IL-3 e IFN- $\gamma$ (CATANIA et al., 1999), sendo este último identificado como importante fator de resistência na infecção por $T$. cruzi (McCABE et al., 1991). O DHEA propicia ainda aumento da resposta humoral (SOMEKH et al., 2000); produção de NO (MANABE et al., 1999) e aumento da citotoxicidade das células NK através de IGF-I (insuline like growth factor) (SOLERTE et al., 1999). As ações do DHEA sobre o sistema imune podem ocorrer de forma indireta por antagonizar os efeitos imunossupressores dos glicocorticoides (BLAUER et al., 1991) ou por sua conversão para outros esteróides. Alternativamente, foi sugerido que suas ações podem ocorrer por efeito direto sobre receptores para DHEA encontrados nas células T (MEIKLE et al., 1992). 
Estudos realizados por SANTOS et al., (2005) e SANTOS et al., (2007), avaliaram a ação do DHEA na fase aguda da doença de Chagas experimental e revelaram o efeito do hormônio na redução da carga parasitária sangüínea e tecidual.

\subsection{Estresse}

Estresse pode ser definido como uma constelação de estímulos (estressores) que desencadeiam uma reação no cérebro (percepção do estresse) a qual ativa, no organismo o sistema fisiológico de resposta de luta ou fuga (resposta ao estresse) (DHABHAR, 2002; McEWEN et al., 1997).

O estresse que pode ser físico ou psicológico, está sob o domínio de 3 variáveis: magnitude, duração e resposta individual (MEYER \& SILVA, 1999; COHEN \& HAMRICK, 2003). Através da avaliação da concentração plasmática de CT, a ativação desse sistema de estresse, pode ser percebida dentro de poucos minutos (CALDEIRA \& FRANCI, 2000). O estresse agudo não repetitivo parece possuir um caráter salubre ao organismo, apresentando melhora da resposta imune celular (SAPOLSKY, 1998; DHABHAR, 2002), já o crônico é prejudicial (McEWEN, 1998). SANTOS e colaboradores (2005) demonstraram que a doença de Chagas experimental associada ao estresse agudo repetitivo tem um profundo efeito sobre o pico da parasitemia e infiltrado inflamatório. Outros dados indicam que a elevada concentração de GC pode estar envolvida nessa resposta (SANTOS et al., 2007). Considerando doença como estímulo estressor, a infecção por T. cruzi, tanto em humanos como em diferentes modelos experimentais ocasiona desequilíbrio da resposta imune (CARDILLO et al., 1996).

Diferentes situações de estresse (agudo ou crônico) levam ao aumento das concentrações plasmáticas dos glicocorticóides (GCs) cortisol (em humanos) e 
corticosterona (em ratos) (CALDEIRA \& FRANCI, 2000; WURTMAN, 2002). Vários modelos experimentais mostram que o estresse aumenta os sinais de depressão, de ansiedade, do estado de passividade, reduz a agressividade em testes de interação social e reduz a procura por alimentos (TANNENBAUM et al., 2002). O estresse também exerce impacto negativo sobre o processo normal de cicatrização de ferimentos (MERCADO et al., 2002). É amplamente conhecido que os GCs inibem a produção de citocinas proinflamatórias como a IL-12, TNF- $\alpha$, IFN- $\gamma$, enquanto estimulam a produção de citocinas anti-inflamtórias como IL-10 e IL-4 (ELENKOV \& CHOROUSOS, 2002; MORASKA et al., 2002). A elevada concentração plasmática de GCs durante os processos infecciosos é responsável pela involução do baço, do timo e aumento da taxa de mortalidade (REGELSON et al., 1994). DHEA é um dos mais abundantes esteróides secretados pela adrenal (EBELING \& KOIVISTO, 1994). Dessa forma, tanto o estresse, a administração exógena de GCs, ou a fase aguda e crônica de diferentes doenças, causam significante redução da concentração plasmática de DHEA (MORALES-MONTOR et al., 2001; MARTINEZ-TABOADA et al., 2002). Esse hormônio possue importantes funções imunorregulatórias (REGELSON et al., 1994; FALLON et al., 1998; OBERBECK et al., 2001).

Recentemente, KROBOTH e colaboradores (2003), demonstraram que a administração de DHEA diminui a concentração plasmática de GCs. Uma ação antiglicocorticóide também foi demonstrada por outros pesquisadores (SACCO et al., 2002). Hipercortisolismo e redução de DHEA em diferentes condições patológicas podem teoricamente resultar num desbalanço entre as vias imunossupressivas e imunoestimuladoras (BEISHUIZEN et al., 2002). Elevada glicocortisolemia favorece a replicação 
dos parasitas durante a infecção por T. cruzi. Prolongada redução da concentração plasmática de DHEA durante diferentes quadros patológicos dão suporte a necessidade de estudos de intervenção com doses substitutivas de DHEA e DHEA-S considerando a ocorrência de efeitos benéficos sobre o bem-estar e o sistema imune.

\subsection{DHEA e infecções}

O DHEA é sintetizado pelas células da zona reticular da adrenal, a partir de moléculas de colesterol, mais especificamente pela 17-hidroxipregnenolona e a 17hidroxiprogesterona. O DHEA pode estar conjugado ao sulfato por uma enzima específica. As formas livres e sulfatadas de DHEA são os principais andrógenos produzidos pela adrenal, embora pequenas quantidades de androstenediona sejam formadas e ainda menores quantidades de testosterona são formadas. DHEA possui reduzida atividade androgênica, mas pode ser convertido em testosterona nos tecidos periféricos (AIRES, 1999).

O tratamento de DHEA é utilizado só ou em associação com outras substâncias como a melatonina na infecção murina por retrovírus, prevenindo a redução da proliferação de células B e T, bem como aumentando a função de resposta de Th-1 e atenuando a elevada produção de interleucinas do grupo Th-2 característico nestas infecções (ZHANG et al., 1999).

Pesquisas realizadas em animais indicam que o DHEA possui efeito direto como estimulador nos linfócitos T, tanto in vivo como in vitro, por aumentar a produção da IL-12, fator importante na medição das respostas imunológicas deste tipo de célula (LORIA et al., 1996). Associado a este fenômeno, o DHEA pode superar os efeitos imunossupressivos do cortisol sobre os linfócitos T, já que este possui nítida ação supressora na produção da IL-2. Trabalhos realizados em roedores mostram a ação protetora do DHEA contra diversas 
infecções letais causadas por vírus, bactérias e parasitas (MORFIN et al., 2000; MORALES-MONTOR et al., 2001; DOS SANTOS et al., 2005). Tratamento com DHEAS elimina a expressão constitutiva de IL-10, reduz a produção da sua forma induzível (SPENCER et al., 1996) e reduz a concentração de IL-4 (REGELSON et al., 1994).

Vários autores têm descrito o uso do DHEA no combate a diversos tipos de infecções, dentre elas a síndrome da imunodeficiência adquirida (AIDS) (CHRISTEFF et al., 1999), infecções bacterianas (BEN NATHAN et al., 1999) e infecções parasitárias como Cryptosporidium parvum (RASMUSSEN et al., 1995), Schistosoma mansoni (MORALESMONTOR et al., 2001) e Trypanosoma cruzi (SANTOS et al., 2005, 2007) e até mesmo contra o vírus da influenza (DANENBERG et al., 1997). 


\section{JUSTIFICATIVA}

Apesar de todo o avanço científico relacionado à resposta imune do hospedeiro e a forma de evasão do parasita aliada às pesquisas para descoberta de uma droga eficiente para o seu tratamento, a doença de Chagas é ainda um grande problema em saúde pública (WHO, 2003). Os poucos medicamentos disponíveis tem ação terapêutica somente na fase inicial da doença, ocasionam inúmeros efeitos colaterais e parecem não possuir a eficiência desejada quando comparada ao uso de placebo (REYES et al., 2005). Alem disso, o potencial da terapia tripanocida em modificar a cardiopatia na fase crônica ainda permanece por ser avaliada.

A procura de novas terapias para o controle da doença de Chagas tem sido o objetivo maior de nosso grupo de pesquisa. O objetivo dessa pesquisa não é encontrar uma droga com ação efetiva tripanossomicida, mas sim proporcionar ao hospedeiro, condições de uma resposta imune mais efetiva amenizando as consequiências patológicas provocadas pela ação do parasita. O interesse em estudar a ação imunomoduladora do DHEA na fase crônica, vem da observação de que humanos e camundongos infectados com $T$. cruzi, apresentam reativação da doença com aumento da parasitemia quando tratados cronicamente com GCs (BRENER \& CHIARI, 1971; MECKERT et al., 1988). Por ser o DHEA um hormônio antagônico do cortisol (BLAUER et al., 1991), cujas ações imunossupressoras são conhecidas, o estudo dos efeitos desse andrógeno durante as fases aguda e crônica da doença de Chagas, será de grande valia no monitoramento da parasitemia e outros aspectos relacionados à infecção. A implicação do DHEA nesta proposta experimental não visa o seu uso como droga destinado a cura, mas sim como imunomodulador, diminuindo a severidade da doença. Além disso, os maiores danos patológicos ocorrem na fase crônica tornando importante o estudo da imunidade durante 
esta fase e a contribuição do processo de envelhecimento na patofisiologia da doença e os benefícios que possam ser obtidos com a suplementação feita pelo uso de DHEA.

A relevância deste trabalho é avaliar a magnitude da resposta humoral e celular na vigência ou não da terapia com DHEA e os níveis de estresse diante da administração do hormônio imunomodulador, a intensidade parasitária sanguínea e tecidual e até mesmo indiretamente a ação deste hormônio sobre o metabolismo através do peso dos animais e avaliação bioquímica para relatar as possíveis alterações causadas pela terapia hormonal. 


\section{OBJETIVOS}

Estudar os efeitos da suplementação de DHEA associado ao estresse repetitivo sobre a resposta imune de ratos Wistar machos jovens e senis infectados com Trypanosoma cruzi durante a fase aguda e crônica, utilizando os seguintes parâmetros:

1- Avaliar a efetividade do tratamento com DHEA sobre a parasitemia durante a fase aguda da doença, para relacionar com a severidade da fase crônica da infecção.

2- Morfometria do corpo neuronal do esôfago e cólon dos animais durante a fase aguda comparando com a fase crônica.

3- Verificar se o tratamento com DHEA reduz ou previne a elevação de corticosterona associando ou não ao estresse durante a fase aguda e crônica da doença de Chagas.

4- Avaliação dos seguintes parâmetros imunológicos: NO, IL-2, IL-4, IL-10, TNF- $\alpha$, IFN- $\gamma$ e linfoproliferação de esplenócitos e timócitos. 


\section{MATERIAL E MÉTODOS}

\subsection{Animais}

No inicio dos experimentos, foram utilizados ratos machos jovens da linhagem Wistar, pesando entre 90 e 100 gramas, provenientes do biotério da Universidade de São Paulo, Campus de Ribeirão Preto. Esses animais eram mantidos em caixas plásticas com maravalha a uma temperatura ambiente de $23 \pm 2^{\circ} \mathrm{C}$, em um ciclo claro/escuro de 12/12 horas, em número de três animais por caixa com ração específica para roedores e água ad libitum. Os animais da fase crônica eram deixados envelhecer por 180 dias. Todos os experimentos foram conduzidos com a aprovação do Comitê de Ética em Experimentação Animal da Universidade de São Paulo, Campus de Ribeirão Preto (protocolo ${ }^{\circ}$ 05.1.682.53.1).

\subsection{Grupos Experimentais}

\section{Grupos Controles: Aguda $(n=5)$ e crônica $(n=5)$}

Controle (C)

Controle tratado com DHEA (D)

Controle Estressado (E)

Controle Estressado e tratado com DHEA (ED)

\section{Grupos Infectados: Aguda (n=5) e crônica (n=5)}

Infectado (I)

Infectado tratado com DHEA (ID)

Infectado Estressado (IE) 
Infectado Estressado e tratado com DHEA (IED)

\subsection{Parasitas}

Utilizou-se a cepa Y de Trypanossoma cruzi, isolada por SILVA \& NUSSENZWEIG (1953), por meio do xenodiagnóstico realizado em uma paciente na fase aguda da infecção chagásica. Desde então, esta cepa vem sendo mantida em camundongos Swiss não isogênicos, por meio de repiques semanais. O estudo da cepa Y já está bem preconizado em diferentes modelos experimentais, inclusive em ratos, não variando muito de hospedeiro para hospedeiro. A forma tripomastigota da cepa $\mathrm{Y}$ possui morfologia fina com picos parasitêmicos precoces, altamente virulenta e patogênica, determinando alta mortalidade e lesões teciduais graves (SCORZA \& SCORZA, 1972). Em ratos, o padrão da curva parasitêmica se mantém semelhante aos de animais de menor porte, com pico compreendido entre o sétimo e o nono dias, onde então, os parasitas desaparecerão da circulação iniciando-se a fase crônica (ANDRADE et al., 1970; UYEMURA et al., 1995).

\subsection{Infecção}

Decorridos os dias de ambientalização, os animais do grupo infectado foram inoculados intraperitonealmente com $1 \times 10^{5}$ tripomastigotas sangüícolas. A contagem dos parasitas foi realizada pelo método de BRENER (1962), que consiste em colocar uma alíquota de $5 \mu$ l de sangue infectado em uma lâmina de microscópio, cobrindo-a com uma lamínula de 22×22 mm. Determina-se o número de parasitas em 50 campos microscópicos, selecionados em várias áreas do preparado. O número encontrado é multiplicado por um fator, calculado para cada microscópio e objetiva, que leva em consideração o número de campos microscópicos existentes na área da lamínula. 


\subsection{Suplementação com DHEA}

Os grupos foram tratados com 0,1 mL de DHEA, dissolvidos em 0,05mL de etanol e igual volume de água destilada, sendo administrados por via subcutânia na dose de 40mg/Kg/dia de DHEA (SANTOS et al., 2007), durante o período de experimentação, uma vez ao dia pela manhã obedecendo rigorosamente o mesmo horário de tratamento. A administração de DHEA para os grupos infectados começou concomitantemente à infecção. Os animais que se encontram na fase Crônica foram tratados seguindo os mesmos critérios.

\subsection{Estímulo ao estresse repetitivo}

Durante a fase aguda da infecção, os animais eram expostos ao vapor de éter por um minuto duas vezes ao dia como estímulo estressor. Os animais a serem estressados eram separados dos outros durante a exposição aos vapores de éter. O frasco contendo éter era mantido rigorosamente fechado em temperatura ambiente, aproximadamente $21^{\circ} \mathrm{C}$ para evitar a emissão de vapores de éter ao ambiente e somente era aberto quando necessário. A metodologia utilizada está de acordo com os métodos aplicados por CALDEIRA \& FRANCI, 2000.

\subsection{Dias de Experimentos}

Os experimentos foram realizados em dias pré-determinados, compostos pelo $7^{\circ}, 14^{\circ}$ e $21^{\circ}$ dias após o inóculo infectante na fase aguda da infecção e no $180^{\circ}$ dias para avaliar a fase crônica da infecção. Esses dias foram escolhidos baseados na curva parasitêmica, onde o pico de parasitemia ocorre entre o sétimo e o nono dia após o inóculo. Para cada dia do experimento foram utilizados 5 animais de cada grupo visto que a diferença no número de amostras pode influenciar nos resultados dos experimentos (SOGAYAR et al., 1993). Para 
análise histológica foram utilizados os mesmos 5 animais de cada grupo, pois nesta situação, um número maior não altera os valores estatísticos da análise de ninhos.

\subsection{Pesagem dos animais e órgãos}

Os animais foram pesados em balança eletrônica nos dias determinados dos experimentos. Os órgãos (coração) foram retirados após a morte dos animais e pesados em balança analítica.

\subsection{Eutanásia e Coleta de sangue}

Os animais foram mortos por decapitação, após anestesia prévia com Tribromoetanol 2,5\%. A decapitação foi escolhida como método de eutanásia para evitar que outras manipulações pudessem causar estresse nos animais, elevando as concentrações plasmáticas de corticosterona e assim interferindo nos parâmetros analisados (CALDEIRA \& FRANCI, 2000).

Após morte dos animais, foram coletados cerca de $2 \mathrm{~mL}$ de sangue em tubo plástico contendo $200 \mu \mathrm{L}$ de heparina sódica ( 1 mL: 5.000 U.I), para determinação da parasitemia. Para obtenção de soro e posterior dosagens imunológicas, foram coletados $2 \mathrm{~mL}$ de sangue em tubo plástico sem anticoagulante. Os frascos foram centrifugados e o soro foi separado e estocado a $-70^{\circ} \mathrm{C}$ para posterior dosagens das citocinas. $\mathrm{O}$ plasma foi armazenado a $-70^{\circ} \mathrm{C}$ para posterior dosagem de corticosterona.

\subsection{Contagem de macrófagos peritoniais}

Os macrófagos foram coletados através da injeção de 5mL de meio RPMI 1640 estéril (Cultlab-Campinas Brasil) na cavidade peritoneal do animal. Após suave massagem 
abdominal, o líquido peritoneal foi retirado e centrifugado, sendo o pellet ressuspendido com RPMI 1640 contendo 10\% de soro bovino fetal e antibiótico. Utilizou-se solução de Turk juntamente com o lavado (1:100) para coloração e contagem de macrófagos em câmara de Neubauer.

\subsection{Preparação da suspensão de células peritoneais e dosagem de Óxido Nítrico}

A técnica de quantificação de óxido nítrico em sobrenadante foi realizada de acordo com DOST et al., 2002. No dia do ensaio, a cavidade intraperitoneal foi lavada com $5 \mathrm{~mL}$ de meio RPMI 1640 a $4^{\circ} \mathrm{C}$, como descrito anteriormente. O lavado foi centrifugado por 10 minutos a 1500rpm e seu sobrenadante desprezado. Ressuspende-se o "pellet" em $1 \mathrm{ml} \mathrm{de}$ RPMI contendo $10 \%$ de soro bovino fetal e antibiótico. Dessa suspensão, retira-se uma alíquota de $10 \mu$ que foi diluída em solução de Turk $(990 \mu \mathrm{L})$, para contagem de células viáveis (macrófagos). Depois de contadas, as concentrações foram acertadas para $5 \times 10^{6}$ $\mathrm{cel} / \mathrm{ml}$.

Foram distribuídos $100 \mu \mathrm{l}$ desta suspensão em placa de 96 poços, ctendo 5 x $10^{6} \mathrm{cel} /$ poço onde foram adicionados $100 \mu \mathrm{L}$ de LPS $(10 \mu \mathrm{g} / \mathrm{mL})$ (E. coli, sorotipo 026:B6, Sigma, USA) para estimulação.

A placa foi levada para estufa contendo $5 \%$ de $\mathrm{CO}_{2}$, durante 48 horas, a $37^{\circ} \mathrm{C}$. Após este período, submeteu-se a placa à centrifugação a 1500rpm durante 4 min. Recolheu-se $100 \mu \mathrm{l}$ do sobrenadante e transferiu-se para outra placa de 96 poços. Em seguida, adicionouse igual volume de reagente de Griess $(50 \mu \mathrm{L}$ de sulfanilamida $1 \%$ (Sigma) e $50 \mu \mathrm{L}$ de N-1naftiletilenodiamina $0.1 \%$ (Sigma) diluídos em solução de ácido fosfórico 5\%), permitindo a revelação da reação por meio de leitor de microplacas, utilizando filtro de 540nm. A 
curva padrão de $200 \mu \mathrm{M}$ a $6 \mu \mathrm{M}$ foi realizada utilizando Nitrito de Sódio (TERENZI et al., 1995; HRUBY et al.,1997).

\subsection{Linfoproliferação}

Células do baço e do timo foram maceradas em peneira de nailon e suspendidas em RPMI 1640 incompleto em tubos falcons e centrifugadas a 1500rpm por 5 minutos e suspensas em RPMI 1640 contendo $10 \%$ soro bovino fetal (FBS; Gibco), 50 U/mL penicilina, $50 \mathrm{U} / \mathrm{mL}$ estreptomicina $(\mathrm{Gibco})$ onde as células esplênicas $\left(5 \times 10^{5}\right.$ células por poço) eram distribuídas em duplicata em microplacas de 96 -poços por $30 \mathrm{~h}$ à $37^{\circ} \mathrm{C}$ e incubada em estufa de $\mathrm{CO}_{2}$ na presença de $1 \mu \mathrm{g} / \mathrm{mL}$ concanavalina A (ConA) (Sigma). Utilizou-se cultura negativa como controle, sem ConA.

Utilizamos a técnica descrita por Mossman (MOSSMAN, 1983), com modificações por Hansen (HANSEN et al., 1989). Imediatamente após a incubação de 30h foi adicionado $50 \mu \mathrm{L}$ de $1 \mathrm{mg} / \mathrm{mL}$ 3-(4,5-dimethyl-2-thiazoly)2,5-diphenyl-2h-tetrazolium bromide (MTT) em cada poço da cultura. Repetiu-se incubação por 1h, em seguida adicionou-se $50 \mu \mathrm{L}$ de DMSO era adicionado e a absorbância era realizada a 570nm. As respostas a mitogenos eram calculadas pela taxa de estimulação de mitógenos.

Fórmula $=[(\mathrm{Ac}-\mathrm{Aa}) / \mathrm{Ac}] \times 100$

Ac= Média dos valores de absorbância obtidos pelo controle negativo.

$\mathrm{Aa}=$ Valores individuais de absorbância obtidos das amostras. 


\subsection{Técnica histológica}

Após remoção e pesagem dos órgãos, esses eram lavados em solução fisiológica 0,9\% e fixados em álcool, formol e ácido acético (ALFAC), processados histologicamente e incluídos em parafina. Cortes histológicos de $6 \mu \mathrm{m}$ foram confeccionados e corados por hematoxilina-eosina. Os cortes foram realizados com intervalo de $70 \mu \mathrm{m}$ para evitar a análise do mesmo ninho com formas amastigotas de T.cruzi (CAMARGOS et al, 2000). Os cortes foram observados em microscópio óptico com aumento de 1000X (imersão) (MELO \& BRENER, 1978).

\subsection{Intensidade do parasitismo tecidual}

O grau de parasitismo foi estimado por meio da análise qualitativa, a partir da determinação do número de ninhos observados em 50 campos microscópicos (400X). Para essa análise foram utilizados cinco animais de cada grupo em estudo (CASTRO \& BRENER, 1985). Os valores foram expressos em \pm S.E.M.

\subsection{Determinação da concentração das citocinas - IL-2, IL-4, IL-10, TNF- $\alpha$, e IFN- $\gamma$}

Placas de 96 poços de fundo chato foram sensibilizadas com $100 \mu \mathrm{L} /$ poço de anticorpo de captura purificado específico para as citocinas citadas acima, previamente preparado na diluição de 1:250 em tampão de sensibilização. As placas foram incubadas “overnight” (16-20 horas de incubação) à temperatura ambiente. Após esse período, as

placas foram lavadas, por três vezes, com tampão de lavagem (PBS + Tween 20 0,05\%) e as ligações não específicas foram bloqueadas com a adição de tampão de diluição (PBS com $10 \%$ de soro bovino fetal (SBF) pH 7,0, seguindo de incubação por mais uma hora em 
temperatura ambiente. Após o tempo de bloqueio, as placas foram novamente lavadas com tampão de lavagem, por três vezes. Para realização da curva foram adicionados os padrões de citocina recombinante $(2000 \mathrm{pg} / \mathrm{mL})$ na quantidade de $100 \mu \mathrm{L} /$ poço, em duplicata, diluidos de forma seriada com tampão de diluição Tween (PBS Tween 0,05\% com SBF 10\% pH 7,0) nas concentrações de 2000 pg/mL a 0 pg/mL em 7 poços da placa, sendo que no oitavo poço adicionou-se somente o tampão para a determinação do branco. Nos demais poços foram adicionados $100 \mu \mathrm{L}$ das amostras experimentais, incubando-se por 2 horas à temperatura ambiente. Após a incubação, as placas foram lavadas três vezes com tampão de lavagem e adicionado o anticorpo de detecção (anticorpos biotinilados anti-citocina) (18 $\mu \mathrm{g} / \mathrm{mL})$. As placas foram novamente incubadas por mais duas horas e em seguida lavadas por mais três vezes. A revelação enzimática foi realizada pela adição de $100 \mu \mathrm{L} /$ poço de estreptavidina-peroxidase diluída em tampão de diluição Tween na proporção de 1:250 e posterior incubação de 1 hora à temperatura ambiente. As placas foram lavadas por mais três vezes sendo adicionado substrato revelador $\left(15 \mathrm{~mL}\right.$ TMB $\left.+15 \mathrm{~mL} \mathrm{de} \mathrm{H}_{2} \mathrm{O}_{2}\right)$ nos poços. Incubou-se por mais 20 minutos, protegendo da luz e parando a reação com a adição de 50 $\mu \mathrm{L}$ de solução de $\mathrm{H}_{2} \mathrm{SO}_{4} 1 \mathrm{M}$.

As densidades ópticas (D.O) das placas foram lidas em leitor de microplaca (Teccan, Modelo Sunrise- $\mu$ Quant) em um comprimento de onda de 450nm. O kit utilizado foi da empresa BD Biosciences, San Diego, U.S.A.: BD OptEIA ${ }^{\mathrm{TM}}$ SET Rat.

\subsection{Corticosterona}

A concentração de corticosterona foi determinada no plasma dos animais de cada grupo experimental estocado à $-70^{\circ} \mathrm{C}$. A técnica utilizada foi por specific two-site enzymelinked immunoabsorbent assay (ELISA) usando-se o protocolo padrão. Os anticorpos para 
captura e detecção de cada uma das amostras foram obtidos do Corticosterone EIA kit (Cayman Chimical). As amostras foram processadas em triplicatas.

\subsection{Quantificação de Neurônios}

Foram retirados de cada animal fragmentos de cerca de $1,5 \mathrm{~cm}$ de comprimento de esôfago distal e intestino grosso (cólon), sendo distendidos em placa de cortiça, tomando o cuidado de mantê-los presos com o auxílio de alfinetes em suas extremidades. Esses conjuntos foram colocados em formol a $4 \%$ tamponado durante 24 horas e a seguir armazenados em solução de etanol a 70\%. Os fragmentos serão incluídos em parafina para serem submetidos a cortes transversais de $5 \mu \mathrm{m}$ de espessura. $\mathrm{O}$ primeiro de cada cinco cortes serão corados com cresil-violeta para diferenciar melhor o neurônio do plexo mientérico facilitando a sua contagem, resultando num total de 40 cortes, que equivalem a $1 \mathrm{~mm}$ de espessura do esôfago e/ou do cólon (POLLI-LOPES et al., 2003). Considerando-se que o diâmetro médio do corpo do neurônio mientérico seja de 16 a 20,6 $\mu$ m (SANTER \& BAKER, 1988), o escalonamento dos cortes evita contagem dupla do mesmo neurônio.

\subsection{Taxa de mortalidade dos animais}

Para verificação da taxa de mortalidade dos animais os mesmos foram observados diariamente.

\subsection{Análise estatística}

Os dados foram analisados estatisticamente pelo programa computacional Graph Pad Prism versão 4.00 para Windows, GraphPad Software, San Diego Califórnia USA. A 
comparação entre os grupos foi realizada por meio de análise de variância: One Way ANOVA e post-test de Bonferroni. Para análise dos resultados de contagem neuronal, assim como para os distintos cálculos matemáticos envolvidos nos estudos morfométricos, serão utilizados programas para computador IBM-PC, em linguagem BASIC AVANÇADO (BÁSICA) desenvolvidos no Deparatamento de Estomatologia da Faculdade de Odontologia de Ribeirão Preto - USP, visando o processamento dos dados experimentais. Foi utilizado o teste não paramétrico de Kurskall Wallis (SIEGEL, 1975). Os resultados foram expressos pela média ( \pm erro padrão da média) e considerados estatisticamente significativos para um $p<0,05$. 


\section{RESULTADOS}

\subsection{Taxa de mortalidade dos animais}

Os animais de todos os grupos em estudo mantiveram-se vivos durante todo o experimento.

\subsection{Peso Corpóreo}

\subsubsection{Grupos Controles}

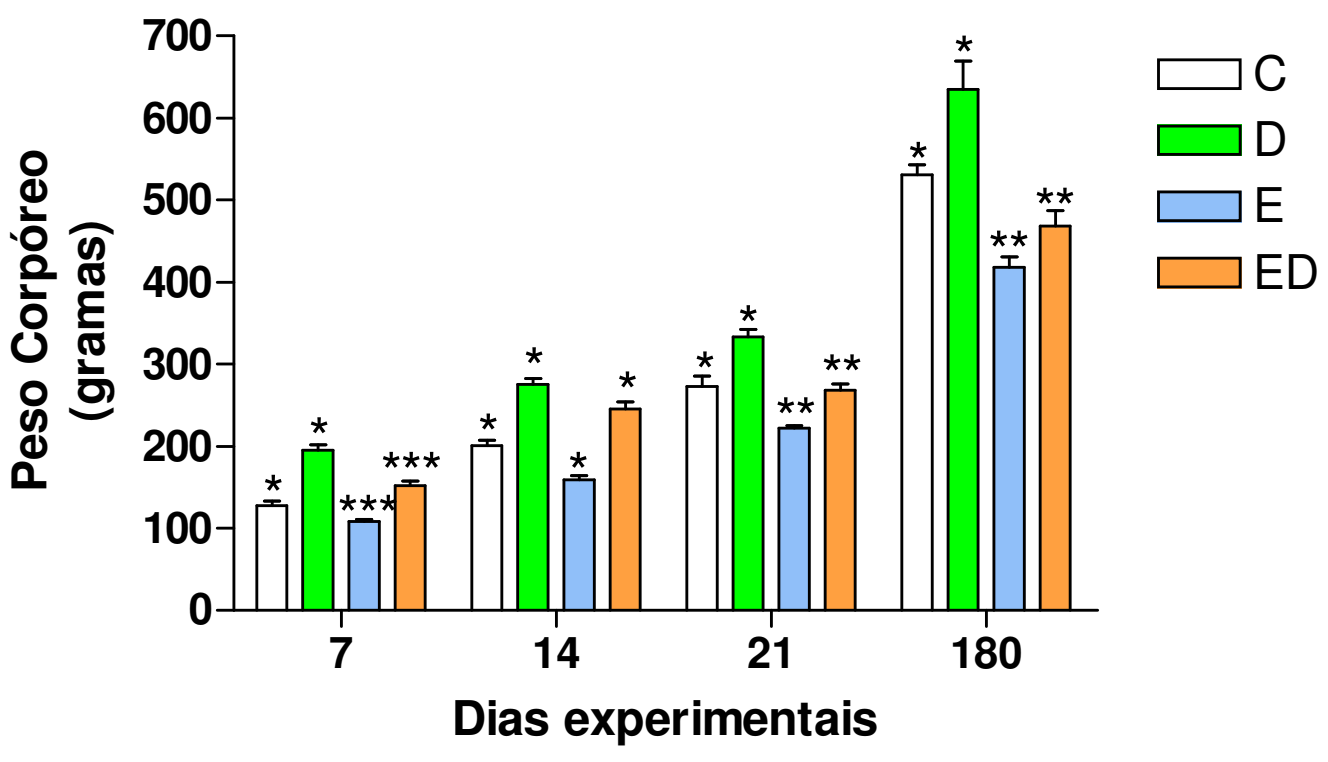

Figura 1. Peso corpóreo de ratos Wistar machos controles no $7^{\circ}, 14^{\circ}, 21^{\circ}$ e $180^{\circ}$ dias, dos seguintes grupos: Controle (C); Controle tratado com DHEA (D); Controle submetido ao estresse (E); Controle submetido ao estresse e tratado com DHEA (ED). Para cada dia e grupo foram utilizados $\mathrm{n}=5$.

$* \mathrm{p}<0,001 \mathrm{C} v s \mathrm{D}\left(7^{\circ}, 14^{\circ}, 21^{\circ}\right.$ e $180^{\circ}$ dias $) ; \mathrm{E} v s \mathrm{ED}\left(14^{\circ}\right.$ dias $)$

$* * \mathrm{p}<0,01 \mathrm{E} v s \mathrm{ED}\left(21^{\circ}\right.$ e $180^{\circ}$ dias $)$;

$* * * \mathrm{p}<0,05 \mathrm{E} v s \operatorname{ED}\left(7^{\circ}\right.$ dias $)$.

Houve aumento significativo do peso corpóreo para os grupos controles em todos os dias de experimento, principalmente os grupos tratados com DHEA (Figura 1). 


\subsubsection{Grupos Infectados}

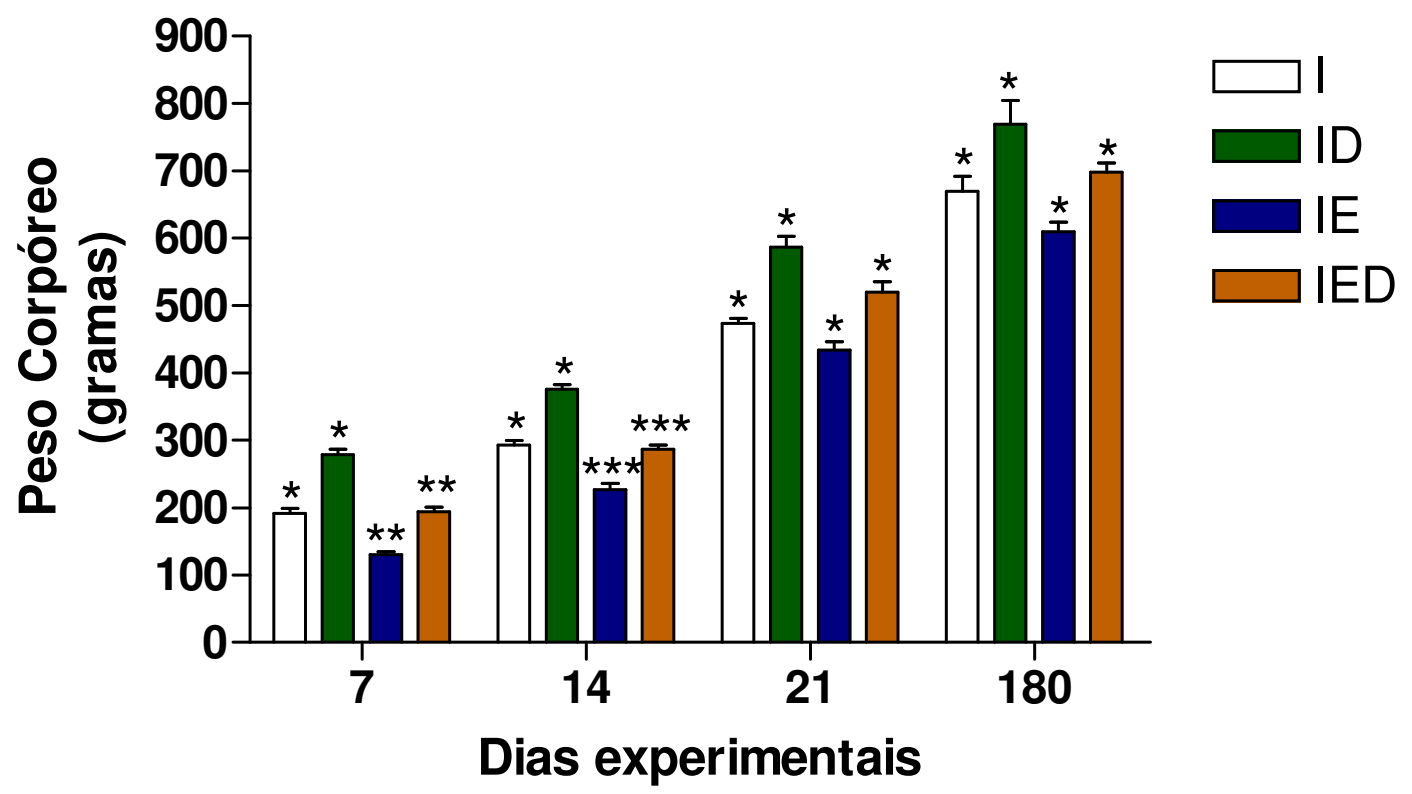

Figura 2. Peso corpóreo de ratos Wistar machos infectados com a cepa $\mathrm{Y}$ de $T$. cruzi, no $7^{\circ}, 14^{\circ}$, $21^{\circ}$ e $180^{\circ}$ dias após a infecção, dos seguintes grupos: Infectado (I); Infectado tratado com DHEA (ID); Infectado submetido ao estresse (IE); Infectado submetido ao estresse e tratado com DHEA (IED). Para cada dia e grupo experimental foram utilizados $n=5$.

${ }^{*} \mathrm{p}<0,001$ I $v s$ ID $\left(7^{\circ}, 14^{\circ}, 21^{\circ}\right.$ e $180^{\circ}$ dias $) ; \operatorname{IE} v s \operatorname{IED}\left(21^{\circ}\right.$ e $180^{\circ}$ dias $) ;$

$* * \mathrm{p}<0,01$ IE vs IED $\left(7^{\circ}\right.$ dias $)$;

$* * * \mathrm{p}<0,05$ IE $v s$ IED $\left(14^{\circ}\right.$ dias $)$.

Houve aumento significativo do peso corpóreo para os grupos infectados em todos os dias de experimento, principalmente os grupos tratados com DHEA (Figura 2). 


\subsection{Peso dos Órgãos}

\subsubsection{Peso do Coração}

\subsubsection{Grupos Controles}

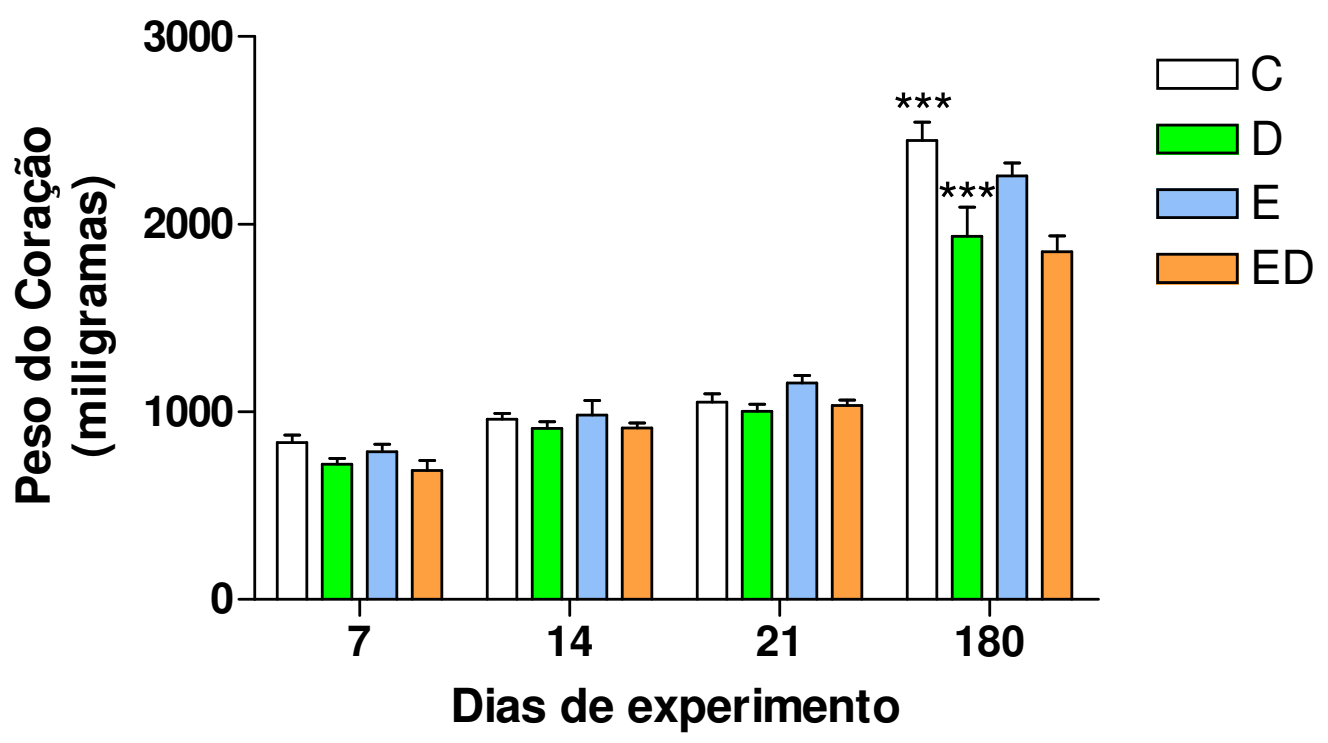

Figura 3. Peso do coração de ratos Wistar machos controle, no $7^{\circ}, 14^{\circ}, 21^{\circ}$ e $180^{\circ}$ dias, dos seguintes grupos: Controle (C), Controle tratado com DHEA (D), Controle Estressado (E), Controle Estressado e tratado com DHEA (ED). Para cada dia e grupo experimental foram utilizados $n=5$. $* * * \mathrm{p}<0,05 \mathrm{C}$ vs $\mathrm{D}\left(180^{\circ}\right.$ dias $)$.

No $180^{\circ}$ dias observou-se uma diminuição significativa do peso do coração, no grupo tratado com DHEA em relação ao grupo controle $(\mathrm{p}<0,05)$. (Figura 3). 


\subsubsection{Grupos Infectados}

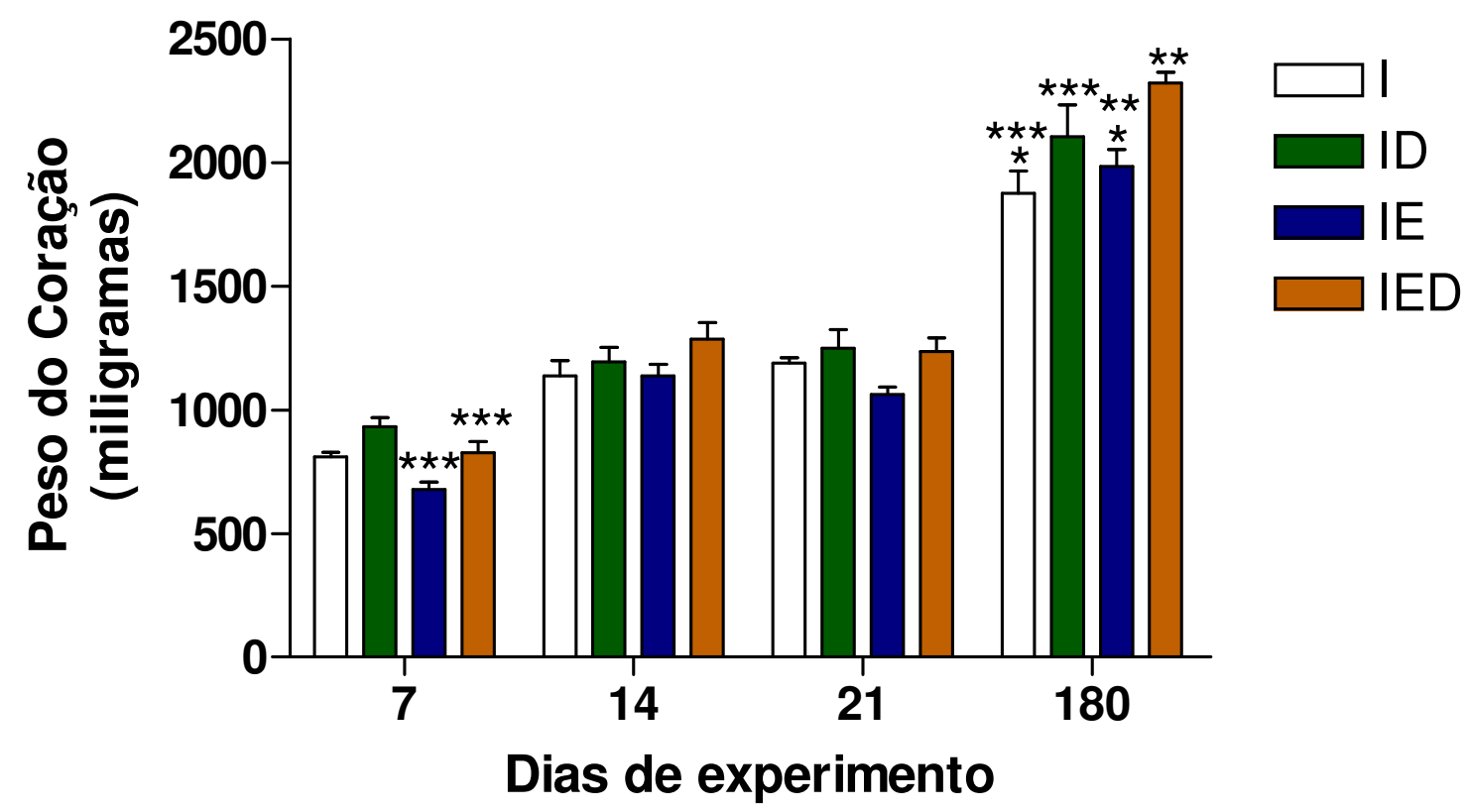

Figura 4. Peso do coração de ratos Wistar machos infectados com a cepa Y de $T$. cruzi, no $7^{\circ}, 14^{\circ}$, $21^{\circ}$ e $180^{\circ}$ dias após a infecção, dos seguintes grupos: Infectado (I), Infectado tratado com DHEA (ID), Infectado Estressado (IE) e Infectado Estressado e tratado com DHEA (IED). Para cada dia e grupo experimental foram utilizados $n=5$.

$* \mathrm{p}<0,001$ I vs IE $\left(180^{\circ}\right.$ dias $)$

$* * \mathrm{p}<0,01 \mathrm{IE} v s \operatorname{IED}\left(180^{\circ}\right.$ dias $)$

***p<0,05 IE vs IED ( $7^{\circ}$ dias $) ;$ I $v s$ ID $\left(180^{\circ}\right.$ dias $)$.

Apenas no $7^{\circ}$ e $180^{\circ}$ dias, os animais infectados e tratados com DHEA apresentaram aumento significativo do peso do coração quando comparados aos animais sem tratamento (Figura 4). 


\subsection{Parasitemia}

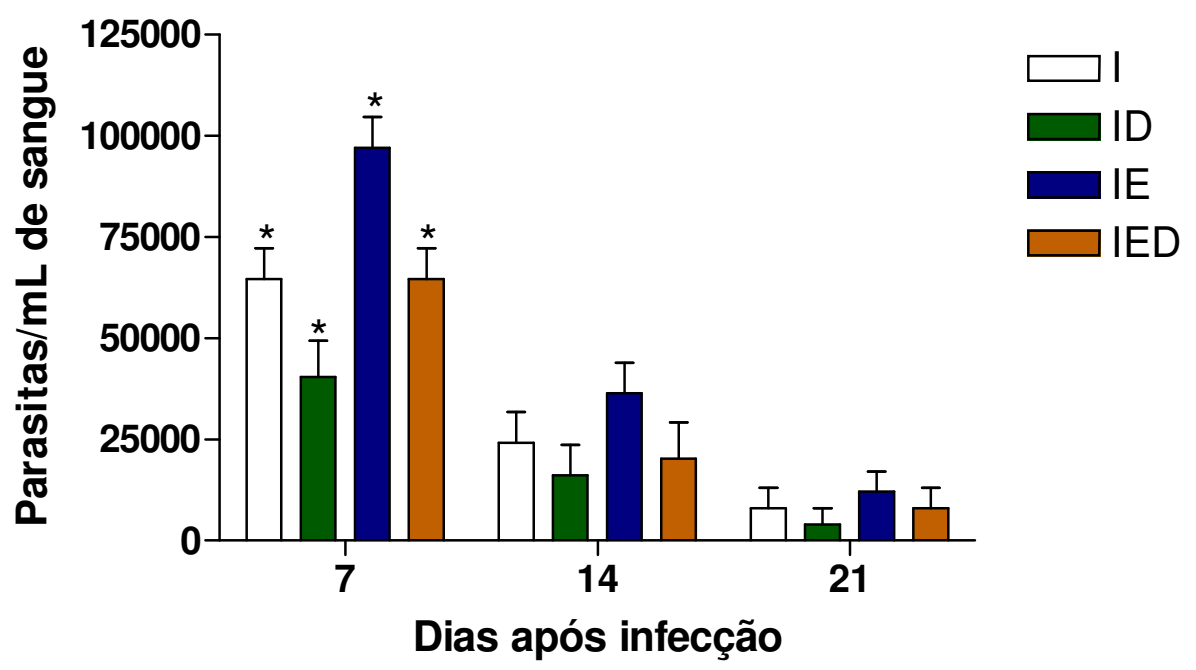

Figura 5. Evolução da parasitemia em ratos Wistar machos infectados com a cepa Y de T. cruzi durante os $7^{\circ}, 14^{\circ}, 21^{\circ}$ dias após a infecção, dos seguintes grupos: Infectado (I), Infectado tratado com DHEA (ID), Infectado estressado (IE) e Infectado estressado tratado com DHEA (IED). Foram utilizados 5 animais para cada grupo em cada dia de experimento. $* \mathrm{p}<0,05$ I $v s$ ID; IE vs IED ( $7^{\circ}$ dias).

O pico parasitêmico ocorreu no $7^{\circ}$ dias após o inóculo para todos os grupos, os animais submetidos ao estresse repetitivo apresentaram maior parasitemia em relação aos animais não estressados, porém os grupos tratados com DHEA demonstraram diminuição no número de parasitas quando comparados ao grupo estressado e infectado (Figura 5). 


\subsection{Contagem Global de macrófagos peritoniais}

Tabela 1. Contagem global de macrófagos peritoniais em ratos Wistar machos controles (não infectados) e infectados com a cepa Y de $T$. cruzi durante os $7^{\circ}, 14^{\circ}, 21^{\circ}$ e $180^{\circ}$ dias de experimento.
Grupos
Macrófagos peritoniais $/ \mathrm{mm}^{3}$ (Média $\pm \mathrm{DP}^{1}$ )

Experimentais

\begin{tabular}{ccccc}
\hline$(\mathrm{n}=5)$ & $7^{\circ}$ dia & $14^{\circ}$ dia & $21^{\circ}$ dia & $180^{\circ}$ dia \\
\hline C & $2800 \pm 365,7$ & $2738 \pm 225,8$ & $2750 \pm 353,6$ & $2150 \pm 358,8$ \\
$\mathbf{D}$ & $3250 \pm 295,8$ & $3125 \pm 312,6$ & $2950 \pm 255$ & $2400 \pm 257,4$ \\
$\mathbf{E}$ & $6800 \pm 520,8^{*}$ & $5488 \pm 1385$ & $5450 \pm 300^{* * *}$ & $1650 \pm 127,5^{*}$ \\
$\mathbf{E D}$ & $8550 \pm 555,7^{*}$ & $7425 \pm 1566^{*}$ & $7100 \pm 539,7^{*}$ & $3300 \pm 390,5$ \\
$\mathbf{I}$ & $24300 \pm 483,5$ & $20050 \pm 538,5$ & $14900 \pm 444,4$ & $9700 \pm 390,5$ \\
ID & $28500 \pm 627,5^{* *}$ & $25150 \pm 983^{* *}$ & $20940 \pm 841^{*}$ & $16740 \pm 609,4 *$ \\
IE & $29000 \pm 524,4^{*}$ & $25150 \pm 1065^{*}$ & $21900 \pm 1231^{*}$ & $17500 \pm 932,1^{*}$ \\
IED & $34600 \pm 831,4^{*}$ & $31550 \pm 686,5^{*}$ & $28400 \pm 578,8^{*}$ & $23100 \pm 407,7 *$
\end{tabular}

${ }^{1}$ DP: Desvio Padrão

Grupos: Controle (C), Controle tratado com DHEA (D), Controle estressado (E), Controle estressado e tratado com DHEA (ED), Infectado (I), Infectado tratado com DHEA (ID), Infectado estressado (IE), Infectado estressado e tratado com DHEA (IED).

*p $<0,001 \mathrm{E}$ vs $\mathrm{C}\left(7^{\circ}, 180^{\circ}\right.$ dias $) ; \mathrm{ED}$ vs $\mathrm{E}\left(7^{\circ}, 14^{\circ}\right.$ e $21^{\circ}$ dias $) ; \operatorname{IED}$ vs $\operatorname{IE}\left(7^{\circ}, 14^{\circ}, 21^{\circ}\right.$ e $180^{\circ}$ dias $)$; IE vs I $\left(7^{\circ}, 14^{\circ}, 21^{\circ}\right.$ e $180^{\circ}$ dias $)$; ID vs I ( $21^{\circ}$ e $180^{\circ}$ dias $)$;

$* * \mathrm{p}<0,01$ ID vs I $\left(7^{\circ}\right.$ e $14^{\circ}$ dias $)$;

$* * * \mathrm{p}<0,05 \mathrm{E}$ vs $\mathrm{ED}\left(21^{\circ}\right.$ dias $)$. 
Nos animais controles foram observadas alterações significativas entre os grupos estressados, estressados tratados com DHEA e controle durante o experimento.

Entre os animais infectados, o grupo estressado apresentou valores estatisticamente menores que os animais estressados e tratados com DHEA e o grupo infectado (Tabela 1). 


\subsection{Linfoproliferação}

\subsubsection{Linfoproliferação de Esplenócitos}

\subsubsection{Grupos Controles}

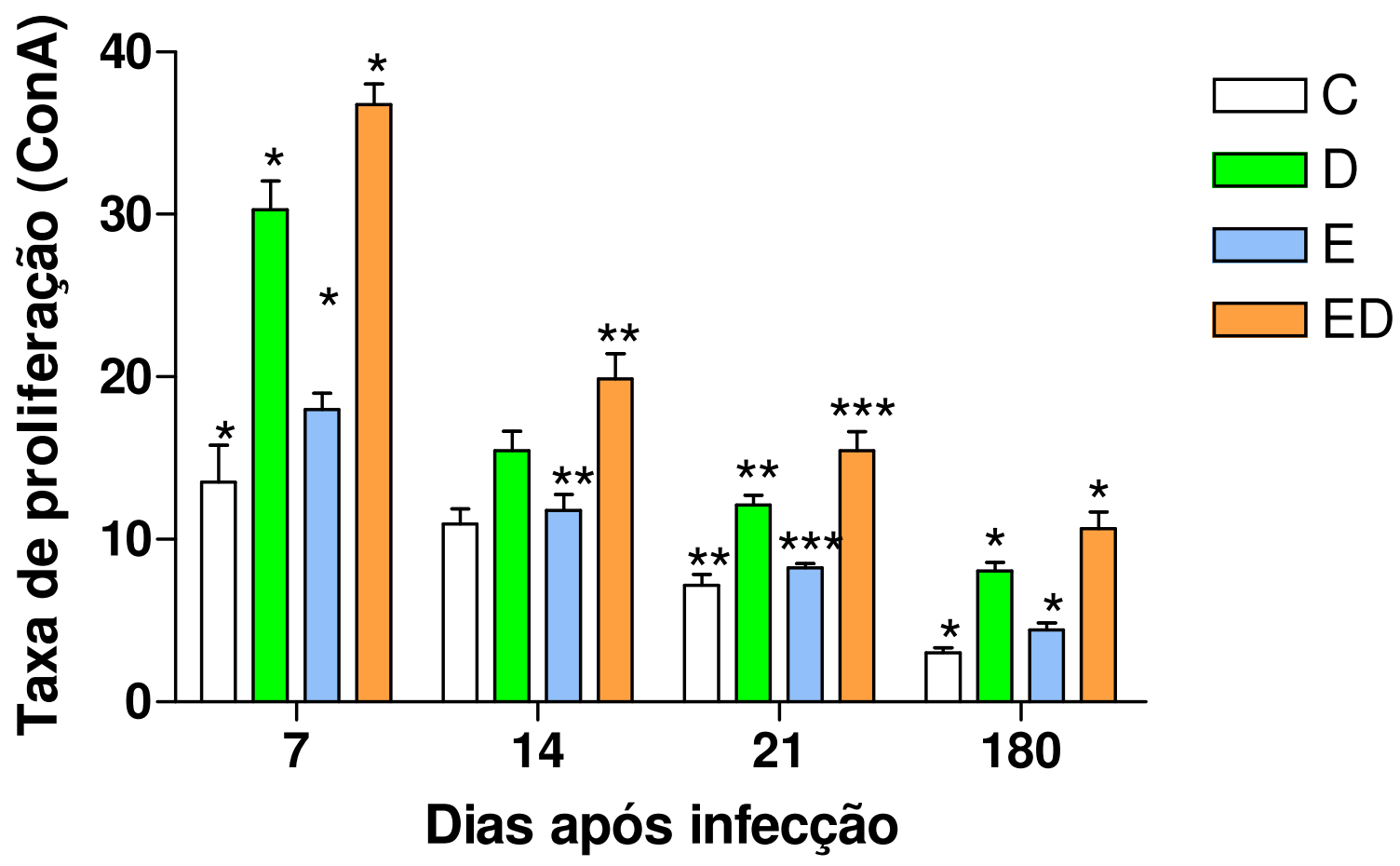

Figura 6. Proliferação de esplenócitos induzidos por ConA $(1 \mu \mathrm{g} / \mathrm{mL})$ de ratos Wistar machos controles durante a fase aguda $\left(7^{\circ}, 14^{\circ}\right.$ e $21^{\circ}$ dia após infecção) e crônica (180 dias após infecção), dos seguintes grupos: Controle (C); Controle tratado com DHEA (D); Controle submetido ao estresse (E); Controle submetido ao estresse e tratado com DHEA (ED). Os dados são expresso em taxa de proliferação.

$* \mathrm{p}<0,001 \mathrm{C} v s \mathrm{D}\left(7^{\circ}\right.$ e $180^{\circ}$ dias $) ; \mathrm{E} v s \mathrm{ED}\left(7^{\circ}\right.$ dias $) ;$

**p<0,01 E vs $\mathrm{ED}\left(14^{\circ}\right.$ dias $) ; \mathrm{C} v s \mathrm{D}\left(21^{\circ}\right.$ dias $)$;

$* * * \mathrm{p}<0,05 \mathrm{D}$ vs $\mathrm{ED}\left(21^{\circ}\right.$ dias $)$.

Os animais submetidos ao tratamento com DHEA apresentaram aumento significativo na porcentagem de proliferação de esplenócitos quando comparados aos animais não tratados (Figura 6). 


\subsubsection{Grupos Infectados}

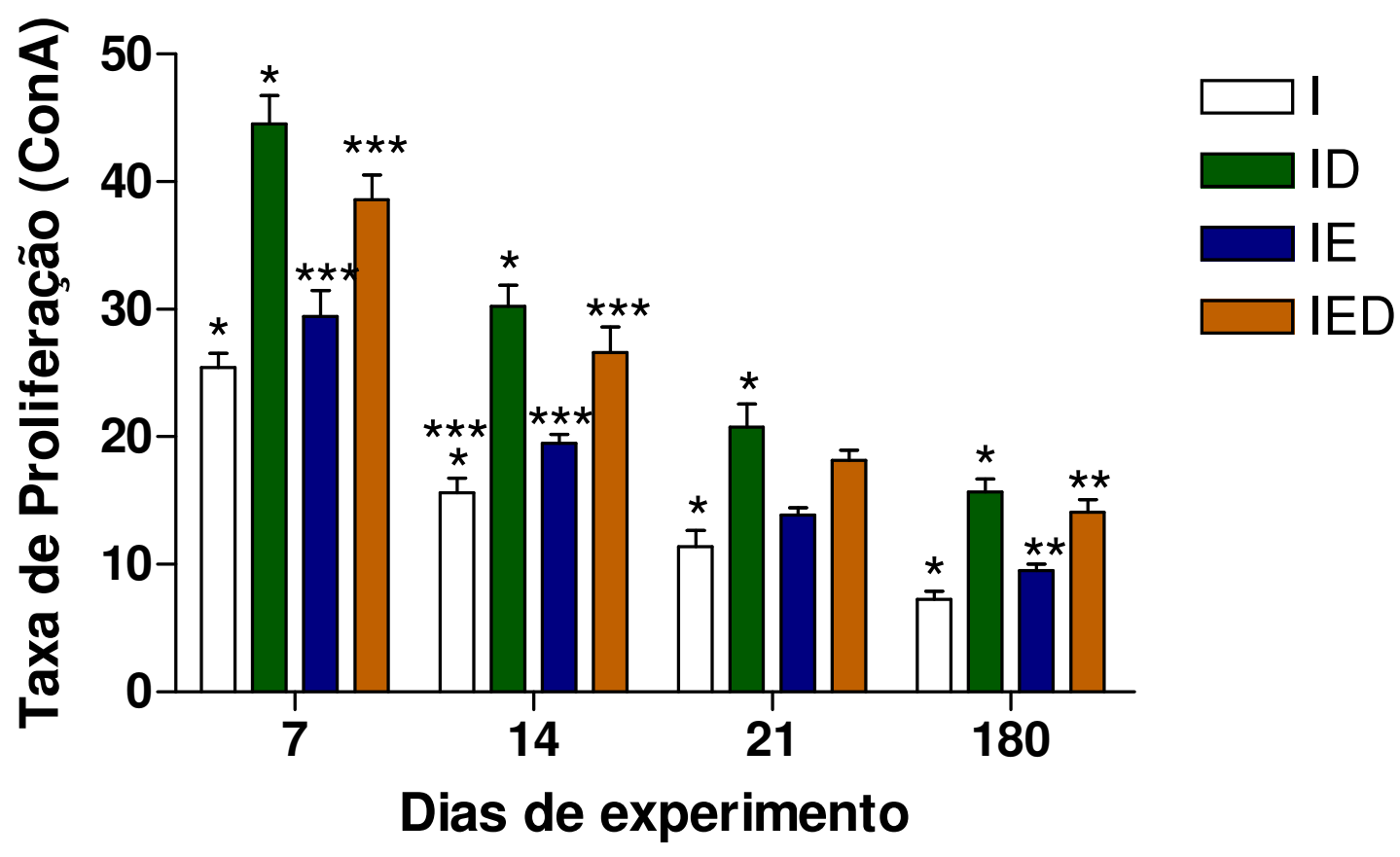

Figura 7. Proliferação de esplenócitos induzidos por ConA $(1 \mu \mathrm{g} / \mathrm{mL})$ de ratos Wistar machos infectados com $1 \times 10^{5}$ formas tripomastigotas sangüícolas da cepa Y de Trypanosoma cruzi durante a fase aguda $\left(7^{\circ}, 14^{\circ}\right.$ e $21^{\circ}$ dia após infecção) e crônica ( $180^{\circ}$ dias após infecção), dos seguintes grupos: Infected (I); Infectado tratado com DHEA (ID); Infectado submetido ao estresse (IE) e Infectado submetido ao estresse e tratado com DHEA (IED). Os dados são expresso em taxa de proliferação.

${ }^{*} \mathrm{p}<0,001$ I $v s \mathrm{ID}\left(7^{\circ}, 14^{\circ}, 21^{\circ}\right.$ e $180^{\circ}$ dias $)$;

$* * \mathrm{p}<0,01$ IE $v s$ IED $\left(180^{\circ}\right.$ dias $)$;

$* * * \mathrm{p}<0,05$ IE $v s$ IED ( $7^{\circ}$ e $14^{\circ}$ dias $) ;$ I $v s$ IE (14 dias).

Nos grupos infectados, a administração concomitante de DHEA elevou a proliferação de células esplênicas estimuladas por concanavalina A (ConA), em relação aos grupos não tratados com DHEA em todos os dias de experimento. Ainda podemos observar 
que os animais estressados e tratados com DHEA apresentaram aumento da taxa de proliferação quando comparado aos outros grupos (Figura 7). 


\subsubsection{Linfoproliferação de Timócitos}

\subsubsection{Grupos Controles}

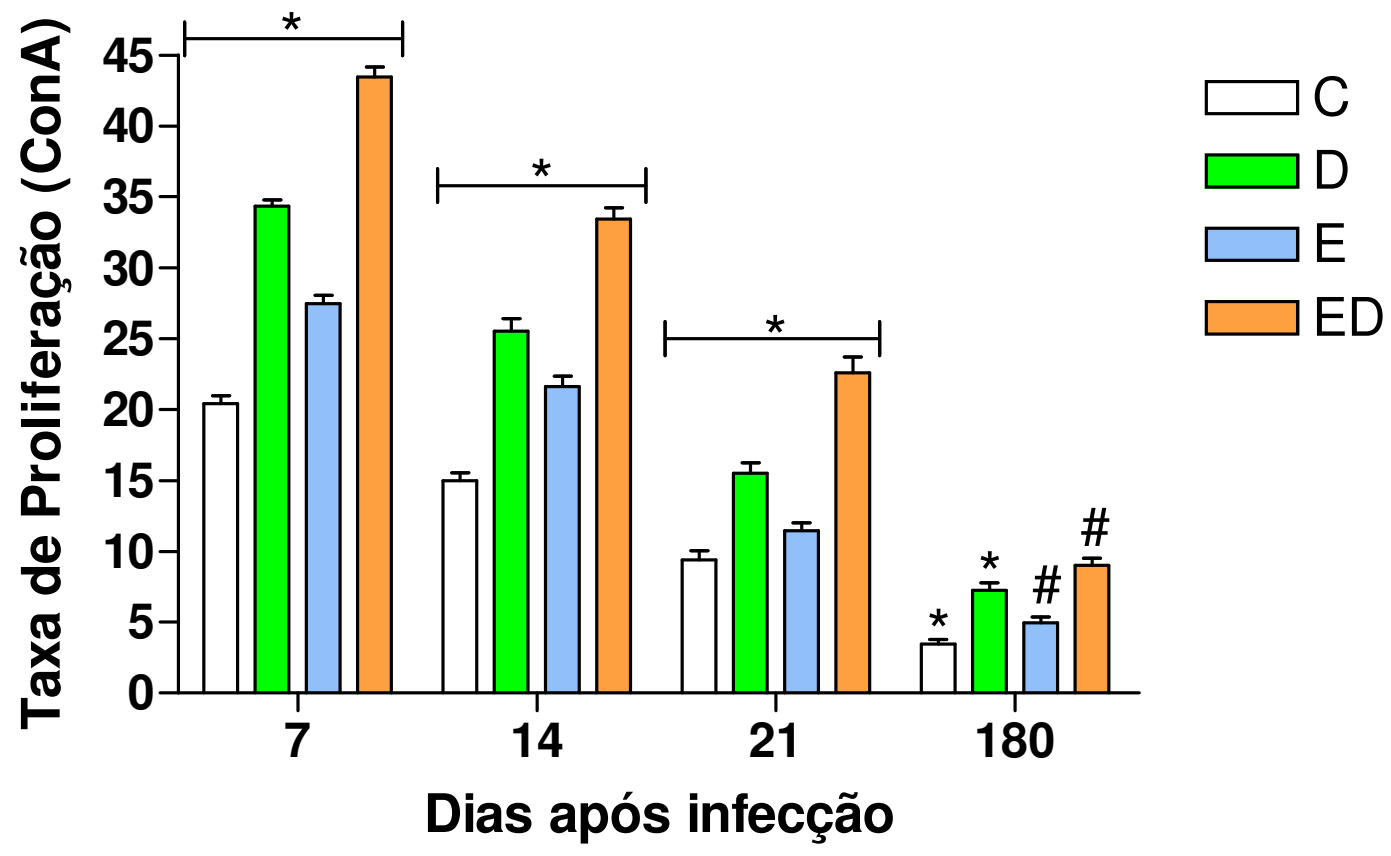

Figura 8. Proliferação de timócitos induzidos por $\operatorname{ConA}(1 \mu \mathrm{g} / \mathrm{mL})$ de ratos Wistar machos durante a fase aguda $\left(7^{\circ}, 14^{\circ}\right.$ e $21^{\circ}$ dia após infecção) e crônica (180 dias após infecção), dos seguintes grupos: Controle (C); Controle tratado com DHEA (D); Controle submetido ao estresse (E); Controle submetido ao estressse e tratado com DHEA (ED). Os dados são expresso em taxa de proliferação.

*p<0,001 C vs D; C vs E; E vs ED; D vs ED para os $7^{\circ}, 14^{\circ}$ e $21^{\circ}$ dias após infecção; C vs D 180 dias após infecção;

$\#$ p $<0,001 \mathrm{E}$ vs $\mathrm{ED} 180^{\circ}$ dias após infecção. 


\subsubsection{Grupos Infectados}

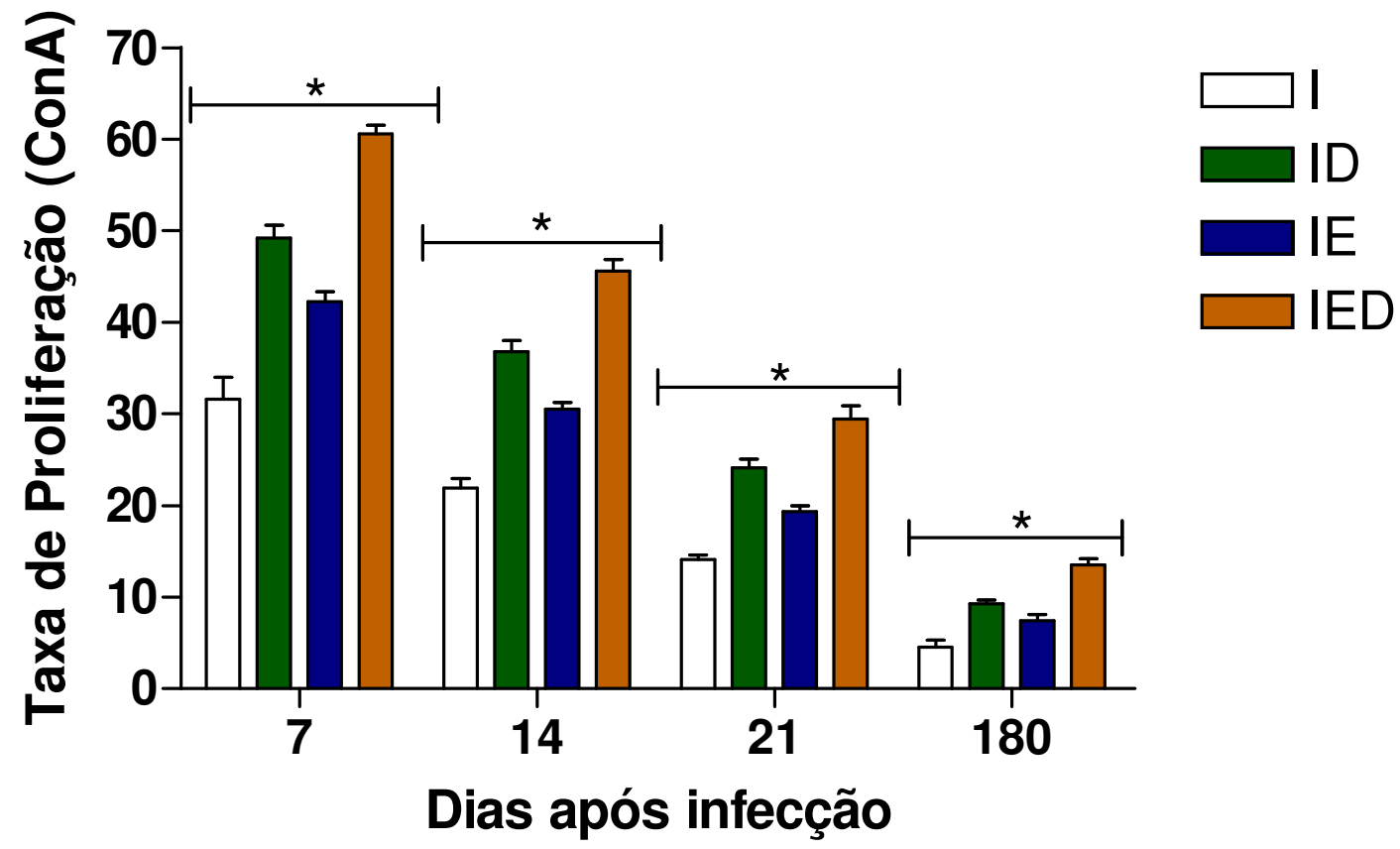

Figura 9. Proliferação de timócitos induzidos por $\operatorname{Con} \mathrm{A}(1 \mu \mathrm{g} / \mathrm{mL})$ de ratos Wistar machos infectados com $1 \times 10^{5}$ formas tripomastigotas sangüícolas da cepa Y de Trypanosoma cruzi durante a fase aguda $\left(7^{\circ}, 14^{\circ}\right.$ e $21^{\circ}$ dia após infecção) e crônica $\left(180^{\circ}\right.$ dias após infecção), dos seguintes grupos: Infectado (I); Infectado tratado com DHEA (ID); Infectado submetido ao estresse (IE) e Infectado submetido ao estresse e tratado com DHEA (IED). Os dados são expresso em taxa de proliferação.

*p<0,001 I vs ID; I vs IE; IE vs IED; ID vs IED para todos os dias após infecção;

Nos grupos controles e infectados, a administração concomitante de DHEA elevou a proliferação de timócitos estimulados por concanavalina A (ConA), em relação aos grupos não tratados com DHEA em todos os dias de experimento (Figura 8 e 9). 


\section{7. Óxido Nítrico}

5.7.1. Grupos Controles
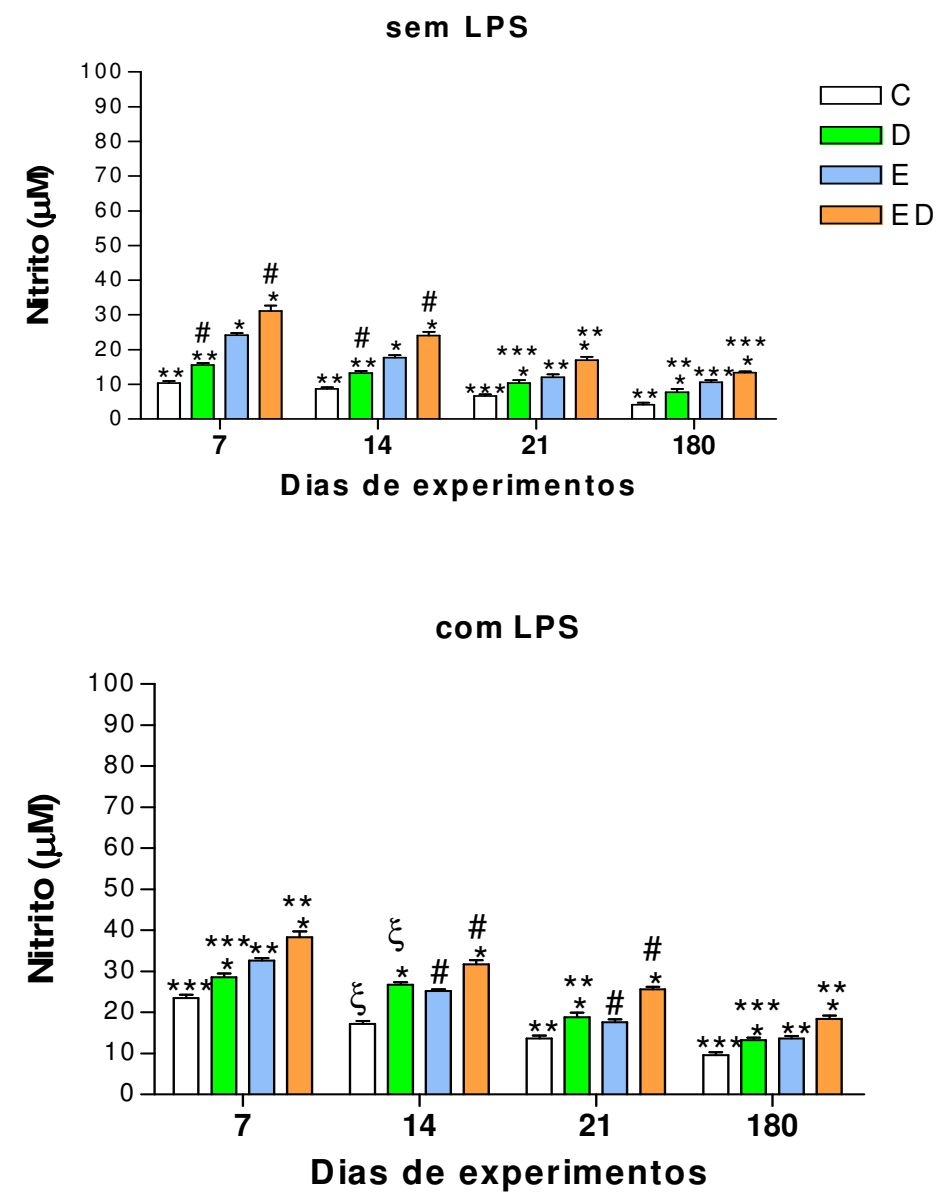

Figura 10. Produção de óxido nítrico expresso em $\mu \mathrm{M}$ de macrófagos peritoneais de ratos Wistar machos controles durante a fase aguda $\left(7^{\circ}, 14^{\circ}\right.$ e $21^{\circ}$ dia após infecção) e crônica $\left(180^{\circ}\right.$ dias após infecção) estimulados e não estimulados por LPS, dos seguintes grupos: Controle (C); Controle tratado com DHEA (D); Controle submetido ao estresse (E); Controle submetido ao estresse e tratado com DHEA (ED).

${ }^{*} \mathrm{p}<0,001 \mathrm{C}$ vs $\mathrm{D}\left(14^{\circ}\right.$ dias após infecção com LPS $)$; D vs $\mathrm{ED}\left(7^{\circ}, 14^{\circ}, 21^{\circ}\right.$ e $180^{\circ}$ dias após infecção com e sem LPS);

$\#$ p<0,001 E vs ED ( $7^{\circ}$ e $14^{\circ}$ dias após infecção, sem LPS e $14^{\circ}$ e $21^{\circ}$ dias após infecção, com LPS); $\xi \mathrm{p}<0,001 \mathrm{C} v s \mathrm{D}\left(14^{\circ}\right.$ dias após infecção, com LPS $)$; 
**p<0,01 C vs D $\left(7^{\circ}, 14^{\circ}\right.$ e $180^{\circ}$ dias após infecção, sem LPS e $21^{\circ}$ dias após infecção, com LPS); E $v s$ ED $\left(21^{\circ}\right.$ dias após infecção, sem LPS e $7^{\circ}$ e $180^{\circ}$ dias após infecção, com LPS);

***p $<0,05 \mathrm{C} v s \mathrm{D}\left(21^{\circ}\right.$ dias após infecção, sem LPS e $7^{\circ}$ e $180^{\circ}$ dias após infecção, com LPS); E vs ED (180 dias após infecção, sem LPS). 


\subsubsection{Grupos Infectados}
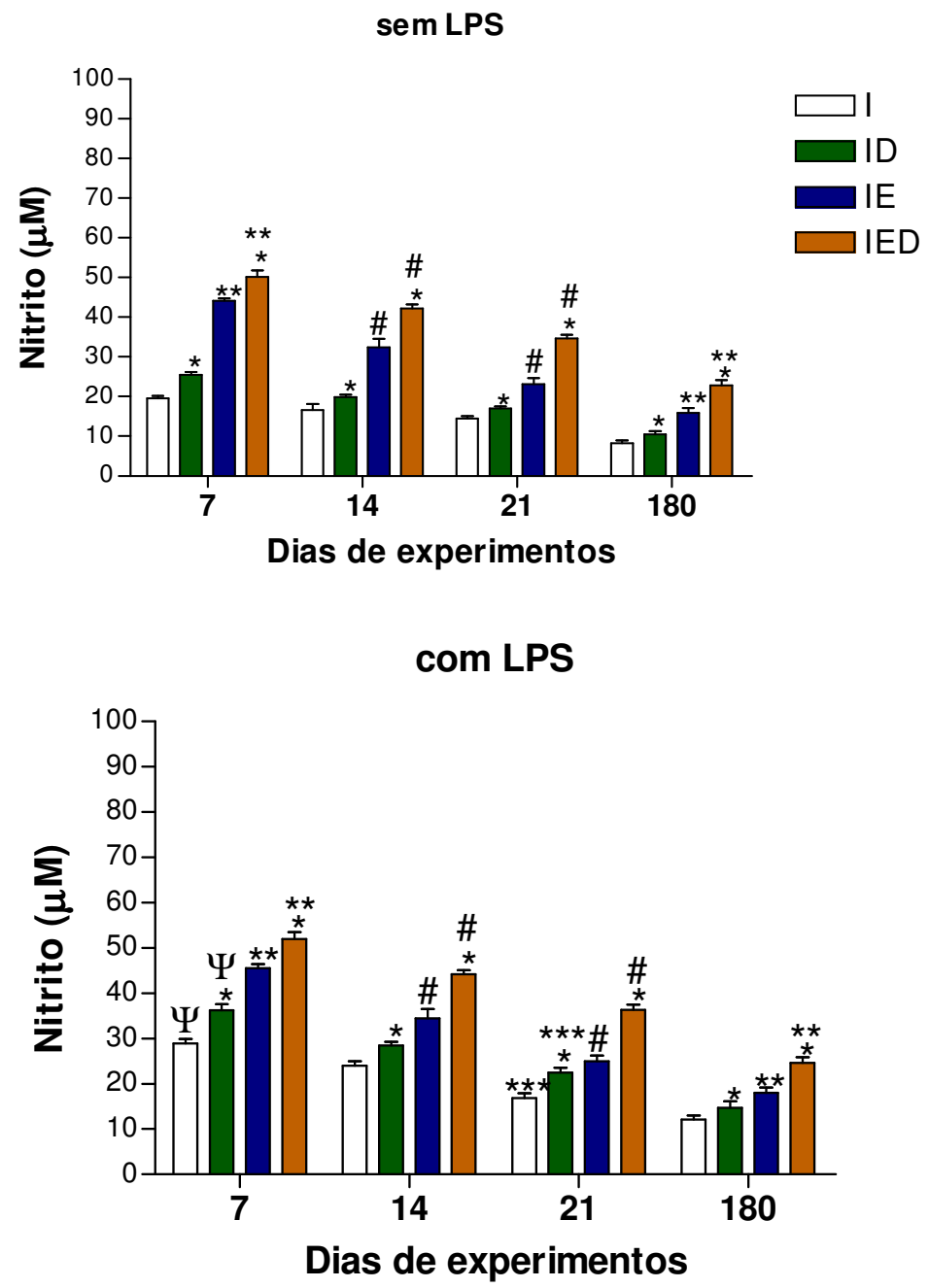

Figura 11. Produção de óxido nítrico expresso em $\mu \mathrm{M}$ em ratos Wistar machos infectados e infectados com a cepa Y de T. cruzi durante a fase aguda $\left(7^{\circ}, 14^{\circ}\right.$ e $21^{\circ}$ dia após infecção) e crônica (180 dias após infecção) estimuladas e não estimuladas por LPS. Nos seguintes grupos: Infectado (I); Infectado tratado com DHEA (ID); Infectado submetido ao estresse (IE) e Infectado submetido ao estresse e tratado com DHEA (IED).

*p<0,001 ID $v s$ IED $\left(7^{\circ}, 14^{\circ}, 21^{\circ}\right.$ e $180^{\circ}$ dias após infecção, com e sem LPS);

$\# \mathrm{p}<0,001$ IE $v s$ IED $\left(14^{\circ}\right.$ e $21^{\circ}$ dias após infecção, com e sem LPS);

**p $<0,01$ IE $v s$ IED ( $7^{\circ}$ e $180^{\circ}$ dias após infecção, com e sem LPS);

$\Psi \mathrm{p}<0,01$ I vs ID ( $7^{\circ}$ dias após infecção, com LPS); 
$* * * \mathrm{p}<0,05$ I $v s$ ID $\left(21^{\circ}\right.$ dias com LPS $)$.

O tratamento alterou a produção de óxido nítrico nos animais controles e infectados apresentando aumento da concentração de NO, principalmente nos animais submetidos ao tratamento com DHEA, enquanto os grupos estimulados por LPS apresentaram concentrações de NO estatisticamente maiores (Figuras 10 e 11). 


\subsection{Dosagem de IL-2}

\subsubsection{Grupos Controles}

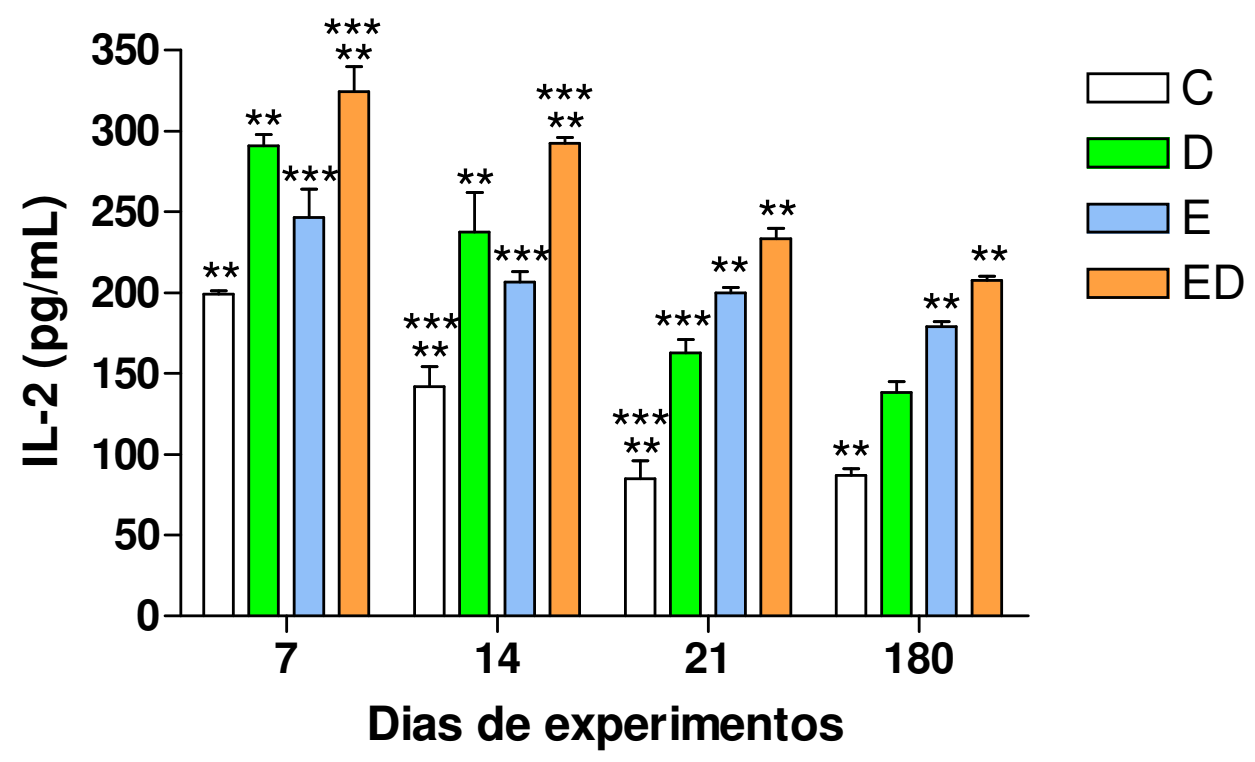

Figura 12. Concentrações de $\mathrm{IL}-2(\mathrm{pg} / \mathrm{mL})$ determinadas no soro de ratos Wistar machos controles durante os $7^{\circ}, 14^{\circ}, 21^{\circ}$ e $180^{\circ}$ dias de experimentos, nos seguintes grupos: Controle (C); Controle tratado com DHEA (D); Controle submetido ao estresse (E); Controle submetido ao estresse e tratado com DHEA (ED). Para cada grupo experimental em cada dia de infecção $n=5$.

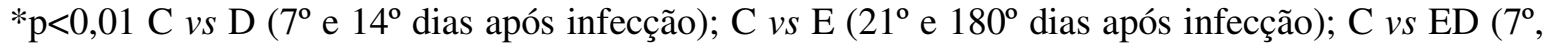
$14^{\circ}, 21^{\circ}$ e $180^{\circ}$ dias após infecção);

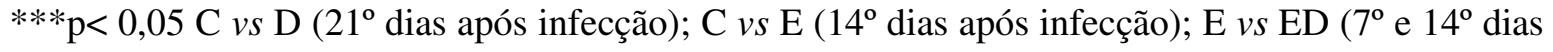
após infecção). 


\subsubsection{Grupos Infectados}

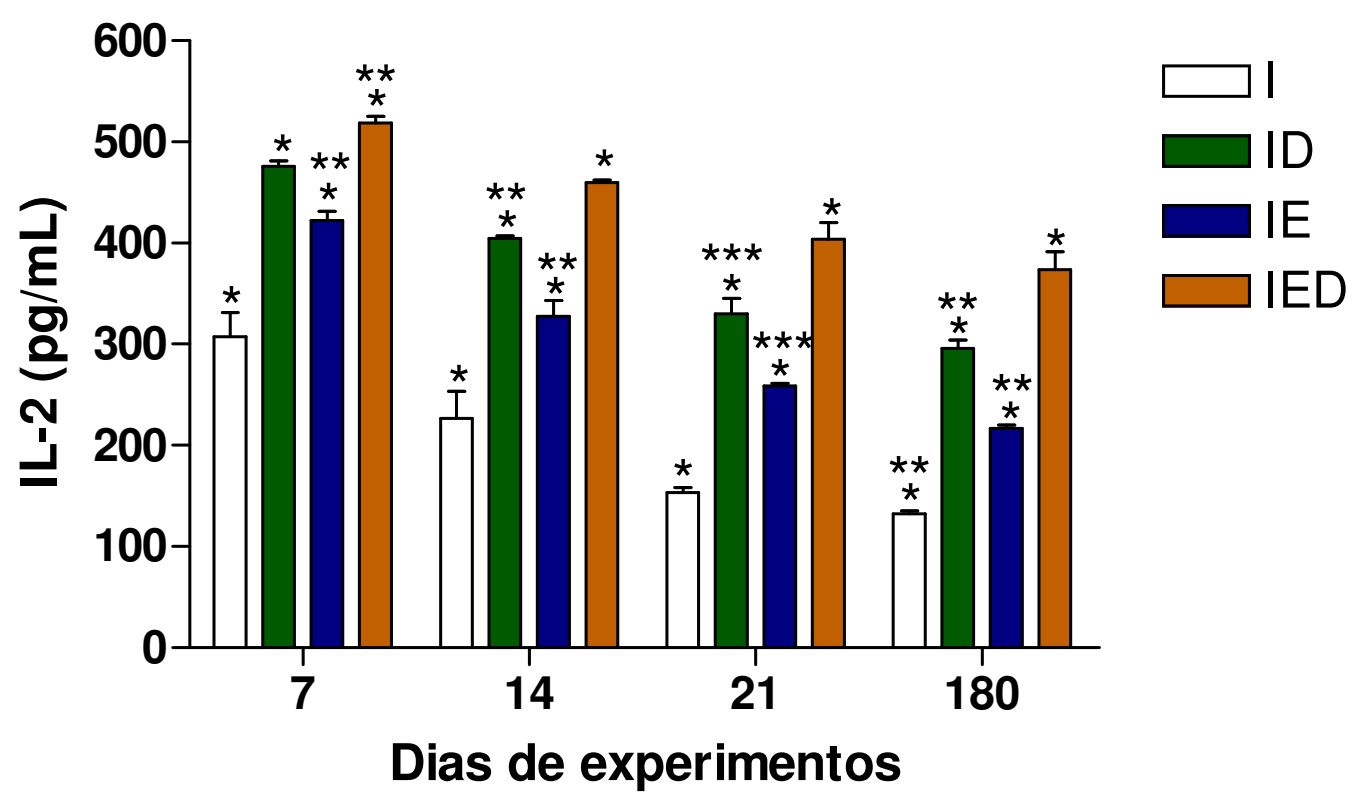

Figura 13. Concentrações de IL-2 (pg/mL) determinadas no soro de ratos Wistar machos infectados com a cepa $\mathrm{Y}$ de $T$. cruzi durante os $7^{\circ}, 14^{\circ}, 21^{\circ}$ e $180^{\circ}$ dias de experimentos, nos seguintes grupos: Nos seguintes grupos: Infectado (I); Infectado tratado com DHEA (ID); Infectado submetido ao estresse (IE) e Infectado submetido ao estresse e tratado com DHEA (IED). Para cada grupo experimental em cada dia de infecção $n=5$.

*p<0,001 I vs ID $\left(7^{\circ}, 14^{\circ}, 21^{\circ}\right.$ e $180^{\circ}$ dias após infecção); I vs IE ( $7^{\circ}, 14^{\circ} \mathrm{e} 21^{\circ}$ dias após infecção); I vs IED ( $7^{\circ}, 14^{\circ}, 21^{\circ}$ e $180^{\circ}$ dias após infecção); IE vs IED (14º $21^{\circ}$ e $180^{\circ}$ dias após infecção);

**p<0,01 I vs IE (180 dias após infecção); ID vs IE (14 e $180^{\circ}$ dias após infecção); IE vs IED ( $7^{\circ}$ dia após infecção);

***p $<0,05$ ID vs IE $\left(21^{\circ}\right.$ dias após infecção).

Tanto nos grupos controles e infectados tratados com DHEA, ocorreu aumento da produção de IL-2, estatisticamente significante quando comparados aos grupos não tratados com DHEA (Figuras 12 e 13). 


\subsection{Dosagem de IFN- $\gamma$}

\subsubsection{Grupos Controles}

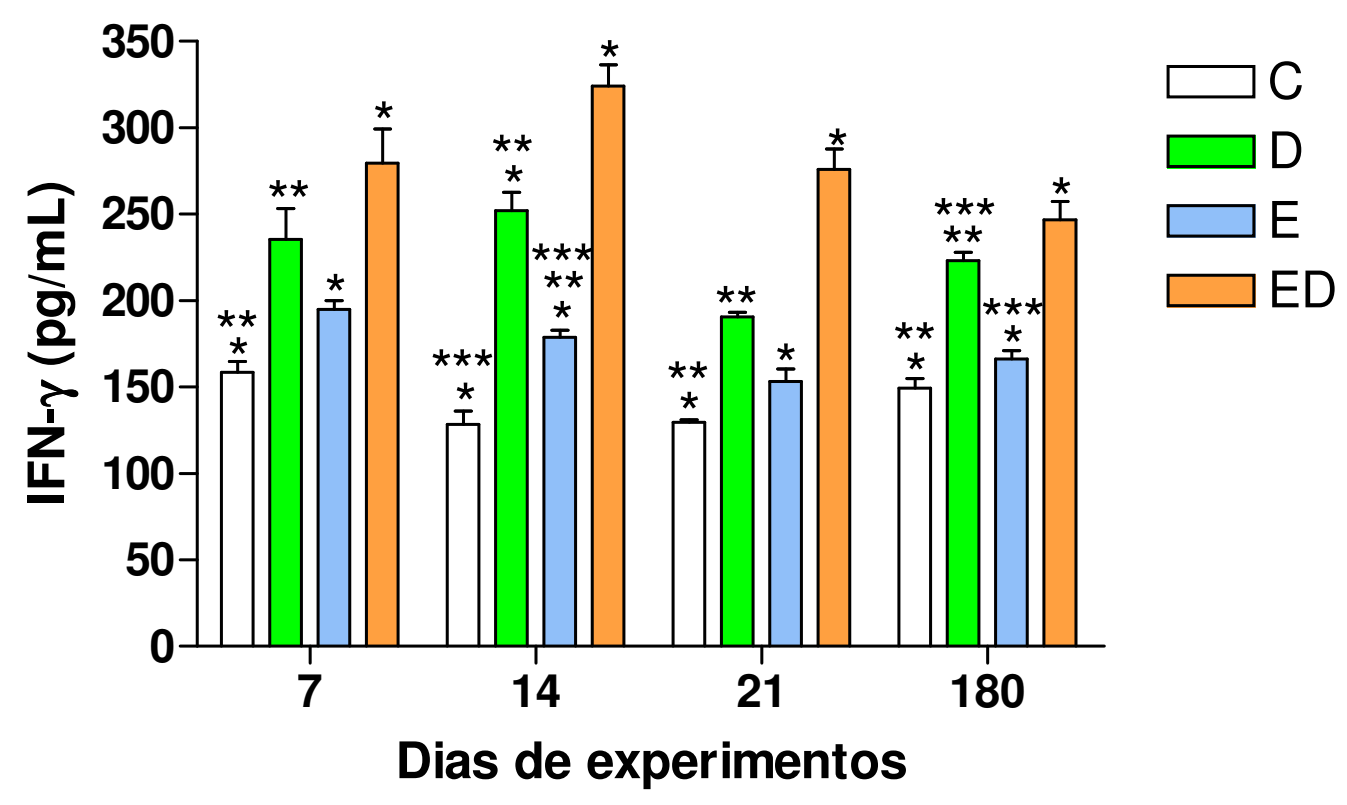

Figura 14. Concentrações de IFN- $\gamma(\mathrm{pg} / \mathrm{mL})$ determinadas no soro de ratos Wistar machos controles durante os $7^{\circ}, 14^{\circ}, 21^{\circ}$ e $180^{\circ}$ dias de experimentos, nos seguintes grupos: Controle $(\mathrm{C})$; Controle tratado com DHEA (D); Controle submetido ao estresse (E); Controle submetido ao estressse e tratado com DHEA (ED). Para cada grupo experimental em cada dia de infecção n=5.

*p<0,001 C vs D (14 dias após infecção); C vs $\mathrm{ED}$ e $\mathrm{E}$ vs $\mathrm{ED}\left(7^{\circ}, 14^{\circ}, 21^{\circ}\right.$ e $180^{\circ}$ dias após infecção);

**p<0,01 C vs D (7º, 21 e 180 dias após infecção); D vs E (14º dias após infecção);

***p<0,05 C vs E (14º dias após infecção); $\mathrm{D} v s \mathrm{E}\left(180^{\circ}\right.$ dias após infecção). 


\subsubsection{Grupos Infectados}

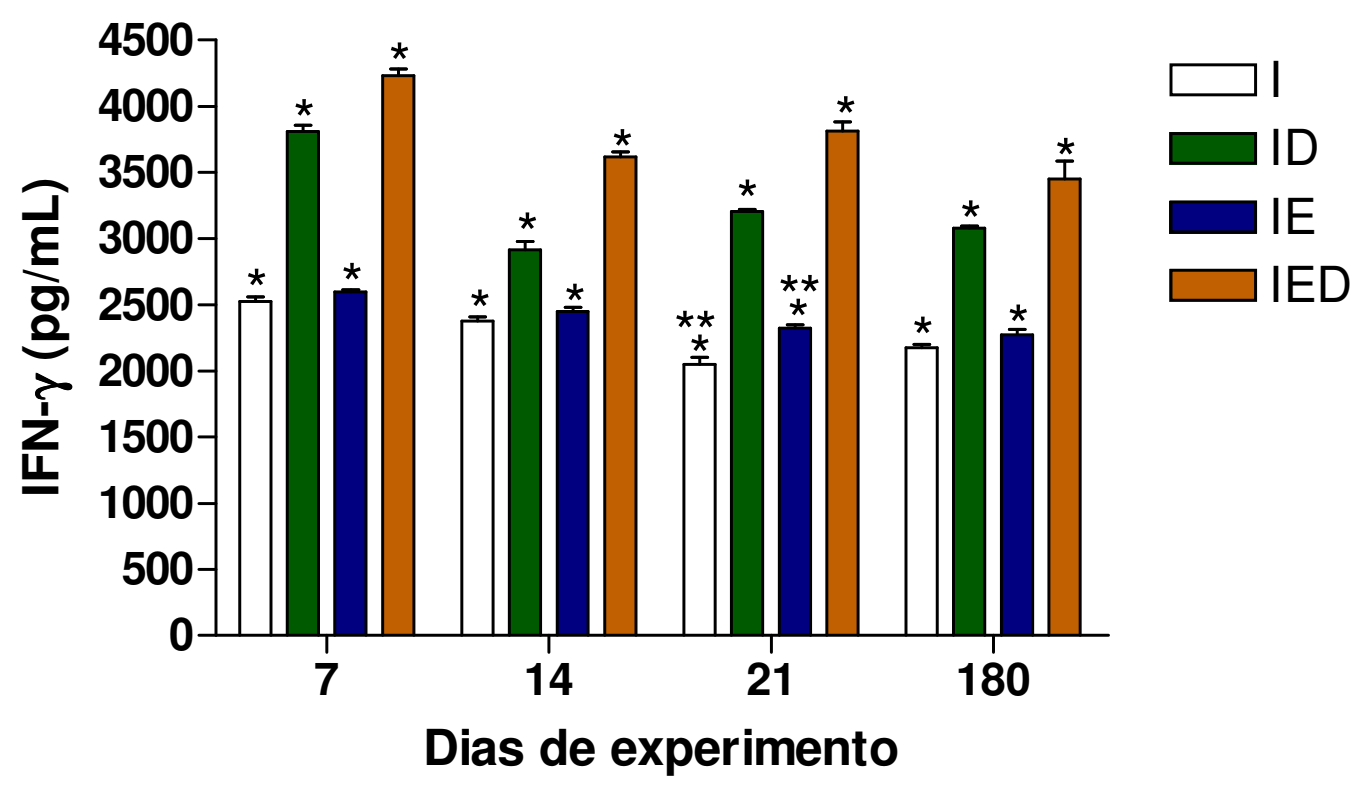

Figura 15. Concentrações de $\mathrm{IFN}-\gamma(\mathrm{pg} / \mathrm{mL})$ determinadas no soro de ratos Wistar machos infectados com a cepa Y de $T$. cruzi durante os $7^{\circ}, 14^{\circ}, 21^{\circ}$ e $180^{\circ}$ dias de experimentos, nos seguintes grupos: Infectado (I); Infectado tratado com DHEA (ID); Infectado submetido ao estresse (IE) e Infectado submetido ao estresse e tratado com DHEA (IED). Para cada grupo experimental em cada dia de infecção $n=5$.

$*_{\mathrm{p}}<0,001$ I $v s$ ID, I $v s$ IED, ID vs IE, ID vs IED, IE $v s$ IED $\left(7^{\circ}, 14^{\circ}, 21^{\circ}\right.$ e $180^{\circ}$ dias após infecção); $* * \mathrm{p}<0,01$ I $v s$ IE $\left(21^{\circ}\right.$ dias após infecção).

Nos grupos controles e infectados tratados com DHEA apresentaram aumento nos níveis de IFN- $\gamma$ quando comparados aos demais grupos estudados (Figuras 14 e 15). 


\subsection{Dosagem de TNF- $\alpha$}

\subsubsection{Grupos Controles}

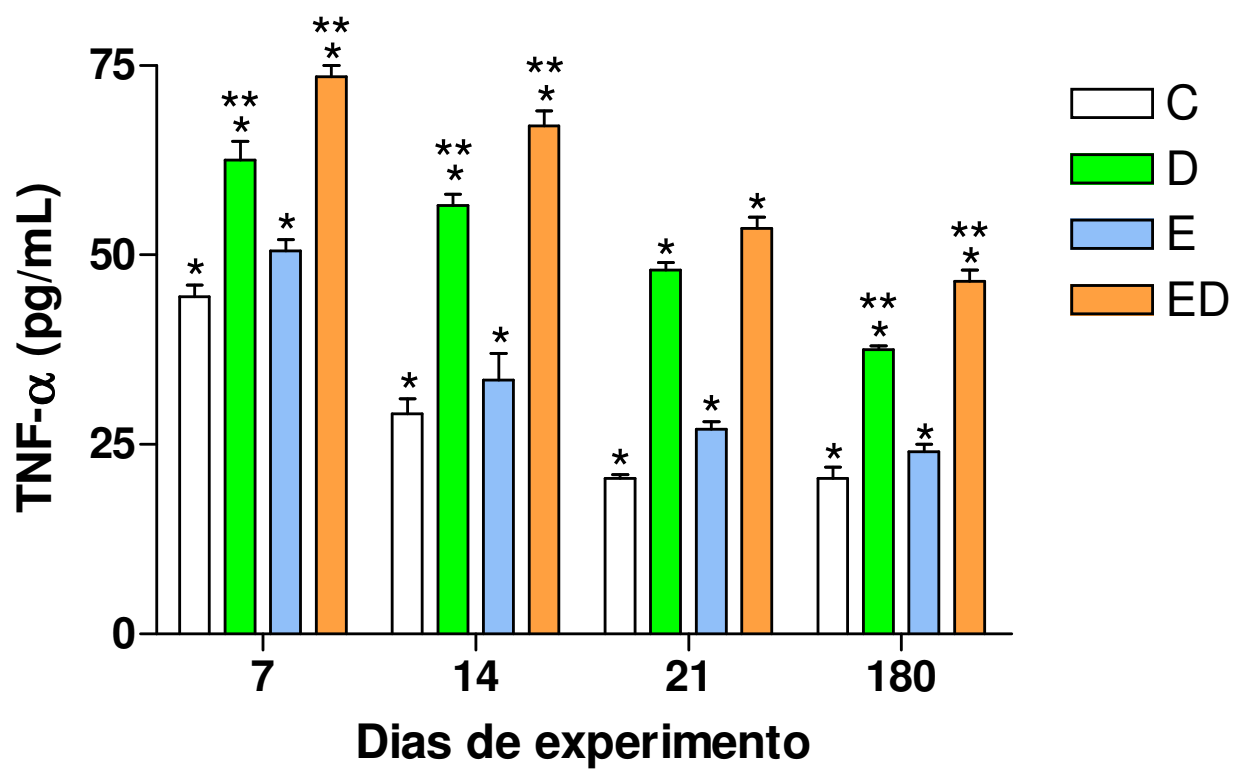

Figura 16. Concentrações de TNF- $\alpha(\mathrm{pg} / \mathrm{mL})$ determinadas no soro de ratos Wistar machos controles durante os $7^{\circ}, 14^{\circ}, 21^{\circ}$ e $180^{\circ}$ dias de experimentos, nos seguintes grupos: Controle (C); Controle tratado com DHEA (D); Controle submetido ao estresse (E); Controle submetido ao estresse e tratado com DHEA (ED). Para cada grupo experimental em cada dia de infecção $n=5$.

*p<0,001 C vs D, C vs ED, D vs E, E vs $\mathrm{ED}\left(7^{\circ}, 14^{\circ}, 21^{\circ}\right.$ e $180^{\circ}$ dias após infecção);

$* * \mathrm{p}<0,01 \mathrm{D} v s \mathrm{ED}\left(7^{\circ}, 14^{\circ}\right.$ e $180^{\circ}$ dias após infecção). 


\subsubsection{Grupos Infectados}

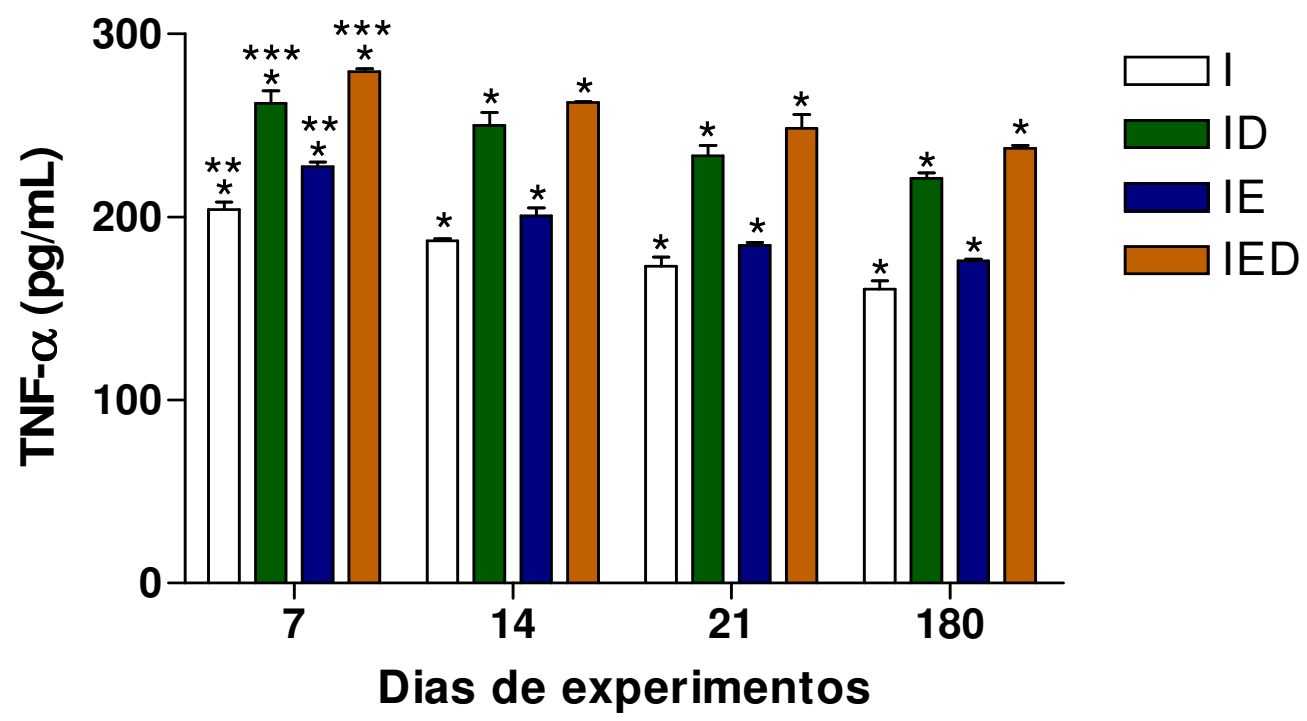

Figura 17. Concentrações de TNF- $\alpha(\mathrm{pg} / \mathrm{mL})$ determinadas no soro de ratos Wistar machos infectados com a cepa $\mathrm{Y}$ de $T$. cruzi durante os $7^{\circ}, 14^{\circ}, 21^{\circ}$ e $180^{\circ}$ dias de experimentos, nos seguintes grupos: Infectado (I); Infectado tratado com DHEA (ID); Infectado submetido ao estresse (IE) e Infectado submetido ao estresse e tratado com DHEA (IED). Para cada grupo experimental em cada dia de infecção $n=5$.

*p<0,001 I vs ID, I vs IED, ID vs IE, IE vs IED (7º $14^{\circ}, 21^{\circ}$ e $180^{\circ}$ dias após infecção);

**p<0,01 I vs IE (7 dias após infecção);

$* * * \mathrm{p}<0.05$ ID vs IED ( $7^{\circ}$ dias após infecção).

Em todos os dias experimentais ocorreu aumento das concentrações de TNF- $\alpha$ para os animais submetidos ao tratamento com DHEA quando comparados aos grupos não suplementados (Figuras 16 e 17). 


\subsection{Dosagem de IL-4}

\subsubsection{Grupos Controles}

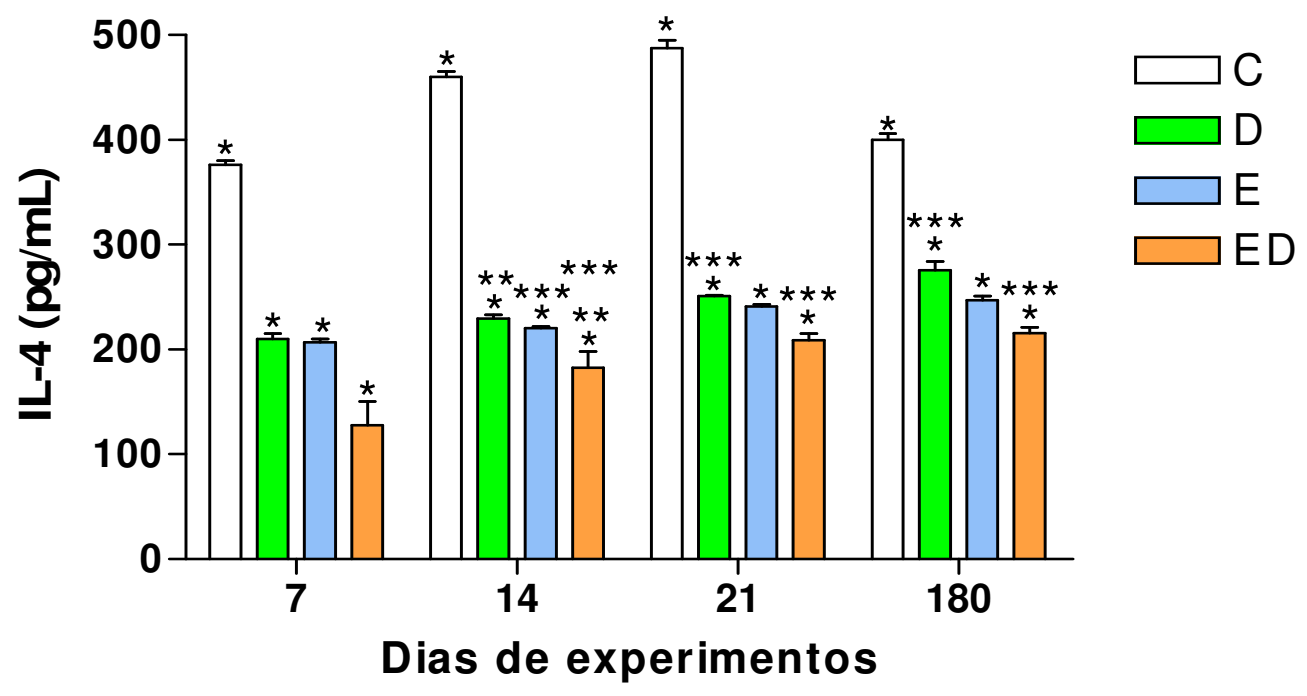

Figura 18. Concentrações de IL-4 (pg/mL) determinadas no soro de ratos Wistar machos controles durante os $7^{\circ}, 14^{\circ}, 21^{\circ}$ e $180^{\circ}$ dias de experimentos, nos seguintes grupos: Controle (C); Controle tratado com DHEA (D); Controle submetido ao estresse (E); Controle submetido ao estresse e tratado com DHEA (ED). Para cada grupo experimental em cada dia de infecção $n=5$.

*p<0,001 C vs D, C vs E, C vs ED $\left(7^{\circ}, 14^{\circ}, 21^{\circ}\right.$ e $180^{\circ}$ dias após infecção); D vs ED (7º dia após infecção); $\mathrm{E} v s \mathrm{ED}$ ( $7^{\circ}$ dia após infecção);

**p<0,01 D vs $\mathrm{ED}\left(14^{\circ}\right.$ dias após infecção);

***p<0,05 D vs $\mathrm{ED}\left(21^{\circ}\right.$ e $180^{\circ}$ dias após infecção); E vs ED (14º dia após infecção).

Os grupos com suplementação de DHEA apresentaram diminuição significativa da concentração de IL-4 quando comparados aos animais controles sem suplementação. (Figura 18). 


\subsubsection{Grupos Infectados}

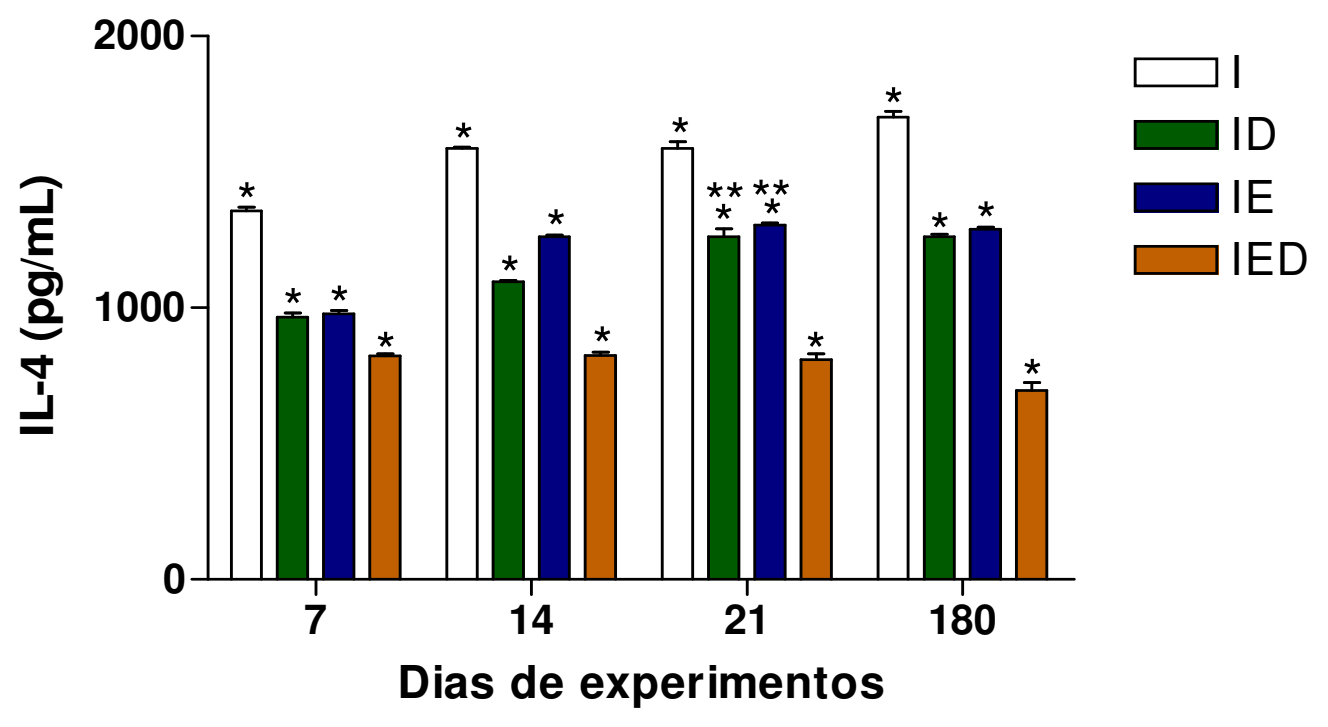

Figura 19. Concentrações de IL-4 (pg/mL) determinadas no soro de ratos Wistar machos infectados com a cepa $\mathrm{Y}$ de $T$. cruzi durante os $7^{\circ}, 14^{\circ}, 21^{\circ}$ e $180^{\circ}$ dias de experimentos, nos seguintes grupos: Infectado (I); Infectado tratado com DHEA (ID); Infectado submetido ao estresse (IE) e Infectado submetido ao estresse e tratado com DHEA (IED). Para cada grupo experimental em cada dia de infecção $n=5$.

$* \mathrm{p}<0,001$ I $v s$ ID, I $v s$ IE, I vs IED, ID vs IED, IE $v s$ IED $\left(7^{\circ}, 14^{\circ}, 21^{\circ}\right.$ e $180^{\circ}$ dias após infecção); ID vs IE (14 dia após infecção);

$* * \mathrm{p}<0,01 \mathrm{ID}$ vs IE $\left(21^{\circ}\right.$ dias após infecção).

Nos grupos de animais infectados houve um aumento na concentração de IL-4 em relação aos grupos controles estudados em todos os dias de experimento. Com aumento significativo para os grupos estressados quando comparado aos grupos tratados com DHEA (Figura 19). 


\subsection{Dosagem de IL-10}

\subsubsection{Grupos Controles}

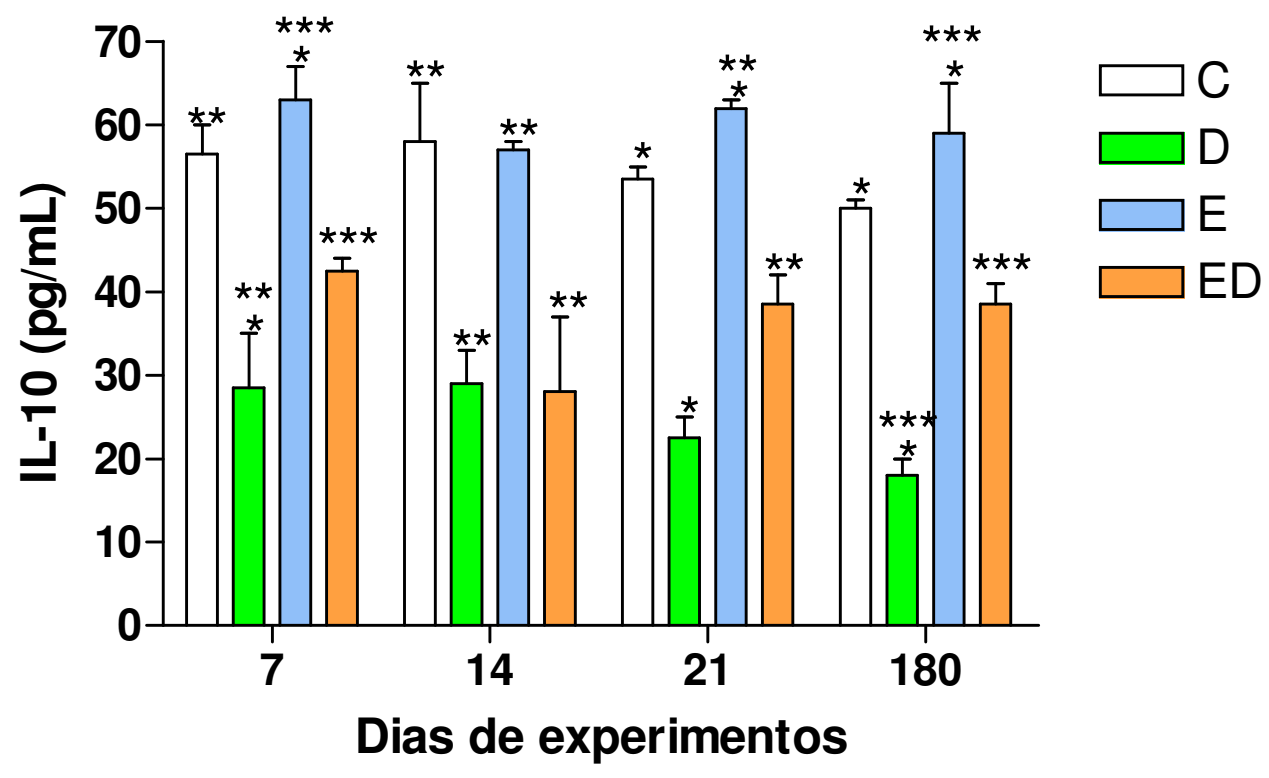

Figura 20. Concentrações de IL-10 (pg/mL) determinadas no soro de ratos Wistar machos controles durante os $7^{\circ}, 14^{\circ}, 21^{\circ}$ e $180^{\circ}$ dias de experimentos, nos seguintes grupos: Controle (C); Controle tratado com DHEA (D); Controle submetido ao estresse (E); Controle submetido ao estresse e tratado com DHEA (ED). Para cada grupo experimental em cada dia de infecção $n=5$.

*p<0,001 C vs $\mathrm{D}\left(21^{\circ}\right.$ e $180^{\circ}$ dias após infecção); E vs $\mathrm{D}\left(7^{\circ}, 21^{\circ}\right.$ e $180^{\circ}$ dias após infecção);

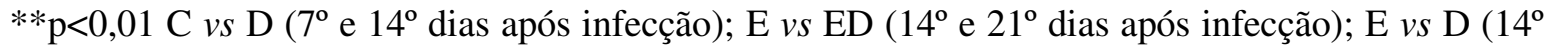
dia após infecção);

***p<0,05 E vs $\operatorname{ED}\left(7^{\circ}\right.$ e $180^{\circ}$ dias após infecção); D vs $\operatorname{ED}\left(180^{\circ}\right.$ dias após infecção). 


\subsubsection{Grupos Infectados}

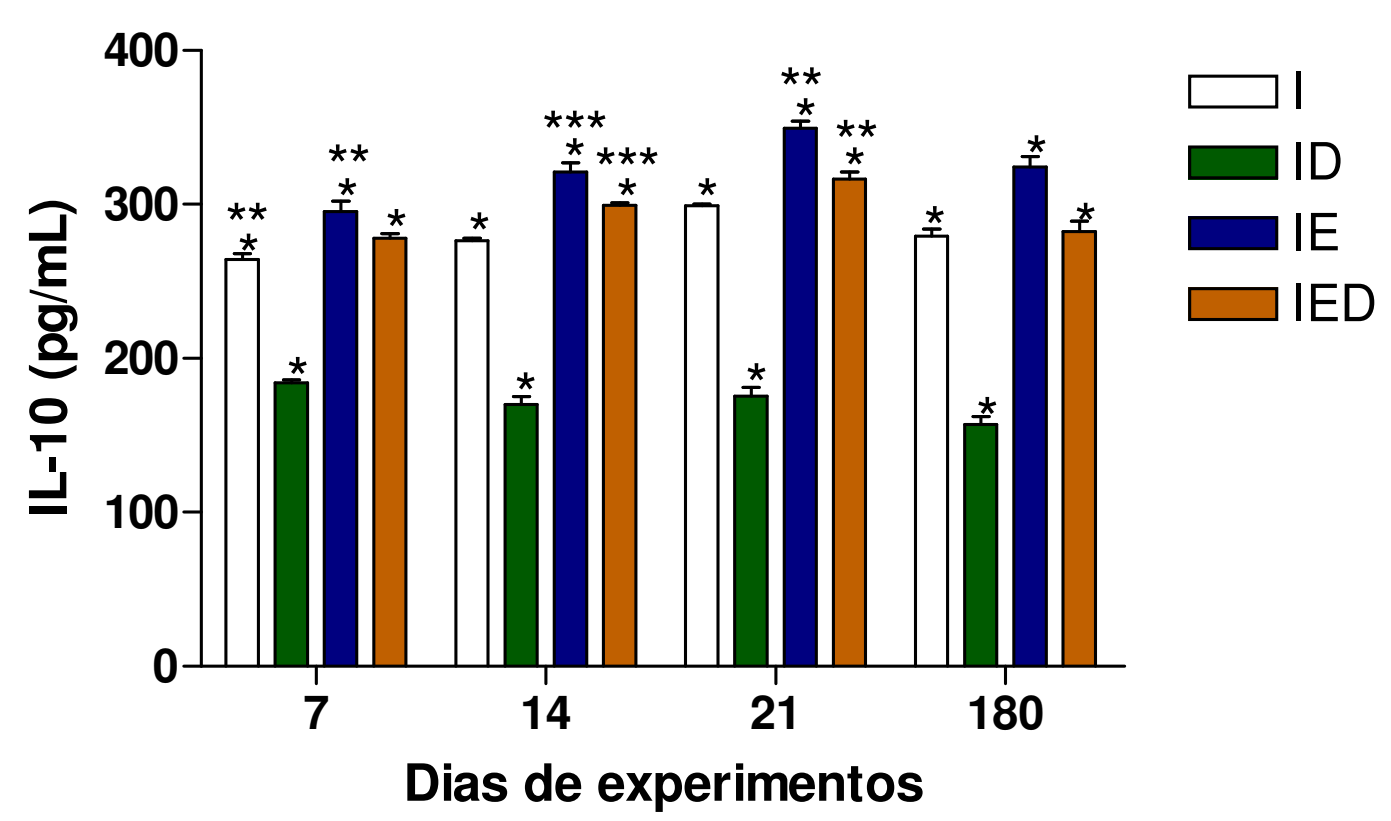

Figura 21. Concentrações de IL-10 (pg/mL) determinadas no soro de ratos Wistar machos controles durante os $7^{\circ}, 14^{\circ}, 21^{\circ}$ e $180^{\circ}$ dias de experimentos, nos seguintes grupos: Nos seguintes grupos: Infectados (I); Infectado tratado com DHEA (ID); Infectado submetido ao estresse (IE); Infectado submetido ao estresse e tratado com DHEA (IED). Para cada grupo experimental em cada dia de infecção $n=5$.

*p<0,001 I vs ID; ID vs IE; ID vs IED (todos os dias após infecção); I vs IE (14º $21^{\circ}$ e $180^{\circ}$ dias após infecção); IE vs IED (180 dias após infecção);

**p<0,01 I vs IE ( $7^{\circ}$ dias após infecção); IE vs IED (21ํdias após infecção);

$* * * \mathrm{p}<0,05$ IE $v s$ IED (14º dias após infecção).

Nos grupos controles e infectados, os animais estressados apresentaram valores significantemente mais elevados quando comparados aos demais grupos estudados (Figura 20 e 21). 


\subsection{Corticosterona}

\subsubsection{Grupos Controles}

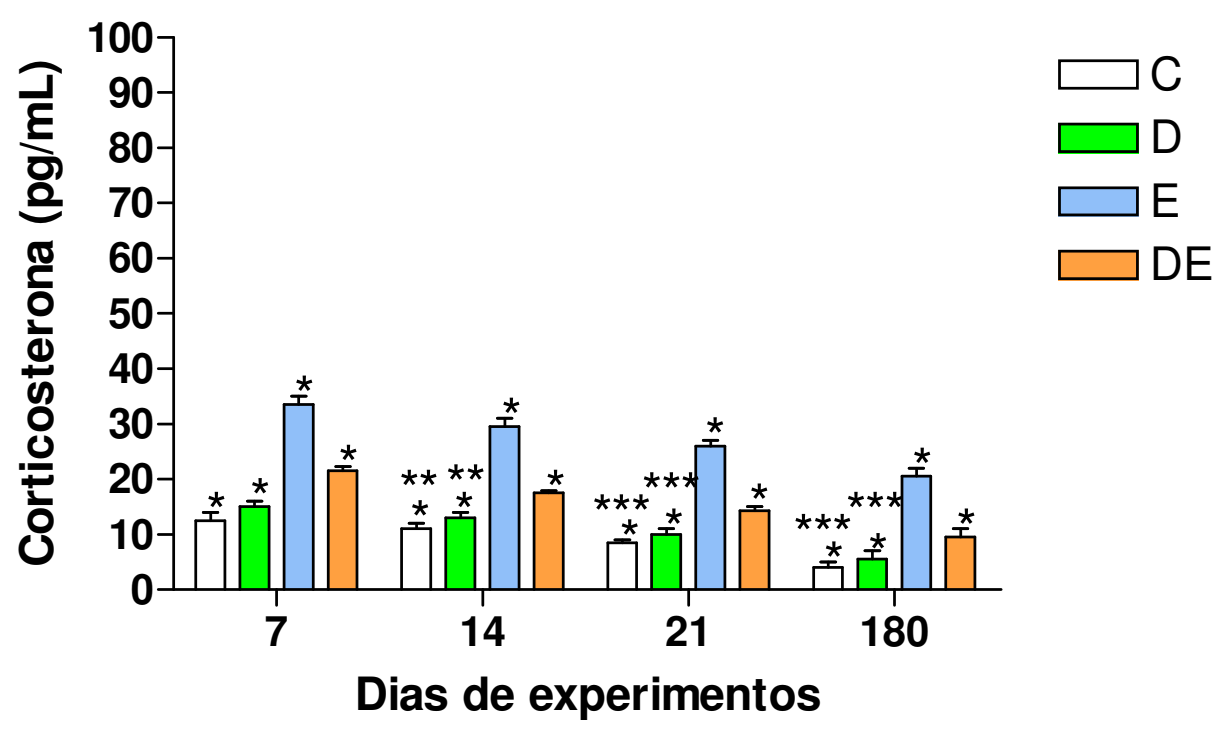

Figura 22. Concentrações de corticosterona $(\mathrm{pg} / \mathrm{mL})$ determinadas no soro de ratos Wistar machos controles durante os $7^{\circ}, 14^{\circ}, 21^{\circ}$ e $180^{\circ}$ dias de experimentos, nos seguintes grupos: Controles (C); Controles tratado com DHEA (D); Controles submetido ao estresse (E); Controles submetido ao estresse e tratado com DHEA (ED). Para cada grupo experimental em cada dia de infecção $n=5$.

*p<0,001 C vs D (7º dias após infecção); C vs E; D vs E; D vs DE; E vs DE (todos os dias após infecção);

**p<0,01 C vs $\mathrm{D}\left(14^{\circ}\right.$ dias após infecção);

***p $<0,05 \mathrm{C}$ vs $\mathrm{D}\left(21^{\circ}\right.$ e $180^{\circ}$ dias após infecção). 


\subsubsection{Grupos Infectados}

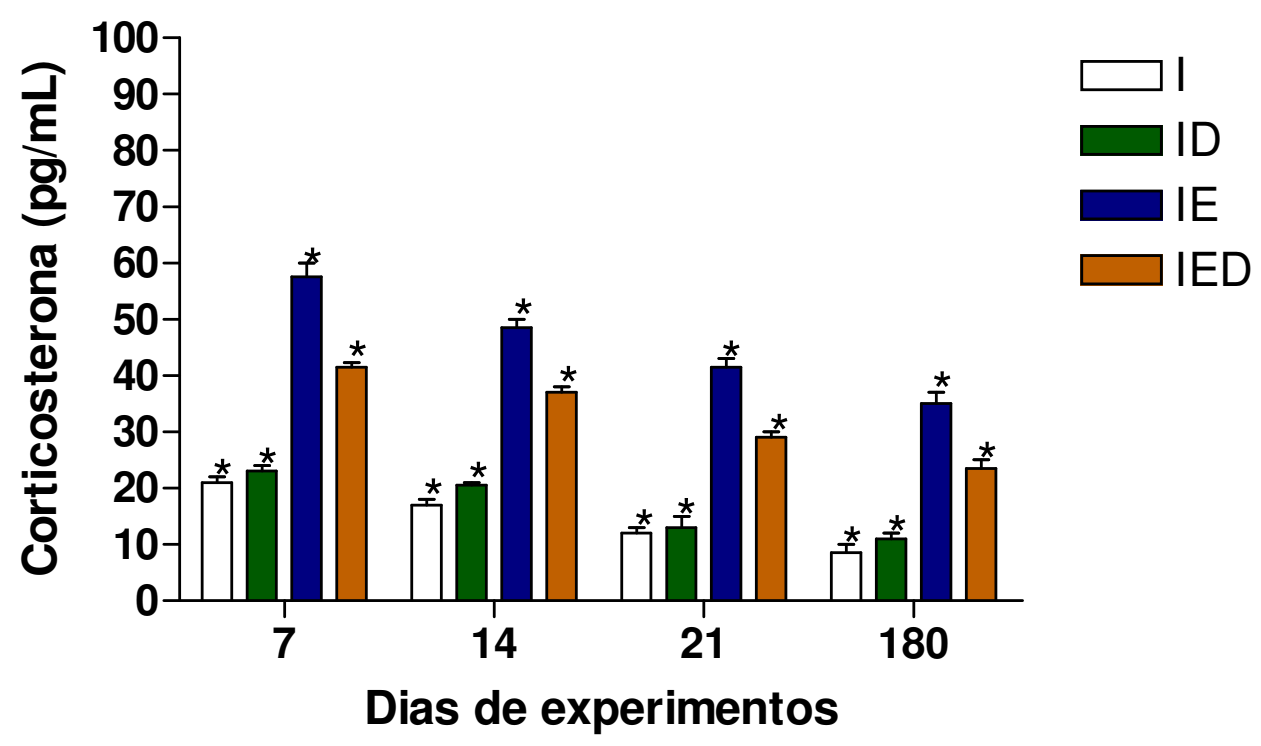

Figura 23. Concentrações de corticosterona (pg/mL) determinadas no soro de ratos Wistar machos controles durante os $7^{\circ}, 14^{\circ}, 21^{\circ}$ e $180^{\circ}$ dias de experimentos, nos seguintes grupos: Infectados (I); Infectado tratado com DHEA (ID); Infectado submetido ao estresse (IE); Infectado submetido ao estresse e tratado com DHEA (IED). Para cada grupo experimental em cada dia de infecção n=5. *p<0,001 I vs IE; ID vs IE; ID vs IED; IE vs IED (para todos os dias após infecção).

Para todos os grupos estressados houve aumento estatisticamente significante nas concentrações de corticosterona. Porém a suplementação com DHEA diminuiu efetivamente as concentrações de corticosterona nos animais controles e infectados (Figuras 22 e 23). 


\subsection{Contagem de Neurônios do Esôfago}

A quantificação do total de neurônios encontrados no plexo mientérico do esôfago de ratos Wistar machos infectados pela cepa Y de Trypanosoma cruzi durante a fase aguda e crônica, encontra-se apresentada na figura 24.
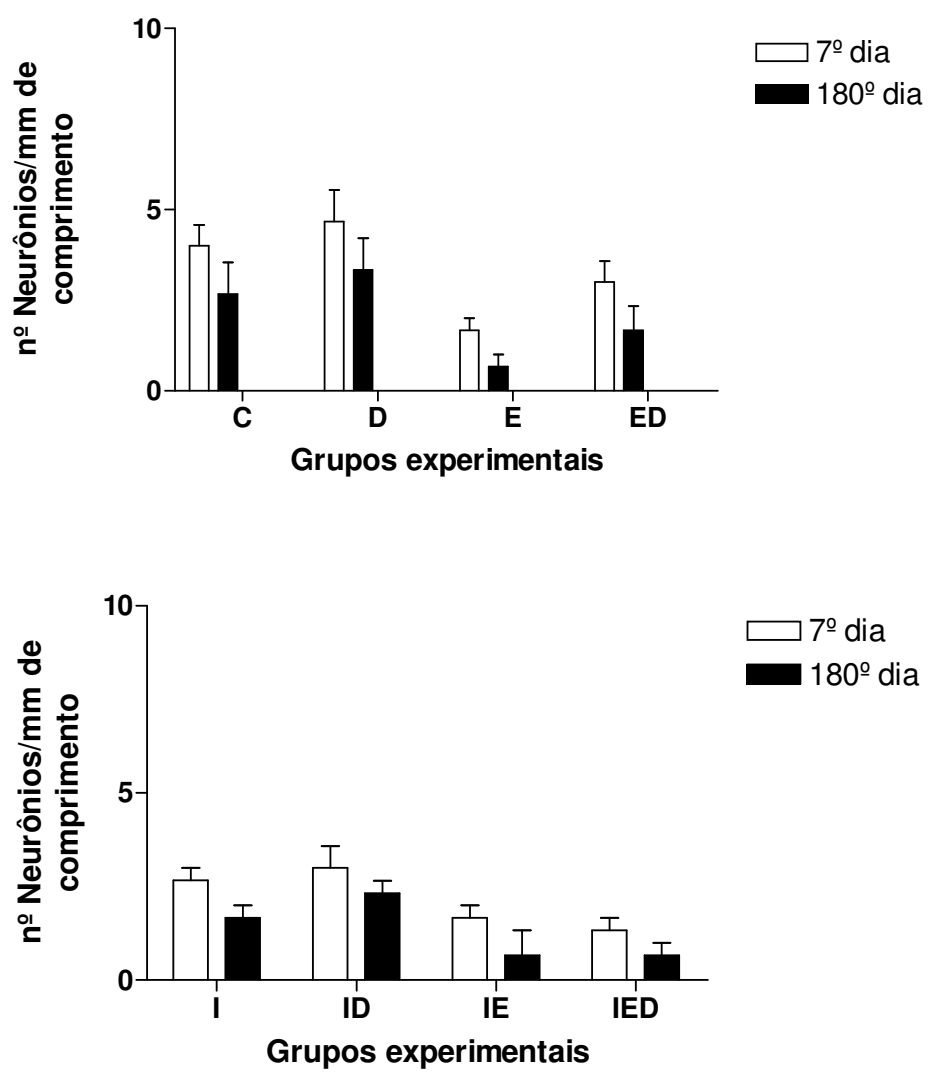

Figura 24. Quantificação de neurônios no esôfago de ratos Wistar machos controles e infectados com a cepa $\mathrm{Y}$ de $T$. cruzi durante a fase aguda da infecção (pico de parasitemia $7^{\circ}$ dia após infecção) e durante a fase crônica da infecção ( $180^{\circ}$ dias após infecção), nos seguintes grupos: Infectados (I); Infectado tratado com DHEA (ID); Infectado submetido ao estresse (IE); Infectado submetido ao estresse e tratado com DHEA (IED). Para cada grupo experimental em cada dia de infecção $n=5$. 


\subsection{Contagem de neurônios do Cólon}

A quantificação do total de neurônios encontrados no plexus mientérico do cólon de ratos Wistar machos infectados pela cepa Y de Trypanosoma cruzi durante a fase aguda e crônica, encontra-se apresentada na figura 25.
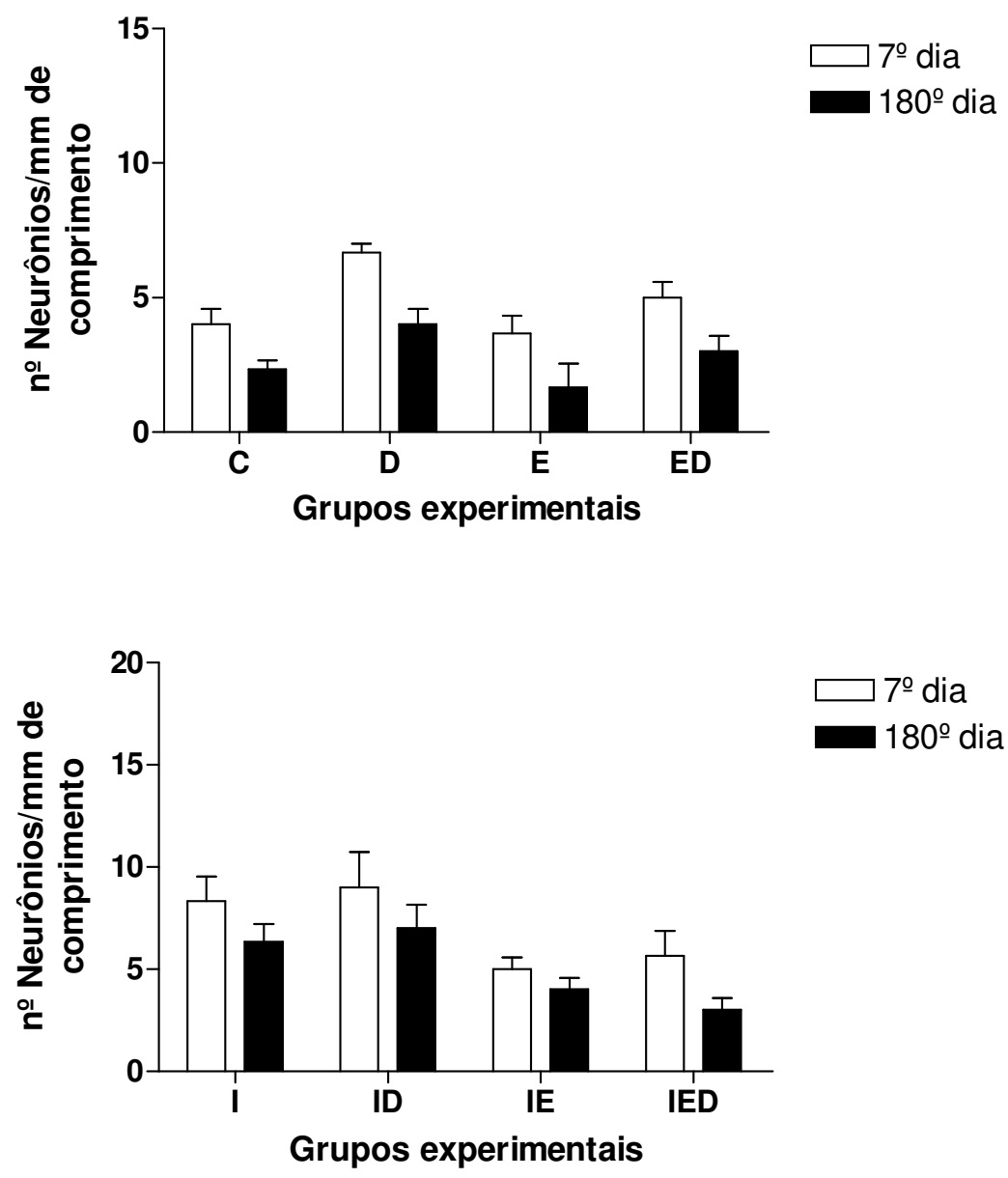

Figura 25. Quantificação de neurônios no cólon de ratos Wistar machos controles e infectados com a cepa Y de $T$. cruzi durante a fase aguda da infecção (pico de parasitemia $7^{\circ}$ dia após infecção) e durante a fase crônica da infecção (180 dias após infecção), nos seguintes grupos: Infectados (I); Infectado tratado com DHEA (ID); Infectado submetido ao estresse (IE); Infectado submetido ao estresse e tratado com DHEA (IED). Para cada grupo experimental em cada dia de infecção $n=5$. 


\subsection{Morfometria do corpo neuronal}

\subsubsection{Esôfago}

Tabela 2. Os parâmetros resultantes do estudo morfométrico do corpo neuronal do esôfago de ratos Wistar machos dos grupos estudados durante o pico da infecção ( $7^{\circ}$ dia após infecção). Foi realizada a comparação entre os grupos Controle (C) e Infectado (I), Controle tratado com DHEA (D) e Infectado tratado com DHEA (ID). Para cada grupo experimental em cada dia de infecção $n=5$.

\begin{tabular}{|c|c|c|c|c|}
\hline Parâmetros & $\mathrm{C}^{*}$ & $\mathrm{I}^{*}$ & $\mathrm{D}^{*}$ & $\mathrm{ID}^{*}$ \\
\hline Diâmetro maior $(\mu \mathrm{m})$ & $76,22 \pm 11,19$ & $62,68 \pm 16,85$ & $70,43 \pm 7,35$ & $67,13 \pm 13,04$ \\
\hline Diâmetro menor $(\mu \mathrm{m})$ & $42,78 \pm 7,81$ & $37,38 \pm 5,19$ & $46,14 \pm 8,23$ & $40,94 \pm 8,38$ \\
\hline Diâmetro médio $(\mu \mathrm{m})$ & $56,99 \pm 8,68$ & $47,99 \pm 6,94$ & $56,82 \pm 6,70$ & $52,18 \pm 8,89$ \\
\hline Relação entre diâmetros & $1,81 \pm 0,25$ & $1,71 \pm 0,58$ & $1,67 \pm 0,32$ & $1,56 \pm 0,28$ \\
\hline Volume $\left(\mu \mathrm{m}^{3}\right)$ & $103071 \pm 48941$ & $61435 \pm 26850$ & $99527 \pm 35774$ & $80544 \pm 40414$ \\
\hline Perímetro $(\mu \mathrm{m})$ & $190,8 \pm 27,8$ & $160,3 \pm 32,2$ & $185,4 \pm 19,6$ & $172,6 \pm 30$ \\
\hline Área $\left(\mu \mathrm{m}^{2}\right)$ & $1845,3 \pm 535,7$ & $2603,2 \pm 811,5$ & $2565,7 \pm 611,1$ & $2197 \pm 742,4$ \\
\hline Relação volume/área & $37,9 \pm 5,7$ & $31,9 \pm 4,6$ & $37,8 \pm 4,4$ & $34,7 \pm 5,9$ \\
\hline Excentricidade & $0,82 \pm 0,05$ & $0,77 \pm 0,10$ & $0,74 \pm 0,10$ & $0,77 \pm 0,10$ \\
\hline Índice de contorno & $3,75 \pm 0,27$ & $3,78 \pm 0,11$ & $3,69 \pm 0,11$ & $3,73 \pm 0,13$ \\
\hline Coeficiente de forma & $0,88 \pm 0,05$ & $0,90 \pm 0,09$ & $0,93 \pm 0,05$ & $0,90 \pm 0,06$ \\
\hline
\end{tabular}


Tabela 3. Os parâmetros resultantes do estudo morfométrico do corpo neuronal do esôfago de ratos Wistar machos dos grupos estudados durante o pico da infecção ( $7^{\circ}$ dia após infecção). Foi realizada a comparação entre os grupos Controle Estressado (E) e Infectado submetido ao estresse (IE), Controle estressado e tratado com DHEA (ED) e Infectado submetido ao estresse e tratado com DHEA (IED). Para cada grupo experimental em cada dia de infecção $n=5$.

\begin{tabular}{|c|c|c|c|c|}
\hline Parâmetros & $\mathrm{E}^{*}$ & IE* & ED* & IED* \\
\hline Diâmetro maior $(\mu \mathrm{m})$ & $72,83 \pm 14,08$ & $71,20 \pm 7,33$ & $82,92 \pm 20,46$ & $78 \pm 11,15$ \\
\hline Diâmetro menor $(\mu \mathrm{m})$ & $54,67 \pm 12,23$ & $44,60 \pm 3,44$ & $51,75 \pm 15,21$ & $41 \pm 11,60$ \\
\hline Diâmetro médio $(\mu \mathrm{m})$ & $62,99 \pm 12,49$ & $56,31 \pm 4,43$ & $65,02 \pm 15,87$ & $56,17 \pm 10,74$ \\
\hline Relação entre diâmetros & $1,60 \pm 0,14$ & $1,35 \pm 0,17$ & $2,02 \pm 0,54$ & $1,68 \pm 0,52$ \\
\hline Volume $\left(\mu \mathrm{m}^{3}\right)$ & $143977 \pm 84531$ & $94869 \pm 40414$ & $168890 \pm 131552$ & $101424 \pm 53086$ \\
\hline Perímetro $(\mu \mathrm{m})$ & $201,4 \pm 39,4$ & $184,4 \pm 15,7$ & $215,1 \pm 50,6$ & $192,1 \pm 30$ \\
\hline Área $\left(\mu \mathrm{m}^{2}\right)$ & $3218,6 \pm 1272,9$ & $2502,4 \pm 39$ & $3501,7 \pm 1773,1$ & $2555,5 \pm 935,7$ \\
\hline Relação volume/área & $37,5 \pm 2,9$ & $42 \pm 8,3$ & $43,3 \pm 10,5$ & $37,4 \pm 7,1$ \\
\hline Excentricidade & $0,77 \pm 0,05$ & $0,64 \pm 0,11$ & $0,84 \pm 0,08$ & $0,75 \pm 0,10$ \\
\hline Índice de contorno & $3,69 \pm 0,05$ & $3,61 \pm 0,05$ & $3,89 \pm 0,26$ & $3,75 \pm 0,24$ \\
\hline Coeficiente de forma & $0,96 \pm 0,03$ & $0,92 \pm 0,03$ & $0,90 \pm 0,10$ & $0,84 \pm 0,11$ \\
\hline
\end{tabular}


Tabela 4. Os parâmetros resultantes do estudo morfométrico do corpo neuronal do esôfago de ratos Wistar machos dos grupos estudados durante o pico da infecção $180^{\circ}$ dia após infecção. Foi realizada a comparação entre os grupos Controle (C) e Infectado (I), Controle tratado com DHEA (D) e Infectado tratado com DHEA (ID). Para cada grupo experimental em cada dia de infecção $n=5$.

\begin{tabular}{ccccc}
\hline Parâmetros & $\mathrm{C}^{*}$ & $\mathrm{I}^{*}$ & $\mathrm{D}^{*}$ & ID* \\
\hline Diâmetro maior $(\mu \mathrm{m})$ & $89 \pm 18,1$ & $61,21 \pm 6,33$ & $62,7 \pm 6,44$ & $57,47 \pm 4,69$ \\
Diâmetro menor $(\mu \mathrm{m})$ & $55,6 \pm 7,73$ & $45,6 \pm 5,56$ & $47,2 \pm 5,88$ & $43,6 \pm 4,03$ \\
Diâmetro médio $(\mu \mathrm{m})$ & $69,95 \pm 9,13$ & $52,77 \pm 5,44$ & $54,35 \pm 5,73$ & $50,06 \pm 3,80$ \\
Relação entre diâmetros & $1,63 \pm 0,39$ & $1,35 \pm 0,14$ & $1,34 \pm 0,13$ & $1,32 \pm 0,12$ \\
Volume $\left(\mu \mathrm{m}^{3}\right)$ & $186682 \pm 74888$ & $79413 \pm 25532$ & $86856 \pm 27311$ & $66803 \pm 15313$ \\
Perímetro $(\mu \mathrm{m})$ & $230,8 \pm 34$ & $168,7 \pm 17$ & $173,6 \pm 17,8$ & $159,7 \pm 11,9$ \\
Área $\left(\mu m^{2}\right)$ & $3895 \pm 1030$ & $2210 \pm 460$ & $2345 \pm 491$ & $1979 \pm 301$ \\
Relação volume/área & $46,6 \pm 6$ & $35,18 \pm 3,63$ & $36,2 \pm 3,8$ & $33,3 \pm 2,5$ \\
Excentricidade & $0,74 \pm 0,13$ & $0,65 \pm 0,10$ & $0,65 \pm 0,08$ & $0,64 \pm 0,08$ \\
Índice de contorno & $3,72 \pm 0,15$ & $3,61 \pm 0,04$ & $3,61 \pm 0,04$ & $3,60 \pm 0,03$ \\
Coeficiente de forma & $0,91 \pm 0,07$ & $0,96 \pm 0,02$ & $0,97 \pm 0,02$ & $0,97 \pm 0,02$ \\
\hline *p<0,001 & & & & \\
\hline
\end{tabular}


Tabela 5. Os parâmetros resultantes do estudo morfométrico do corpo neuronal do esôfago de ratos Wistar machos dos grupos estudados durante o pico da infecção $180^{\circ}$ dia após infecção. Foi realizada a comparação entre os grupos Controle Estressado (E) e Infectado submetido ao estresse (IE), Controle estressado e tratado com DHEA (ED) e Infectado submetido ao estresse e tratado com DHEA (IED). Para cada grupo experimental em cada dia de infecção $n=5$.

\begin{tabular}{ccccc}
\hline Parâmetros & $E^{*}$ & IE* & ED* & IED* \\
\hline Diâmetro maior $(\mu \mathrm{m})$ & $87,20 \pm 15,66$ & $74,63 \pm 18,28$ & $62,29 \pm 5,21$ & $58,34 \pm 5,47$ \\
Diâmetro menor $(\mu \mathrm{m})$ & $52,80 \pm 11,21$ & $38,32 \pm 11,18$ & $47,99 \pm 4,58$ & $44,22 \pm 4,62$ \\
Diâmetro médio $(\mu \mathrm{m})$ & $67,03 \pm 6,30$ & $53,35 \pm 13,88$ & $54,62 \pm 4,31$ & $50,70 \pm 4,37$ \\
Relação entre diâmetros & $1,99 \pm 0,26$ & $1,75 \pm 0,64$ & $1,33 \pm 0,14$ & $1,30 \pm 0,12$ \\
Volume $\left(\mu \mathrm{m}^{3}\right)$ & $161150 \pm 49480$ & $95653 \pm 78062$ & $86917 \pm 20408$ & $69879 \pm 18430$ \\
Perímetro $(\mu \mathrm{m})$ & $224,58 \pm 22,95$ & $182,32 \pm 45,65$ & $174,04 \pm 13,54$ & $161,97 \pm 13,82$ \\
Área $\left(\mu \mathrm{m}^{2}\right)$ & $3553 \pm 698$ & $2379 \pm 1269$ & $2357 \pm 370$ & $2036 \pm 354$ \\
Relação volume/área & $44,69 \pm 4,20$ & $35,57 \pm 9,25$ & $36,42 \pm 2,88$ & $33,82 \pm 2,91$ \\
Excentricidade & $0,86 \pm 0,05$ & $0,73 \pm 0,19$ & $0,63 \pm 0,08$ & $0,64 \pm 0,09$ \\
Índice de contorno & $3,87 \pm 0,12$ & $3,78 \pm 0,27$ & $3,60 \pm 0,04$ & $3,60 \pm 0,04$ \\
Coeficiente de forma & $0,89 \pm 0,12$ & $0,84 \pm 0,05$ & $0,97 \pm 0,02$ & $0,97 \pm 0,02$ \\
*P<0,001 & & & & \\
\hline
\end{tabular}




\subsubsection{Cólon}

Tabela 6. Os parâmetros resultantes do estudo morfométrico do corpo neuronal do cólon de ratos Wistar machos dos grupos estudados durante o pico da infecção $7^{\circ}$ dia após infecção. Foi realizada a comparação entre os grupos Controle (C) e Infectado (I), Controle tratado com DHEA (D) e Infectado tratado com DHEA (ID). Para cada grupo experimental em cada dia de infecção $n=5$.

\begin{tabular}{lcccc}
\hline \multicolumn{1}{c}{ Parâmetros } & C*** & I*** & D* & ID* \\
\hline Diâmetro maior $(\mu \mathrm{m})$ & $73,85 \pm 19,54$ & $55,1 \pm 6,24$ & $71,17 \pm 7,82$ & $63,36 \pm 6,32$ \\
Diâmetro menor $(\mu \mathrm{m})$ & $34,45 \pm 11,50$ & $30,05 \pm 6,07$ & $48,33 \pm 5,21$ & $34,06 \pm 6,93$ \\
Diâmetro médio $(\mu \mathrm{m})$ & $50,23 \pm 14,37$ & $40,49 \pm 5,10$ & $55,29 \pm 5,26$ & $49 \pm 6,27$ \\
Relação entre diâmetros & $2,21 \pm 0,39$ & $1,89 \pm 0,38$ & $2,16 \pm 0,41$ & $1,32 \pm 0,11$ \\
Volume $\left(\mu \mathrm{m}^{3}\right)$ & $83933 \pm 88342$ & $36380 \pm 14739$ & $90847 \pm 25172$ & $48,33 \pm 5,21$ \\
Perímetro $(\mu \mathrm{m})$ & $176,2 \pm 47,6$ & $137 \pm 15,1$ & $176,3 \pm 16,6$ & $170,9 \pm 18,3$ \\
Área $\left(\mu m^{2}\right)$ & $2135 \pm 1373$ & $1307 \pm 340,6$ & $2422 \pm 453,2$ & $1914 \pm 469,9$ \\
Relação volume/área & $33,49 \pm 9,58$ & $26,99 \pm 3,40$ & $36,86 \pm 3,51$ & $32,66 \pm 4,18$ \\
Excentricidade & $0,88 \pm 0,05$ & $0,88 \pm 0,05$ & $0,87 \pm 0,07$ & $0,64 \pm 0,07$ \\
Índice de contorno & $3,97 \pm 0,19$ & $3,95 \pm 0,16$ & $3,95 \pm 0,19$ & $3,60 \pm 0,03$ \\
Coeficiente de forma & $0,80 \pm 0,08$ & $0,86 \pm 0,08$ & $0,97 \pm 0,02$ & $0,81 \pm 0,08$ \\
\hline *p<0,001, ***p<0,05 & & & & \\
\hline
\end{tabular}


Tabela 7. Os parâmetros resultantes do estudo morfométrico do corpo neuronal do cólon de ratos Wistar machos dos grupos estudados durante o pico da infecção $7^{\circ}$ dia após infecção. Foi realizada a comparação entre os grupos Controle Estressado (E) e Infectado submetido ao estresse (IE), Controle estressado e tratado com DHEA (ED) e Infectado submetido ao estresse e tratado com DHEA (IED). Para cada grupo experimental em cada dia de infecção $\mathrm{n}=5$.

\begin{tabular}{lcccc}
\hline \multicolumn{1}{c}{ Parâmetros } & E*** & IE*** & ED*** & IED*** \\
\hline Diâmetro maior $(\mu \mathrm{m})$ & $63,2 \pm 14,2$ & $61 \pm 19,2$ & $60,9 \pm 9,4$ & $70,2 \pm 10,2$ \\
Diâmetro menor $(\mu \mathrm{m})$ & $35,7 \pm 9,1$ & $35,6 \pm 7,7$ & $36,5 \pm 7,4$ & $32,9 \pm 6,16$ \\
Diâmetro médio $(\mu \mathrm{m})$ & $47,1 \pm 9$ & $46,5 \pm 12,7$ & $47 \pm 6,8$ & $47,9 \pm 7,2$ \\
Relação entre diâmetros & $1,8 \pm 0,4$ & $1,7 \pm 0,2$ & $2,1 \pm 0,3$ & $1,7 \pm 0,3$ \\
Volume $\left(\mu \mathrm{m}^{3}\right)$ & $64373 \pm 53437$ & $60558 \pm 32726$ & $61013 \pm 25497$ & $58097 \pm 24952$ \\
Perímetro $(\mu \mathrm{m})$ & $158,7 \pm 31,2$ & $154,8 \pm 44,69$ & $167,7 \pm 23,2$ & $155,9 \pm 23,2$ \\
Área $\left(\mu \mathrm{m}^{2}\right)$ & $1821 \pm 1009$ & $1806 \pm 665$ & $1839 \pm 525$ & $1775 \pm 518$ \\
Relação volume/área & $31,4 \pm 8,5$ & $31 \pm 6$ & $31,9 \pm 4,8$ & $31,3 \pm 4,5$ \\
Excentricidade & $0,79 \pm 0,12$ & $0,79 \pm 0,06$ & $0,88 \pm 0,09$ & $0,79 \pm 0,05$ \\
Índice de contorno & $3,8 \pm 0,1$ & $3,7 \pm 0,1$ & $3,95 \pm 0,1$ & $3,75 \pm 0,1$ \\
Coeficiente de forma & $0,90 \pm 0,05$ & $0,88 \pm 0,08$ & $0,90 \pm 0,07$ & $0,81 \pm 0,06$ \\
\hline ***p & & & & \\
\hline
\end{tabular}


Tabela 8. Os parâmetros resultantes do estudo morfométrico do corpo neuronal do cólon de ratos Wistar machos dos grupos estudados durante o pico da infecção $180^{\circ}$ dia após infecção. Foi realizada a comparação entre os grupos Controle (C) e Infectado (I), Controle tratado com DHEA (D) e Infectado tratado com DHEA (ID). Para cada grupo experimental em cada dia de infecção $n=5$.

\begin{tabular}{lcccc}
\hline \multicolumn{1}{c}{ Parâmetros } & C*** & I*** & D*** & ID*** \\
\hline Diâmetro maior $(\mu \mathrm{m})$ & $69,2 \pm 8,5$ & $66,5 \pm 15,7$ & $63,7 \pm 5,7$ & $56,6 \pm 4,69$ \\
Diâmetro menor $(\mu \mathrm{m})$ & $52,3 \pm 5,9$ & $39 \pm 14,8$ & $48,7 \pm 4,7$ & $42,8 \pm 4,4$ \\
Diâmetro médio $(\mu \mathrm{m})$ & $60,1 \pm 6,5$ & $50,5 \pm 14,2$ & $55,7 \pm 4,7$ & $49,2 \pm 4,1$ \\
Relação entre diâmetros & $1,3 \pm 0,1$ & $1,8 \pm 0,4$ & $1,3 \pm 0,1$ & $1,3 \pm 0,1$ \\
Volume $\left(\mu \mathrm{m}^{3}\right)$ & $117899 \pm 39699$ & $85196 \pm 90540$ & $92492 \pm 24306$ & $63758 \pm 16213$ \\
Perímetro $(\mu \mathrm{m})$ & $191,9 \pm 21,2$ & $169,3 \pm 44,1$ & $177,6 \pm 15$ & $157,1 \pm 12,8$ \\
Área $\left(\mu \mathrm{m}^{2}\right)$ & $2873 \pm 633$ & $2161 \pm 1364$ & $2454 \pm 422$ & $1916 \pm 323$ \\
Relação volume/área & $40 \pm 4,3$ & $33,7 \pm 9,4$ & $37,1 \pm 3,1$ & $32,8 \pm 2,7$ \\
Excentricidade & $0,64 \pm 0,07$ & $0,78 \pm 0,17$ & $0,64 \pm 0,07$ & $0,64 \pm 0,10$ \\
Índice de contorno & $3,60 \pm 0,04$ & $3,80 \pm 0,21$ & $3,60 \pm 0,03$ & $3,60 \pm 0,04$ \\
Coeficiente de forma & $0,97 \pm 0,02$ & $0,88 \pm 0,09$ & $0,97 \pm 0,02$ & $0,97 \pm 0,02$ \\
\hline ***p<0,05 & & & & \\
\hline
\end{tabular}


Tabela 9. Os parâmetros resultantes do estudo morfométrico do corpo neuronal do cólon de ratos Wistar machos dos grupos estudados durante o pico da infecção $180^{\circ}$ dia após infecção. Foi realizada a comparação entre os grupos Controle Estressado (E) e Infectado submetido ao estresse (IE), Controle estressado tratado com DHEA (ED) e Infectado submetido ao estresse e tratado com DHEA (IED). Para cada grupo experimental em cada dia de infecção $n=5$.

\begin{tabular}{lcccc}
\hline \multicolumn{1}{c}{ Parâmetros } & E* & IE* & ED*** & IED*** \\
\hline Diâmetro maior $(\mu \mathrm{m})$ & $84 \pm 4,2$ & $70,5 \pm 7,2$ & $66,4 \pm 13,9$ & $53,4 \pm 5,4$ \\
Diâmetro menor $(\mu \mathrm{m})$ & $39,5 \pm 2,12$ & $53 \pm 5,40$ & $35,4 \pm 7,67$ & $40 \pm 4,31$ \\
Diâmetro médio $(\mu \mathrm{m})$ & $57,60 \pm 3$ & $61,14 \pm 5,68$ & $48,32 \pm 9,44$ & $46,24 \pm 4,32$ \\
Relação entre diâmetros & $2,13 \pm 0,01$ & $1,34 \pm 0,12$ & $1,90 \pm 0,32$ & $1,34 \pm 0,14$ \\
Volume $\left(\mu \mathrm{m}^{3}\right)$ & $100479 \pm 15650$ & $122789 \pm 36971$ & $65784 \pm 41470$ & $53113 \pm 14603$ \\
Perímetro $(\mu \mathrm{m})$ & $200,5 \pm 10,28$ & $195,2 \pm 18,26$ & $163,9 \pm 32,4$ & $147,7 \pm 13,7$ \\
Área $\left(\mu \mathrm{m}^{2}\right)$ & $2609 \pm 271$ & $2960 \pm 568$ & $1900 \pm 768$ & $1693 \pm 312$ \\
Relação volume/área & $38,4 \pm 2$ & $40,7 \pm 3,8$ & $32,2 \pm 6,3$ & $30,8 \pm 2,8$ \\
Excentricidade & $0,88 \pm 0$ & $0,65 \pm 0,07$ & $0,84 \pm 0,06$ & $0,65 \pm 0,08$ \\
Índice de contorno & $3,93 \pm 0$ & $3,60 \pm 0,04$ & $3,83 \pm 0,15$ & $3,61 \pm 0,05$ \\
Coeficiente de forma & $0,97 \pm 0,02$ & $0,81 \pm 0$ & $0,86 \pm 0,06$ & $0,97 \pm 0,02$ \\
\hline *p<0,001, ***p<0,05 & & & & \\
\hline
\end{tabular}




\subsection{Parasitismo Tecidual do Coração}

Tabela 10. Análise quantitativa dos ninhos de amastigotas no coração de ratos Wistar machos infectados com a cepa Y de T. cruzi, nos animais infectados (I), infectados tratados com DHEA (ID), infectados estressados (IE) e infectados estressados e tratado com DHEA (IED) em todos os dias de experimentos.

\begin{tabular}{cccccc}
\hline Grupos Experimentais & $\mathrm{N}^{\circ}$ de animais & $7^{\circ}$ & $14^{\circ}$ & $21^{\circ}$ & $180^{\circ}$ \\
\hline I & 5 & $7.2 \pm 0.86^{*}$ & $3.2 \pm 0.86^{*}$ & $0 \pm 0$ & $0 \pm 0$ \\
ID & 5 & $9.6 \pm 1.2$ & $3 \pm 0.70$ & $0 \pm 0$ & $0 \pm 0$ \\
IE & 5 & $12.2 \pm 0.86^{*}$ & $9.6 \pm 1.2^{*}$ & $3 \pm 0.70$ & $1.4 \pm 0.51$ \\
IED & 5 & $9.6 \pm 1.2$ & $9.6 \pm 1.2$ & $3 \pm 0.70$ & $0 \pm 0$ \\
& & & &
\end{tabular}

Os animais estressados apresentaram aumento significante no número de ninhos de amastigotas quando comparado aos animais submetidos a terapia com DHEA (Tabela 10). 


\subsection{Análise Cariométrica}

\subsubsection{Coração}

Tabela 11. Valores médios dos parâmetros nucleares do coração de ratos Wistar machos dos grupos: Controle (C) e Infectado (I), Controle tratado com DHEA (D) e Infectado tratado com DHEA (ID) durante a fase aguda (pico de parasitemia $7^{\circ}$ dia após infecção). Para cada grupo experimental em cada dia de infecção $n=5$.

\begin{tabular}{lcccc}
\hline \multicolumn{1}{c}{ Parâmetros } & C* & I* & D* & ID* \\
\hline Diâmetro maior $(\mu \mathrm{m})$ & $55,1 \pm 6,2$ & $59,3 \pm 7,5$ & $58 \pm 6,8$ & $64 \pm 47,6$ \\
Diâmetro menor $(\mu \mathrm{m})$ & $30,05 \pm 6,07$ & $40,22 \pm 5,43$ & $41,66 \pm 5,34$ & $42,46 \pm 6,46$ \\
Diâmetro médio $(\mu \mathrm{m})$ & $40,49 \pm 5,10$ & $48,76 \pm 5,59$ & $49 \pm 5,38$ & $51 \pm 11,41$ \\
Relação entre diâmetros & $1,89 \pm 0,38$ & $1,49 \pm 0,20$ & $1,40 \pm 0,17$ & $1,53 \pm 1,20$ \\
Volume $\left(\mu \mathrm{m}^{3}\right)$ & $36380 \pm 14739$ & $63078 \pm 22144$ & $64125 \pm 21541$ & $84530 \pm 15702$ \\
Perímetro $(\mu \mathrm{m})$ & $137 \pm 15$ & $158 \pm 18$ & $157 \pm 17$ & $170 \pm 97$ \\
Área $\left(\mu \mathrm{m}^{2}\right)$ & $1307 \pm 340$ & $1891 \pm 436$ & $1914 \pm 423$ & $2150 \pm 1550$ \\
Relação volume/superfície & $26,9 \pm 3,40$ & $32,5 \pm 3,73$ & $32,7 \pm 3,59$ & $34 \pm 7,61$ \\
Excentricidade & $0,82 \pm 0,08$ & $0,72 \pm 0,08$ & $0,68 \pm 0,08$ & $0,69 \pm 0,09$ \\
Índice de contorno & $3,83 \pm 0,17$ & $3,66 \pm 0,07$ & $3,63 \pm 0,06$ & $3,68 \pm 0,51$ \\
Coeficiente de forma & $0,86 \pm 0,08$ & $0,94 \pm 0,04$ & $0,96 \pm 0,03$ & $0,95 \pm 0,09$ \\
\hline *p<0,001 & & & & \\
\hline
\end{tabular}


Tabela 12. Valores médios dos parâmetros nucleares do coração de ratos Wistar machos dos grupos: Estressado (E) e Infectado submetido ao estresse (IE), Controle estressado e tratado com DHEA (ED) e Infectado submetido ao estresse e tratado com DHEA (IED) durante a fase aguda (pico de parasitemia $7^{\circ}$ dia após infecção). Para cada grupo experimental em cada dia de infecção $n=5$.

\begin{tabular}{lcccc}
\hline \multicolumn{1}{c}{ Parâmetros } & E* & IE* & ED* & IED* \\
\hline Diâmetro maior $(\mu \mathrm{m})$ & $59,3 \pm 8,5$ & $59,9 \pm 11,6$ & $59,2 \pm 8,7$ & $64,9 \pm 15,1$ \\
Diâmetro menor $(\mu \mathrm{m})$ & $41,11 \pm 6,1$ & $38,1 \pm 5,4$ & $42,8 \pm 8,5$ & $41,75 \pm 6,4$ \\
Diâmetro médio $(\mu \mathrm{m})$ & $49,2 \pm 6,2$ & $47,5 \pm 6,4$ & $50,3 \pm 8,2$ & $51,8 \pm 8,8$ \\
Relação entre diâmetros & $1,46 \pm 0,23$ & $1,59 \pm 0,34$ & $1,40 \pm 0,18$ & $1,56 \pm 0,32$ \\
Volume $\left(\mu \mathrm{m}^{3}\right)$ & $65572 \pm 26148$ & $59453 \pm 24873$ & $72339 \pm 41023$ & $79536 \pm 45192$ \\
Perímetro $(\mu \mathrm{m})$ & $159 \pm 20$ & $156 \pm 23$ & $161 \pm 25$ & $169 \pm 32$ \\
Área $\left(\mu \mathrm{m}^{2}\right)$ & $1935 \pm 498$ & $1808 \pm 496$ & $2042 \pm 709$ & $2170 \pm 778$ \\
Relação volume/área & $32,8 \pm 4,14$ & $31,7 \pm 4,32$ & $33,5 \pm 5,48$ & $34,5 \pm 5,89$ \\
Excentricidade & $0,70 \pm 0,09$ & $0,74 \pm 0,10$ & $0,68 \pm 0,11$ & $0,73 \pm 0,10$ \\
Índice de contorno & $3,65 \pm 0,09$ & $3,70 \pm 0,14$ & $3,63 \pm 0,06$ & $3,69 \pm 0,13$ \\
Coeficiente de forma & $0,95 \pm 0,04$ & $0,92 \pm 0,06$ & $0,96 \pm 0,03$ & $0,93 \pm 0,06$ \\
\hline *p<0,001 & & & & \\
\hline
\end{tabular}


Tabela 13. Valores médios dos parâmetros nucleares do coração de ratos Wistar machos dos grupos: Controle (C) e Infectado (I), Controle tratado com DHEA (D) e Infectado tratado com DHEA (ID) durante a fase crônica $\left(180^{\circ}\right.$ dia após infecção). Para cada grupo experimental em cada dia de infecção $\mathrm{n}=5$.

\begin{tabular}{lcccc}
\hline Parâmetros & C* & I* & D* & ID* \\
\hline Diâmetro maior $(\mu \mathrm{m})$ & $54,6 \pm 7,4$ & $61,2 \pm 8,9$ & $56,1 \pm 8,4$ & $57,1 \pm 7,1$ \\
Diâmetro menor $(\mu \mathrm{m})$ & $39,1 \pm 5,1$ & $39,7 \pm 4,5$ & $37,4 \pm 5,5$ & $41 \pm 4,9$ \\
Diâmetro médio $(\mu \mathrm{m})$ & $46,1 \pm 5,7$ & $49,1 \pm 5,2$ & $45,7 \pm 5,7$ & $48,3 \pm 5,2$ \\
Relação entre diâmetros & $1,40 \pm 0,15$ & $1,56 \pm 0,25$ & $1,52 \pm 0,26$ & $1,40 \pm 0,18$ \\
Volume $\left(\mu \mathrm{m}^{3}\right)$ & $53938 \pm 20057$ & $64335 \pm 20481$ & $52373 \pm 20340$ & $61189 \pm 20081$ \\
Perímetro $(\mu \mathrm{m})$ & $148 \pm 18$ & $160 \pm 18$ & $148 \pm 19$ & $155 \pm 17$ \\
Área $\left(\mu \mathrm{m}^{2}\right)$ & $1700 \pm 421$ & $1920 \pm 406$ & $1666 \pm 425$ & $1856 \pm 402$ \\
Relação volume/área & $30,7 \pm 3,8$ & $32,7 \pm 3,4$ & $30,4 \pm 3,8$ & $32,2 \pm 3,4$ \\
Excentricidade & $0,69 \pm 0,07$ & $0,74 \pm 0,09$ & $0,73 \pm 0,09$ & $0,68 \pm 0,08$ \\
Índice de contorno & $3,63 \pm 0,05$ & $3,68 \pm 0,10$ & $3,67 \pm 0,11$ & $3,63 \pm 0,07$ \\
Coeficiente de forma & $0,96 \pm 0,03$ & $0,93 \pm 0,05$ & $0,93 \pm 0,05$ & $0,96 \pm 0,03$ \\
\hline *p<0,001 & & & & \\
\hline
\end{tabular}


Tabela 14. Valores médios dos parâmetros nucleares do coração de ratos Wistar machos dos grupos: Estressado (E) e Infectado submetido ao estresse (IE), Controle estressado e tratado com DHEA (ED) e Infectado submetido ao estresse e tratado com DHEA (IED) durante a fase crônica ( $180^{\circ}$ dia após infecção). Para cada grupo experimental em cada dia de infecção $n=5$.

\begin{tabular}{lcccc}
\hline Parâmetros & E* & IE* & ED* & IED* \\
\hline Diâmetro maior $(\mu \mathrm{m})$ & $54,4 \pm 7$ & $62,7 \pm 9,8$ & $56,2 \pm 6,2$ & $59 \pm 9,1$ \\
Diâmetro menor $(\mu \mathrm{m})$ & $37,6 \pm 5,5$ & $39,9 \pm 5,6$ & $39,5 \pm 4$ & $40,3 \pm 5,4$ \\
Diâmetro médio $(\mu \mathrm{m})$ & $45,1 \pm 5,5$ & $49,9 \pm 6,3$ & $47,1 \pm 4,2$ & $48,6 \pm 6,1$ \\
Relação entre diâmetros & $1,46 \pm 0,22$ & $1,59 \pm 0,27$ & $1,43 \pm 0,17$ & $1,48 \pm 0,22$ \\
Volume $\left(\mu \mathrm{m}^{3}\right)$ & $50466 \pm 20161$ & $68150 \pm 25292$ & $56075 \pm 15356$ & $63406 \pm 25312$ \\
Perímetro $(\mu \mathrm{m})$ & $146 \pm 17$ & $163 \pm 21$ & $151 \pm 14$ & $157 \pm 20$ \\
Área $\left(\mu m^{2}\right)$ & $1626 \pm 412$ & $1986 \pm 495$ & $1757 \pm 318$ & $1891 \pm 490$ \\
Relação volume/área & $30,11 \pm 3,68$ & $33,27 \pm 4,20$ & $31,41 \pm 2,84$ & $32,46 \pm 4,12$ \\
Excentricidade & $0,71 \pm 0,09$ & $0,75 \pm 0,08$ & $0,70 \pm 0,08$ & $0,71 \pm 0,09$ \\
Índice de contorno & $3,65 \pm 0,08$ & $3,70 \pm 0,11$ & $3,64 \pm 0,06$ & $3,65 \pm 0,08$ \\
Coeficiente de forma & $0,94 \pm 0,04$ & $0,92 \pm 0,05$ & $0,95 \pm 0,03$ & $0,94 \pm 0,04$ \\
\hline *p<0,001 & & & & \\
\hline
\end{tabular}




\subsection{Histopatologia do Coração}

\subsubsection{Grupos Controles $\left(1^{\circ}\right.$ dia $)$}
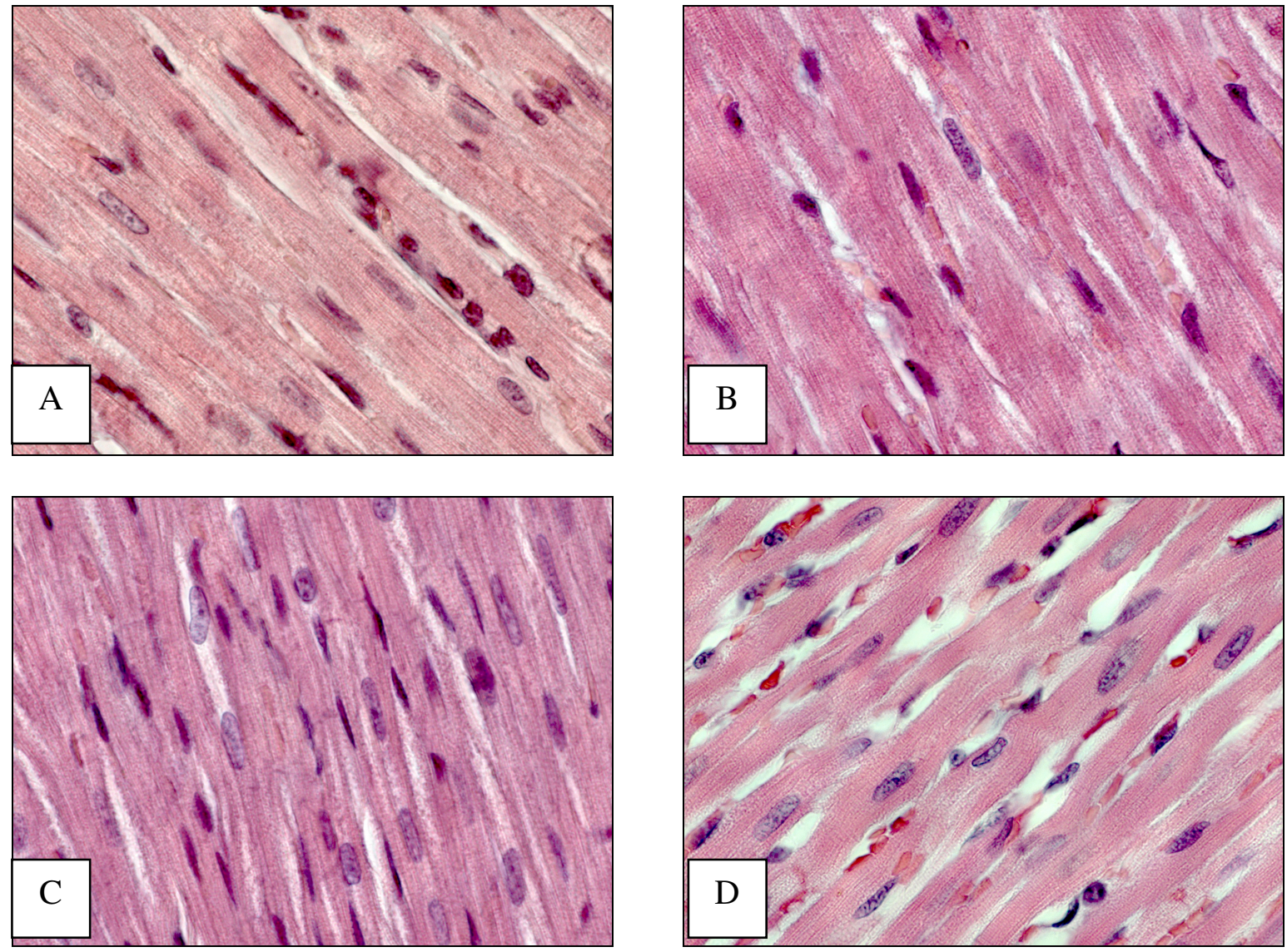

Figura 26. Cortes histológicos $(6 \mu \mathrm{m})$ de corações de ratos Wistar machos não infectados (controles) colhidos no $14^{\mathrm{o}}$ dia de experimento, nos seguintes grupos: A: grupo Controle, B: Controle tratado com DHEA, C: Controle estressado, D: Controle submetido ao estresse e tratado com DHEA. Coloração: hematoxilina-eosina (1000x). 


\subsubsection{Grupos Controles $\left(180^{\circ} \mathrm{dia}\right)$}
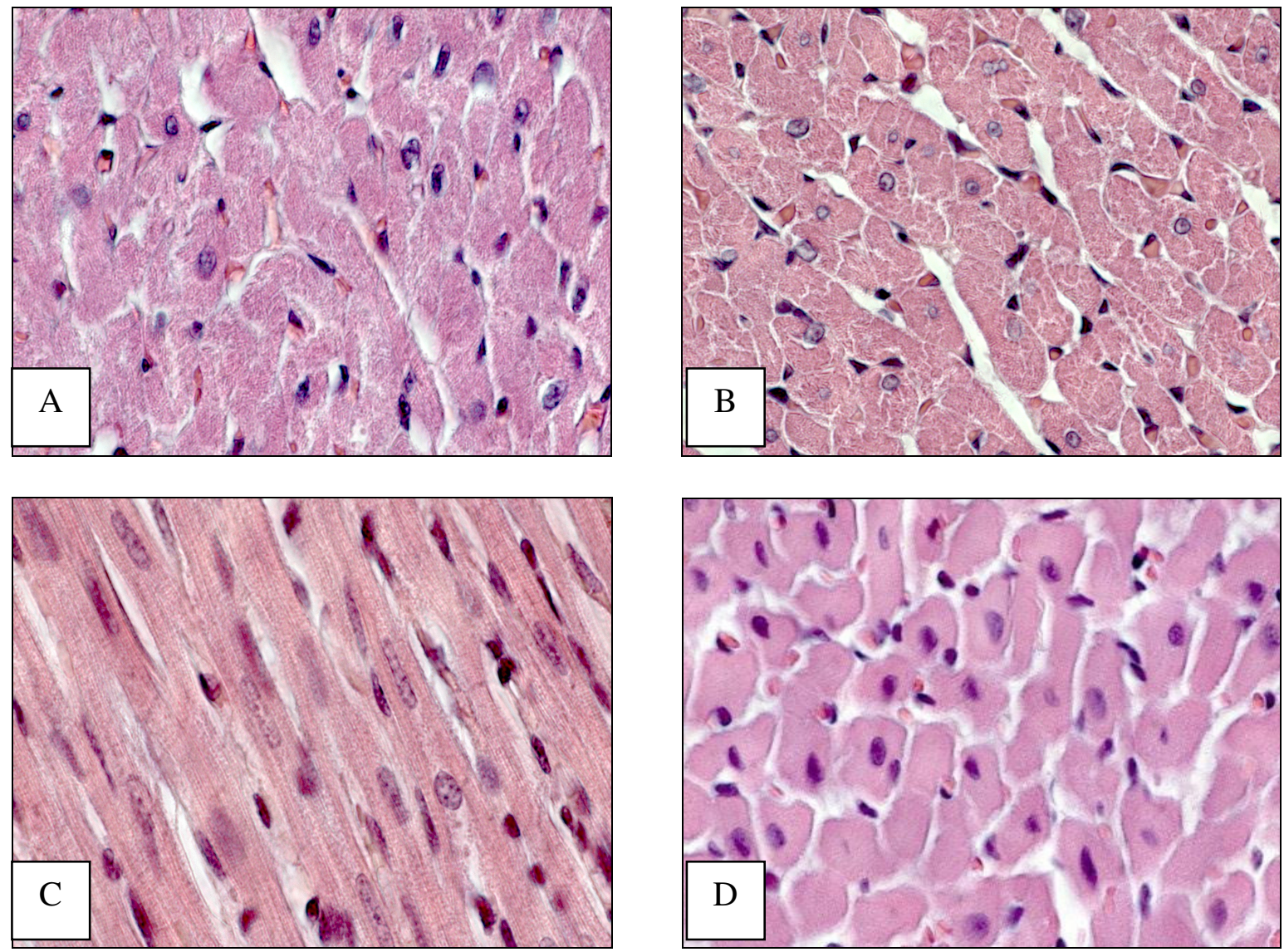

Figura 27. Cortes histológicos $(6 \mu \mathrm{m})$ de corações de ratos Wistar machos não infectados (controles) colhidos no $180^{\circ}$ dia de experimento, nos seguintes grupos: A: grupo Controle, B: Controle tratado com DHEA, C: Controle estressado, D: Controle submetido ao estresse e tratado com DHEA. Coloração: hematoxilina-eosina (1000x). 


\subsubsection{Grupos Infectados $\left(14^{\circ} \mathrm{dia}\right)$}
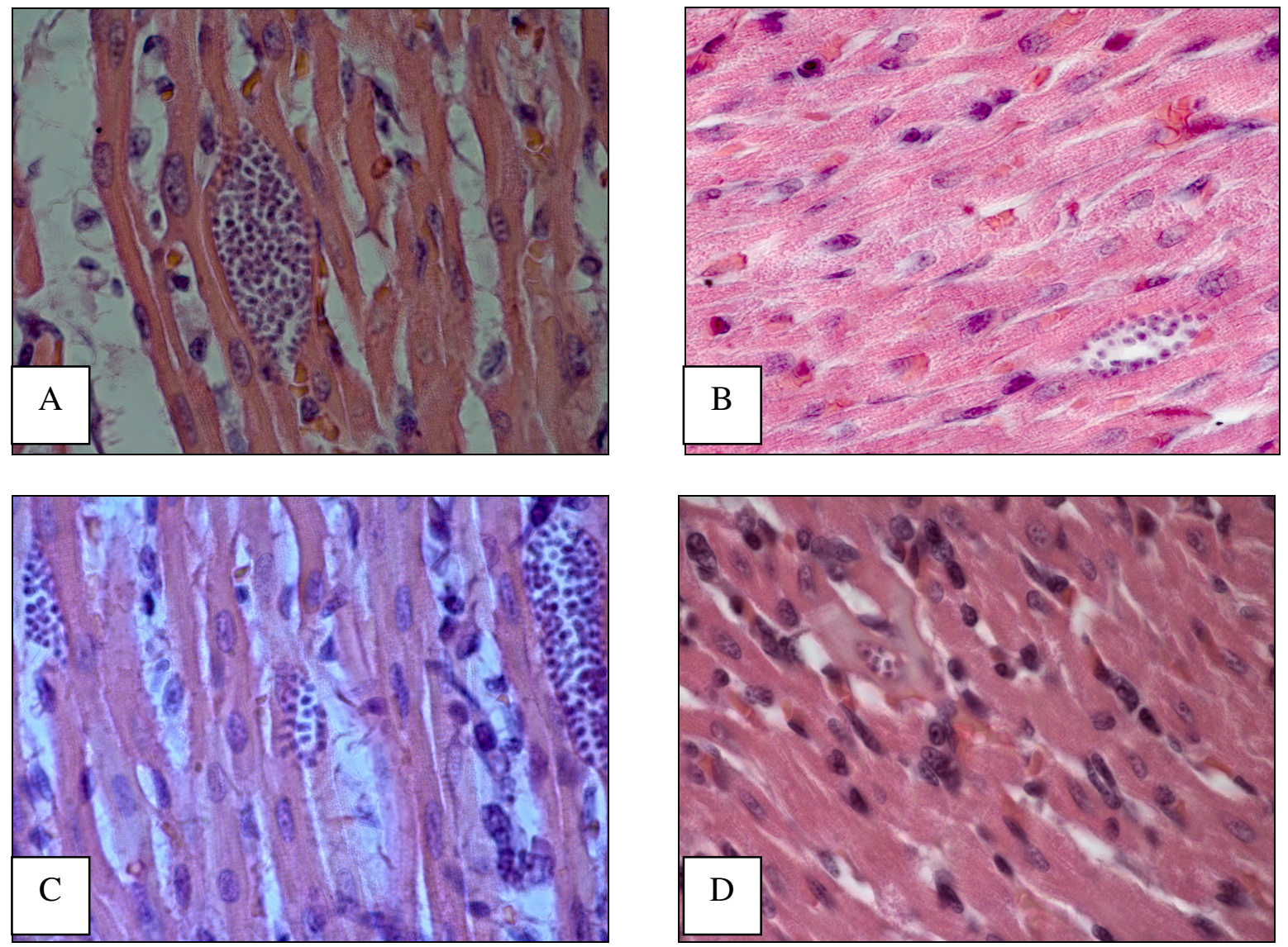

Figura 28. Cortes histológicos $(6 \mu \mathrm{m})$ de corações de ratos Wistar machos infectados i.p. com 100.000 formas tripomastigotas sangüícolas da cepa Y de Trypanosoma cruzi colhidos no $14^{\circ}$ dia de experimento, nos seguintes grupos: A: grupo Infectado, B: Infectado tratado com DHEA, C: Infectado estressado, D: Infectado submetido ao estresse e tratado com DHEA. Coloração: hematoxilina-eosina (1000x). 


\subsubsection{Grupos Infectados $\left(180^{\circ}\right.$ dia $)$}
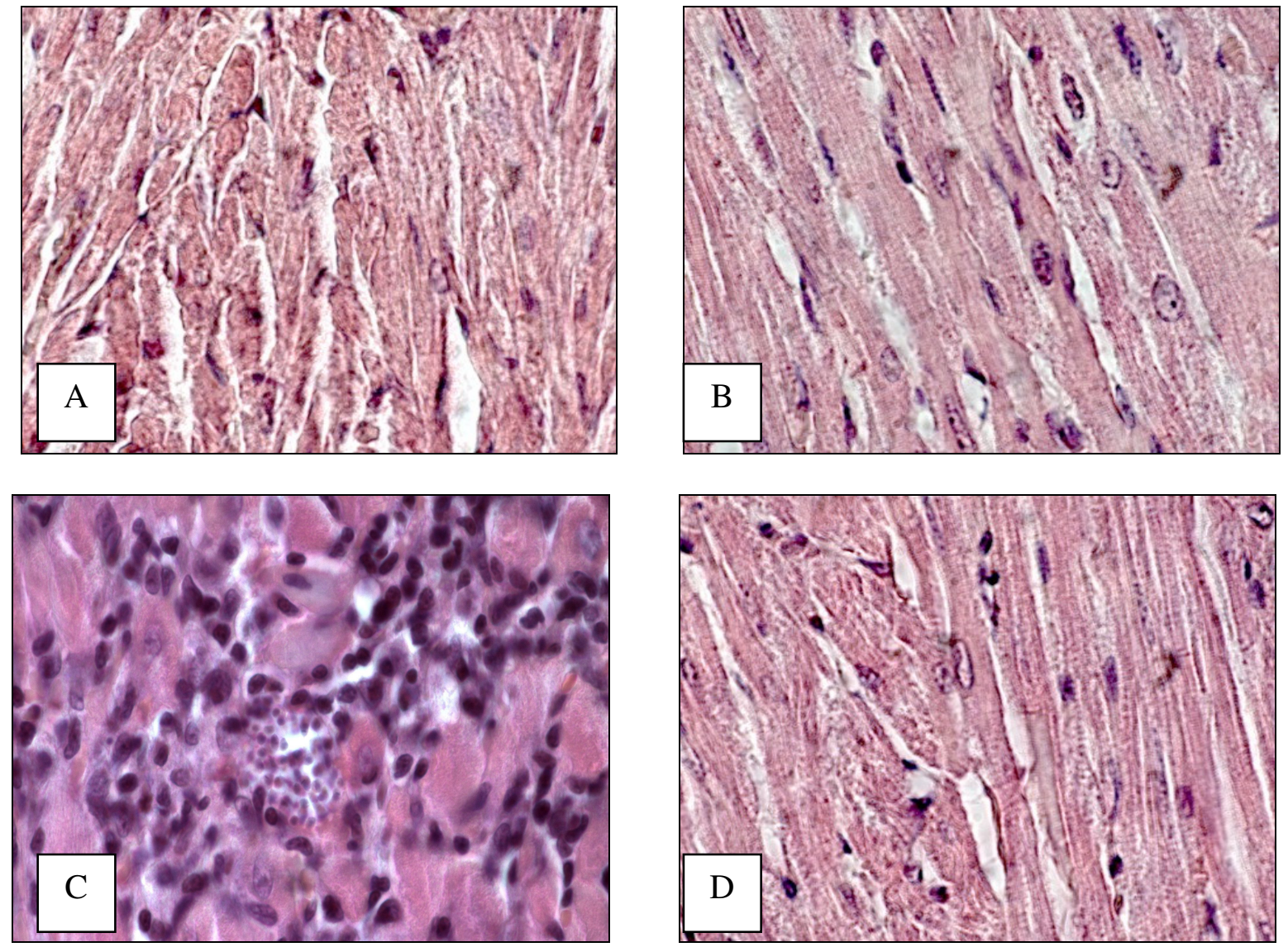

Figura 29. Cortes histológicos $(6 \mu \mathrm{m})$ de corações de ratos Wistar machos infectados i.p. com 100.000 formas tripomastigotas sangüícolas da cepa Y de Trypanosoma cruzi colhidos no $180^{\circ}$ dia de experimento, nos seguintes grupos: A: grupo Infectado, B: Infectado tratado com DHEA, C: Infectado estressado, D: Infectado submetido ao estresse e tratado com DHEA. Coloração: hematoxilina-eosina (1000x). 


\section{DISCUSSÃO}

Neste trabalho avaliamos o efeito da administração de dehidroepiandrosterona (DHEA) durante o curso da infecção pela cepa Y de $T$. cruzi em animais estressados ou sem estresse na fase aguda e crônica da infecção.

Como modelo experimental foi utilizado ratos da linhagem Wistar, já que os mesmos têm sido amplamente empregados para investigações sobre aspectos gerais da doença de Chagas experimental (CAMARGOS et al., 2000, SANTOS et al., 2005, SANTELLO et al., 2008a e 2008b; BRAZÃO et al., 2008; CAETANO et al., 2009; FILIPIN et al., 2008). A infecção nesse animal progride até a terceira semana, quando normalmente ocorre o óbito, ou então, os animais passam para a fase crônica, dependendo da patogenicidade da cepa. Em nosso estudo o pico de parasitemia ocorreu no sétimo dia após o inóculo, não ocorrendo mortalidade dos animais devido aos mesmos serem resistentes à cepa $\mathrm{Y}$ de $T$. cruzi. Outros estudos indiretamente confirmam nossos dados dentre eles o trabalho de NAGIB et al. (2007) trabalhando com ratos infectados com duas diferentes cepas de T.cruzi, JG menos virulenta e CL-Brener mais virulenta, onde a cepa JG apresentou baixa mortalidade, reduzida parasitemia, leve miocardite e discreta miosite.

O peso corpóreo dos animais tratados com DHEA e submetidos ao estresse repetitivo foi avaliado e demonstrou significância durante o processo evolutivo da infecção (Figura 1 e 2). RASMUSSEN et al. (1995), relataram que o tratamento com DHEA pode promover um aumento da massa muscular traduzido por aumento do peso corpóreo em camundongos. Os nossos dados estão de acordo, visto que o aumento do peso corpóreo dos animais tratados com DHEA foi significativo.

Dehidroepiandrosterona (DHEA) é um esteróide secretado pelas glândulas adrenais, tecido gonadal e células do sistema nervoso central (BAULIEU \& ROBEL 1998). DHEA é 
considerado como precursor biosintético de praticamente todos hormônios esteróides, incluindo testosterona e 17 $\alpha$-estradiol (LABRIE et al., 1995; LONGCOPE, 1995). No plasma, DHEA está predominantemente presente como DHEA-S. DHEA-S é convertido na forma ativa de DHEA por sulfatase intracelular que são expressos em número de células, incluindo monócitos e macrófagos (LONGCOPE, 1986).

No tocante ao peso cardíaco, constatamos que somente os animais tratados com DHEA apresentaram redução significativa quando comparados aos animais sem tratamento. (Figuras 26, 27, 28 e 29, Tabelas 11, 12, 13 e 14).

Estudos pioneiros de SANTOS et al., 2007, confirmam nossos dados onde os autores relataram que o tratamento de ratos Wistar com doses diárias de DHEA durante a infecção aguda pela cepa Y de T. cruzi ocasionou redução significante do peso cardíaco.

Ao longo do curso da doença de Chagas, as populações de linfócitos passam por mudanças importantes na sua dinâmica, incluindo expansão, diferenciação, morte e migração. Durante a fase aguda da infecção, ocorre uma intensa supressão das respostas linfoproliferativas à mitógenos e antígenos (KIERSZENBAUM \& SZTEIN, 1994 ; ABRAHAMSOHN \& COFFMAN, 1996). Nossos dados são complementares a essas observações, onde a administração de DHEA mesmo associada ao estresse provocou um aumento significativo na porcentagem de linfoproliferação quando comparados sos grupos não suplementados. BRAZÃO et al. (2008) trabalhando com ratos infectados com a cepa Y de T.cruzi, relatou que a suplementação de zinco produziu um efeito estimulatório sobre a proliferação de timócitos e esplenócitos, indiretamente corroborando com nossos dados.

Sabe-se que os macrófagos desempenham importante papel sobre a resposta imune do hospedeiro durante a fase aguda da doença de Chagas, sendo a primeira linha de defesa do organismo contra patógenos intracelulares (TALIAFERRO \& PIZZI, 1995; SAVINO et 
al., 2007). Para tal avaliamos o numero de macrófagos peritoniais em animais submetidos ao estresse repetitivo e suplementação de DHEA, e novamente a suplementação induziu um significativo aumento destas células (Tabela 1). SANTOS et al., (2007) confirmam nossos dados onde relatam que a suplementação de DHEA também ocasionou elevação do número de macrófagos.

A produção de óxido nítrico (NO) é uma importante defesa durante a infecção por T. cruzi (BERGERON \& OLIVIER, 2006). A síntese de NO ocorre através da conversão de L-arginine à citrulina por diferentes isoformas de NO sintetases. A presença de NO aparece em resposta a estímulos inflamatórios resultando na produção de grande quantidade desta substância, ocorrendo geralmente na patogenia da doença de Chagas (SILVA et al., 2005). Nossos dados demonstraram que os animais com suplementação de DHEA, estimulados ou não com LPS, apresentaram valores estatisticamente significantes em relação aos animais não suplementados. Quanto aos animais estressados e com suplementação de DHEA apresentaram aumento significativo em relação aos animais não submetidos ao estresse repetitivo, sendo que os animais com suplementação de DHEA apresentaram valores maiores quando comparado aos animais somente estressados.

Quanto à concentração de interleucinas TNF e IFN por nós avaliadas, demonstram que os níveis destas se encontravam mais elevados tanto na fase aguda como na crônica da infecção, sendo que nos animais suplementados com DHEA apresentaram aumento significativo em relação aos grupos que não receberam suplementação, embora os animais submetidos ao estresse apresentassem concentrações maiores quando comparados aos animais que não foram submetidos ao estresse repetitivo. Apesar de estarem aumentadas durante a fase crônica da infecção as mesmas apresentavam valores menores quando comparados aos valores encontrados na fase aguda. 
Inúmeros trabalhos corroboram os dados acima apresentados. $\mathrm{Na}$ infecção por $T$. cruzi em modelos murinos, a incapacidade de produzir IFN- $\gamma$ é letal (TORRICO et al., 1991). Estudos clínicos demonstram a correlação inversa entre a severidade da fase crônica da doença e a capacidade de células T CD8+ que secretam IFN- $\gamma$ (LAUCELLA et al., 2004). Entretanto, para o aumento da resistência da infecção por $T$. cruzi tanto a funcionabilidade como capacidade de as células $\mathrm{T} \mathrm{CD}^{+}$produzir IFN- $\gamma$ são requeridas. A ativação de macrófagos por IFN- $\gamma$ e/ou TNF- $\alpha$, e síntese de NO, são consideradas as moléculas mais importantes para a morte de amastigotas intracelulares (VESPA et al., 1994; SILVA et al., 1995).

Em estudos in vitro e in vivo em células ou animais infectados por T. cruzi ocorre uma indução das células mononucleares para produzir altos níveis de citocinas próinflamatórias (DUTRA et al., 2005). Entretanto em camundongos, a taxa essencial de ativação de macrófagos, citocinas como IL-12, IFN- $\gamma$ e TNF- $\alpha$ no controle da fase aguda está ligada a parasitemia como demonstrado por (ROPERT et al., 2003). No estudo de NAGIB et al, (2007), a cepa clone CL-Brener apresentou ótima capacidade para induzir altos níveis de duas citocinas pro-inflamatórias durante a fase aguda, quando comparado com a infecção pela cepa JG, tanto em ratos jovens como adultos. Os níveis de IFN- $\gamma$ e TNF- $\alpha$ são também elevados em ratos jovens infectados com a cepa Sylvio X10 7 de $T$. cruzi (CHANDRASEKAR et al., 1998) ou cepa Y (RACHID et al., 2006) durante a fase aguda. Há evidencias que IFN- $\gamma$ e TNF- $\alpha$ são produzidos pelos cardiomiócitos pelo menos no inicio da fase aguda da infecção na qual não observamos um infiltrado de leucócitos (CHANDRASEKAR et al., 1998). Entretanto a resposta inflamatória é essencial para controlar a infecção aguda por T. cruzi (TEIXEIRA et al., 2002). Em ratos jovens, os níveis 
séricos de IL-10 aumentam significantemente durante a fase aguda, sem diferença entre a cepa CL-Brener e a JG. Entretanto a relação IL-10/IFN- $\gamma$ era muito mais alta na infecção induzida pela cepa JG (NAGIB et al., 2007). Em humanos, IL-10 é produzida por células mononucleares periféricas de pacientes na fase crônica indeterminada e com sinais cardíacos (DUTRA et al., 1997). Em outro experimento utilizando pacientes na forma indeterminada da doença de Chagas, mostraram que os monócitos e células $\mathrm{T}$ destes pacientes produziam mais IL-10 que monócitos de pacientes com cardiomiopatia chagásica (SOUZA et al., 2004).

Nossos dados corroboram com estes descritos na literatura, onde foi observado que a concentração de distintas interleucinas do grupo Th1 representados por IFN, TNF e NO apresentaram aumento significativo nos animais submetidos à terapia com DHEA inclusive nos animais submetidos ao estresse repetitivo, quando comparados aos animais que não foram tratados.

Diversos trabalhos demonstram que a presença de glicocorticoides ocasiona a inibição da proliferação de células T induzidas por mitógenos. RAMIREZ \& SILVA, (1997), expõe diferentes situações quando adiciona glicocorticóides diminuindo a estimulação de linfoproliferação com ConA e isto deveria ser uma conseqüência da inibição da síntese de NO desencadeado pelo hormônio. A resposta imune protetora contra T. cruzi parece estar associada à presença de IFN- $\gamma$ (ABRAHAMSOHN \& COFFMAN, 1996), TNF- $\alpha$ (SILVA et al., 1995; CASTAÑOS-VELEZ et al., 1998) e o controle do parasitismo tecidual parece ser dependente da síntese de NO (GAZZINELLI et al., 1992; VESPA et al., 1994; HOLSCHER et al., 1998). Em nosso trabalho, encontramos uma redução da resposta TH2 representados através das concentrações de IL-4 e IL-10, nos animais suplementados 
com DHEA quando comparados aos animais sem esta suplementação ou submetidos ao estresse (Figuras 18, 19, 20 e 21).

A perda das respostas proliferativas de linfócitos e a reduzida capacidade de produção de IL-2 é uma constante durante a fase aguda da infecção por $T$. cruzi (TARLETON, 1988). A habilidade do DHEA em regular a proliferação de citocinas sugere um importante papel na mediação da resposta imune inflamatória. Alguns estudos com DHEA sobre a função de células T são conflitantes. Alguns relatam que o DHEA aumenta as concentrações de IL-2 e conseqüentemente a proliferação de células T tanto em humanos como em murinos (SUZUKI et al., 1991), enquanto outros notaram uma inibição na proliferação de linfócitos e produção de IL-2 na presença de DHEA (LORIA et al., 1996; YOUNG et al., 2001).

Sabemos que o estresse está relacionado à indução de várias doenças, incluindo hipertensão, diabetes, depressão, imunosupressão, disfunção reprodutiva entre outras (KIOUKIA- FOUGIA et al., 2002; FEDERICI \& LAURO, 2005; GIDRON et al., 2006). Inúmeros são os fatores que podem influenciar na patogenia das doenças tais como a intensidade e duração do estímulo estressor, tipo de cepa de patógeno envolvido e sexo (KIOUKIA- FOUGIA et al., 2002). Desde que uma das metas do presente estudo era demonstrar in vivo que o estresse repetitivo poderia afetar a resposta proliferativa de esplenócitos, um dos dados mais significantes de nosso experimento foi à diminuição da taxa de proliferação nos animais estressados que se encontravam na fase crônica quando comparados aos grupos não estressados. Nosso dado está de acordo com os estudos de LYSLE et al., 1990 que observaram redução dos efeitos proliferativos na vigência do estresse. 
A esplenomegalia encontra-se normalmente relacionada a uma ativação das células B e T e refletem o perfil celular vigente durante a fase aguda da infecção, que acompanha o estado de imunossupressão resultante da ativação de linfócitos nos órgãos linfóides do camundongo infectado. In vivo a replicação parasitária parece ser controlada por linfócitos T CD8+, considerado uma importante fonte de IFN- $\gamma$. De fato, camundongos que carecem de linfócitos CD8+ são mais suscetíveis à infecção, apresentando altos níveis de parasitemia sanguínea e tecidual. Outros estudos revelam que o estresse induz modificações importantes no número e atividade das células imunes (TSENG et al., 2005).

A imunidade mediada por células é responsável pelo controle da fase aguda da infecção (TRISCHMANN, 1984), sendo a ativação de macrófagos por citocinas derivada dos linfócitos Th1 considerada o principal mecanismo de defesa do hospedeiro contra o parasita (BRENER \& GAZZINELLI, 1997).

Esse fato se deve provavelmente a ação conjunta de mecanismos da resposta celular, que foi avaliada neste trabalho por meio da quantificação de NO, proliferação de células esplênicas e tímicas, IL-2, IL-4, IL-10, IFN- $\gamma$ e TNF- $\alpha$ que podem vir a corroborar com os dados descritos na literatura quanto ao papel das interleucinas no controle parasitário na fase aguda da infecção (SILVA et al., 1995; ALIBERTI et al., 1999).

Os glicocorticóides regulam uma escala de processos biológicos, tais como, proliferação de células, inflamação, imunidade e a diminuição na ativação de células natural Killer (NK) (IWAKABE et al., 1998; SAPERSTEIN et al., 1992; WU et al., 2000), supressão na fagocitose de macrófagos (LU et al., 1998), a liberação de óxido nítrico (NO) e TNF- $\alpha$ (AARSTAD et al., 1991; BROWN \& ZWILLING, 1994; KIZAKI et al., 1996), alterando a sensibilidade do IFN- $\gamma$ (ZWILLING et al., 1992), inibindo a proliferação de 
células T, produzindo IL-2 e IFN- $\gamma$ (IWAKABE et al., 1998; LI et al.,1997), modulando a expressão MHC de classe II (ZWILLING et al., 1990), efetuando o equilíbrio de células T do tipo 1 e 2 (Th1/Th2) (IWAKABE et al., 1998), e modulando a produção de anticorpos (FUKUI et al., 1997; KOMORI et al., 1996; OKIMURA et al., 1986). É bem aceitável que, a suscetibilidade à infecção e a defesa do hospedeiro contra a invasão de patógenos pode ser alterada em conseqüência aos efeitos de modulação do estresse sobre a resposta imune (BIONDI \& ZANNINO, 1997; YANG \& GLASER, 2000). Estressores químicos como o vapor de éter pode ser utilizado para aumentar a ativação do eixo HPA, aumentando os níveis de corticosterona no plasma em poucos minutos (CALDEIRA \& FRANCI, 2000).

Em nosso trabalho, observamos que os níveis de corticosterona nos grupos submetidos ao estresse repetitivo mostraram aumento significativo quando comparados aos animais submetidos ao estresse repetitivo e suplementados com DHEA. A suplementação de DHEA provocou redução significativa dos níveis de corticosterona em todos os grupos suplementados (Figura 22 e 23).

No tocante a patogenia de órgãos ocos, a doença de Chagas se caracteriza por uma invasão do plexo entérico e degeneração dos neurônios entéricos, sendo esta a causa normalmente atribuída para as desordens digestivas em pacientes crônicos.

RIBEIRO e colaboradores (2008) comparam a resposta imune celular em pacientes com problemas digestivos na fase indeterminada da doença de Chagas tomando como base a proliferação de linfócitos e a produção de citocinas após a estimulação com antígenos ou mitógenos. Os resultados indicaram que os pacientes com forma digestiva não apresentaram a característica imunossupressão favorecendo a formação de reação inflamatória que pode contribuir com as lesões no sistema nervoso mientérico. As 
manifestações da forma digestiva são atribuídas à destruição dos nervos do plexo mientérico que leva a alteração dos movimentos peristálticos, hipertrofia muscular e dilatação. (TOSTES et al., 1994).

Estudos experimentais utilizando-se camundongos demonstraram que a resposta immune Th1 caracteriza-se pela produção de IFN- $\gamma$ e TNF- $\alpha$ contribuindo pra o controle parasitário (ALIBERTI et al., 1996; MARTINS et al., 1999), enquanto a IL-4 e IL-10 estão relacionadas a continuidade do parasitismo (ABRAHAMSOHN \& COFFMAN, 1996; REED et al., 1994). A resposta imune Th-1 desempenha um papel protetor através da ativação da óxido nítrico sintetase induzida (iNOS), que converte L-arginina em óxido nitrico (RADOMSKI et al., 1990). NO exerce ação tripanosomicida potente por si só ou em combinação com o peróxido de hidrogênio (OLIVEIRA et al., 1997). Por outro lado, NO encontra-se envolvido com a denervação do plexo nervoso mientérico durante a fase aguda da infecção em camundongos infectados por T. cruzi (ARANTES et al., 2004). A resposta imune direcionada contra os parasitas ou componentes do próprio hospedeiro desempenham um papel importante do desenvolvimento das lesões observadas durante a fase crônica da doença. A destruição de células ganglionares adjacentes a ruptura de ninhos de parasitas e células contendo amastigotas desintegrados tem sido demonstrado em humanos e modelos experimentais (KÖBERLE, 1963).

A presença de anticorpos anti-neurônios (RIBEIRO et al., 1979) e a intensidade do processo inflamatório observada dá suporte para o envolvimento do sistema imune e o processo de destruição de células do plexo mientérico. Recentemente estudos utilizando modelos experimentais indicaram que o NO serve como importante mediador dos danos aos nervos durante a infecção experimental por T. cruzi. 
No megacólon os distúrbios de mobilidade estão associados ao aumento do cólon e constipação, sendo o reto e o cólon sigmóide os segmentos mais comprometidos (Prata, 1999), que exibem um espessamento luminal e hipertrofia muscular. Lesões inflamatórias no sistema nervoso entérico estão associadas a uma substancial redução no número de neurônios, ficando esta redução responsável pelas mega síndromes (Tostes et al., 1994).

A análise histopatológica e cariométrica das células cardíacas revelou que a administração de DHEA diminuiu o número de ninhos de amastigotas bem como seu tamanho mesmo nos animais submetidos ao estresse repetitivo. O volume nuclear das células cardíacas de animais estressados na fase aguda foi menor quando comparados aos animais tratados com DHEA, enquanto que na fase crônica o volume nuclear foi maior nos animais estressados em relação aos animais tratados com DHEA. Nossos dados estão de acordo com o apresentado por SANTOS e colaboradores (2005), onde a análise quantitativa histopatologica do coração mostrou nos grupos infectados e estressados uma intensa destruição tecidual com infiltração de células mononucleares e fibras cardíacas desorganizadas, além de apresentar maior número e tamanho de ninhos de amastigota quando comparados aos grupos não estressados. 


\section{Conclusão}

A administração de DHEA provocou uma marcante redução dos níveis de parasitas circulantes para todos os animais tratados quando comparados aos animais sem tratamento, além de promover direcionamento efetivo da resposta imune do hospedeiro, para o tipo Th1, controlando as ações patogênicas decorrentes do parasitismo.

A administração de DHEA frente ao estresse repetitivo pode ser considerada um mecanismo eficaz para o controle da evolução da infecção experimental com T. cruzi em ratos Wistar na fase aguda da infecção, refletindo suas ações nas manifestações crônicas de infecção experimental, tais como a redução de carga parasitária e infiltrado inflamatório no coração.

Dessa forma concluímos que a administração de DHEA promove efeitos antagônicos à elevação de corticosterona plasmática provocada pelo estresse repetitivo aliado à infecção experimental, podendo ser utilizado como substância alternativa imunomoduladora em casos de infecção por patógenos. 


\section{REFERÊNCIAS BIBLIOGRÁFICAS}

AARSTAD, H.J.; KOLSET, S.O.; SELJELID, R. The effects of stress in vivo on the function of mouse macrophages in vitro. Scand. J. Immunol, v.33, p.673-681, 1991.

ABRAHAMSOHN, I.A.; COFFMAN, R.L. Trypanosoma cruzi: IL-10, TNF, IFN, and IL12 regulate innate and acquired immunity to infection. Experimental Parasitology, v.84, p.23, 1996.

ADAD, S.J.; ANDRADE, D.C.S.; LOPES, E.R.; CHAPADEIRO, E. Contribuição ao estudo da anatomia patológica do megaesôfago chagásico. Revista do Instituto de Medicina Tropical, v.33, p.443-450, 1991.

AIRES, M.M. Fisiologia. Editora Guanabara Koogan. Rio de Janeiro. 1999.

ANDRADE, S.G.; CARVALHO, M.L.; FIGUEIRA, R.M. Caracterização morfobiológica e histopatológica de diferentes cepas do Trypanosoma cruzi. Gaz. Med. Bahia, v.70, p.3242, 1970.

ALIBERTI, J.C.S.; CARDOSO, M.A.G.; MARTINS, G.A. Interleukin-12 mediates resistance to Trypanosoma cruzi in mice and is produced by murine macrophages in response to live trypomastigotas. Infection and Immunity, v.64, p. 961-1967, 1996.

ALIBERTI, J.C.S.; MACHADO, F.S.; SOUTO, J.T.; CAMPANELLI, A.P.; TEIXEIRA, M.M.; GAZZINELLI, R.T.; SILVA, J.S. Beta-Chemokines enhance parasite uptake and promote nitric oxide-dependent microbiostatic activity in murine inflamatory macrophages infected with Trypanosoma cruzi. Infection and Immunity, v.67, p. 4819-4826, 1999.

ARANTES, R.M.; MARCHE, H.H.; BAHIA, M.T.; CUNHA, F.Q.; ROSSI, M.A.; SILVA, J.S. Interferon-gamma-induced nitric oxide causes intrinsic intestinal denervation in Trypanosoma cruzi-infected mice. Am J Phatol, v.164, p.1361-8, 2004. 
ARIT, W.; CALliES, F.; VAN VLIJMEN, J.C.; KOEHLER, I.; REINCKE, M.; BIDLINGMAIER, M.; HUEBLER, D.; OETTEL, M.; ERNEST, M.; SCHULTE, H.M.; ALLOLIO, B. Dehydroepiandrosterone replacement in women with adrenal insufficiency. N. Engl. J. Med, v. 341, p.1013-1020, 1999.

ARLT, W.; HEWISON, M. Hormones and immune function: implications of aging. Aging Cell, v.3, p.209-216, 2002.

BAULIEU, E.E.; ROBEL, P. Dehydroepiandrosterone (DHEA) and dehydroepiandrosterone sulfate (DHEAS) as neuroactive neurosteroids. Proceedings of the National Academy of Sciences of the United States of America, v.14, p.4089-91, 1998.

BEISHUIZEN, A.; THYS, A.G.; VERMES, I. Decreased levels of dehydroepiandrosterone sulphate in severe critical illness: a sign of exhausted adrenal reserve? Crit.Care, v.6, p.434-8, 2002.

BEN NATHAN, D.; PADGETT, D.A.; LORIA, R.M. Androstenediol and dehydroepiandrosterone protect mice against lethal bacterial infections and lipopolysaccharide toxicity. J. Med. Microbiol, v.48, p. 425-431, 1999.

BERGERON, M.; OLIVIER, M. Trypanosoma cruzi mediated IFH-gamma inducible nitric oxide output in macrophages is regulated by iNOS mRNA stability. Journal of Immunology, v. 177, p.6271-6280, 2006.

BIONDI, M.; ZANNINO, L.G. Psychological stress, neuroimmunomodulation, and susceptibility to infectious diseases in animals and man: A review. Psychother. Psychosom, v.66, p.3-26, 1997.

BLAUER, K.L.; POTH, M.; ROGERS, W.M.; BERNTON, E.W. Dehydroepiandrosterone antagonizes the suppressive effects of dexamethasone on lymphocyte proliferation. Endocrinology, v.129, p.3174-3179, 1991. 
BRAZÃO, V.; DEL VECCHIO FILIPIN, M.; CAETANO, L.C.; TOLDO, M.P.; CAETANO, L.N.; DO PRADO JR, J.C. Trypanosoma cruzi: the effects of zinc supplementation during experimental infection. Experimental Parasitology, v. 118, p.549$554,2008$.

BRENER, Z. Therapeutic activity and criterion of cure in mice experimentally infected with Trypanosoma cruzi. Revista do Instituto de Medicina Tropical. São Paulo, v.4, p.389-96, 1962.

BRENER, Z.; CHIARI, E. The effects of some immunosuppressive agents in experimental chronic Chagas' disease. Trans.of the Royal Soc. Trop. Med. and Hyg, v.65, p.629-636, 1971.

BRENER, Z.; GAZZINELLI, R.T. Immunological control of Trypanosoma cruzi infection and pathogenesis of Chagas' disease. Int Arch Allergy Immunol, v.114, p.103-10, 1997.

BRENER, Z.; ANDRADE, Z.A.; BARRAL-NETO, M. Trypanosoma cruzi e Doença de Chagas. ed. 2, Editora Guanabara Koogan, RJ, p. 55-56, 2000.

BROWN, D.H.; ZWILLING, B.S. Activation of the hypothalamicpituitary-adrenal- axis differentially affects the anti-mycobacterial activity of macrophages from BCG-resistant and susceptible mice. Journal of Neuroimmunology. v.53, p.181-187, 1994.

CAETANO, L.C.; ZUCOLOTO, S.; KAWASSE, L.M.; TOLDO, M.P.; DO PRADO, J.C. Influence of Trypanosoma cruzi chronic infection in the depletion of esophageal neurons in Calomys callosus. Digestive Disease and Sciences, v.51, p.1976-1800, 2006.

CAETANO, L.C.; ZUCOLOTO, S.; KAWASSE, L.M.; ALONSO TOLDO, M.P.; DO PRADO JR, J.C. Could cyclophosphamide exert a protective role avoiding esophagic neuron loss in Calomys callosus infected with Trypanosoma cruzi? Digestive Disease and Science. v.53, p.2020-2026, 2008(a). 
CAETANO, L.C.; ZUCOLOTO, S.; KAWASSE, L.M.; TOLDO, M.P.A.; DO PRADO JR, J.C. Does cyclophosphamide play a protective role against neuronal loss in chronic T. cruzi infection? Digestive Disease and Science, v. 53, p. 2929-2934, 2008(b).

CAETANO, LC.; BRAZÃO. V.; FILIPIN, M.DEL.V.; SANTELLO, F.H.; CAETANO, L.N.; TOLDO, M.P.A.; CALDEIRA, J.C.; DO PRADO JR, J.C. Effects of repetitive stress during the acute phase of Trypanosoma cruzi infection on chronic Chagas' disease in rats. Stress, v.12, p.144-151, 2009.

CALDEIRA, J.C.; FRANCI, C.R. Prolactin and Corticosterone secretion in response to acute stress after paraventricular nucleus lesion by ibotenic acid. Brain Research Bulletin, v.52, p.483-489, 2000.

CAMARGOS, E.R.S.; FRANCO, D.J.; GARCIA, C.M.M.G.; DUTRA, A.P.; TEIXEIRAJUNIOR, A.L.; CHIARI, E.; MACHADO, C.R.S. Infection with different Trypanosoma cruzi populations in rats, cardiac sympathetic denervation and involvement of digestive organs. Am. J. Trop. Med. Hyg, v.62, p.604-612, 2000.

CARDILlO, F.; VOLTARELli, J.C.; REED, S.G.; SILVA, J.S. Regulation of Trypanosoma cruzi infection in Mice by Gamma Interferon and Interleukin 10: Role of NK Cells. Infection and Immunity, v.64, p128-134, 1996.

CASSON, P.R.; ANDERSEN, R.N.; HERROD, H.G.; STENTZ, F.B.; STRAUGHN, A.B.; ABRAHAM, G.E.; BUSTER, J.E. Oral dehydroepiandrosterone in physiologic doses modulates immune function in postmenopausal women. Am. J. Obstet. Gynecol, v.169, p.1536-1539, 1993.

CASTAÑOS-VELlES, E.; MAERLAN, S.; OSORIO, L.; ABERG, F.; BIBERFELD, P.; ÖRN, A.; ROTTENBERG, M. Trypanosoma cruzi infection in tumor necrosis factor receptor p-55- deficient mice. Infection and Immunity, v.66, p.2960-2968, 1998. 
CASTRO, M.A.P.; BRENER, Z. Estudo parasitológico e anátomo-patológico da fase aguda da doença de Chagas em cães inoculados com duas diferentes cepas do Trypanosoma cruzi. Revista da Sociedade Brasileira de Medicina Tropical, v.18, p.233-239, 1985.

CATANIA, R.A.; ANGElE, M.K.; AVAlA, A.; CIOFFI, W.G.; BLAND, K.L.; CHAURY, I.H. Dehydroepiandrosterone restores immune function following trauma haemorrhage by a direct effect on t lymphocytes. Cytokine, v.11, p.443-450, 1999.

CHAGAS, C. Nova tripanossomíase humana. Estudos sobre a morfologia e o ciclo evolutivo do Schizotrypanum cruzi n.gen., n, sp., agente etiológico de uma nova entidade mórbida para o homem. Memórias do instituto Oswaldo Cruz, v.1, p.159-218, 1909.

CHANDRASEKAR, B.; MELBY, P.C.; PENNICA, D.; FREEMAN, G.L. Overexpression of cardiotrophin-1 and gp130 during experimental acute Chagasic cardiomyopathy. Immunology Letter, v.61, p.89-95, 1998.

CHRISTEFF, N.; MELCHIOR, J.C.; MAMMES, O.; GHERBI, N.; DALLE, M.T.; NENUS, E.A. Correlation between increase cortisol: DHEA ratio and malnutrition in HIVpositive men. Nutrition, v.15, p.534-539, 1999.

COHEN, S.; HAMRICK, N. Stable individual differences in physiological response to stressors: implications for stress-elicited changes in immune related health. Brain Behav. Immunity, v. 17, p.407-414, 2003.

COSTA, R.B. Grado de denervación em indivíduos chagásicos "sintomáticos” y “asintomáticos”. Bol Chil Parasitol, v. 24, p.75-7, 1969.

DANENBERG, H.D.; BEN YEHUDA, A.; ZAKAYRONES, Z.; GROSS, D.J.; FRIEDMAN, G. Dehydroepiandrosterone treatment is not beneficial to the immune response to influenza in elderly subjects. J. Clin. Endocrin. Met, v.82, p.2911-2914, 1997. 
DEBONNEUIL, E.H.; QUILLARD, J.; BAULIEU, E.E. Hypoxia and dehydroepiandrosterone in old age: a mouse survival study. Respir Res, v.18, p.144, 2006.

DHABHAR, F.S. Stress-induced augmentation of immune function the role of stress hormones, leukocyte trafficking, and cytokines. Brain. Behav. Immun, v.16, p.785-798, 2002.

DOS SANTOS, C.D.; TOLDO, M.P.; DO PRADO JUNIOR, J.C. Trypanosoma cruzi: the effects of dehydroepiandrosterone (DHEA) treatment during experimental infection. ActaTropica, v.95, p.109-15, 2005.

DOST, C.K.; ALBUQUERQUE, S.; HEMLEBEN, V.; ENGELS, W.; PRADO J.C, JR. Molecular genetic characterization of different Trypanosoma cruzi strains and comparison of their development in Mus musculus and Calomys callosus. Parasitology Research, v.88, p. $609-616,2002$.

DUTRA, H.S.; ROSSI, M.I.; AZEVEDO, S.P.; EL-CHEIKH, M.C.; BOROJEVIC, R. Haematopoietic capacity of colony-forming cells mobilized in hepatic inflammatory reactions as compared to that of normal bone marrow cells. Research in Immunology, v.148, p.437-44, 1997.

DUTRA, W.O.; ROCHA, M.O.; TEIXEIRA, M.M. The clinical immunology of human Chagas disease. Trends in Parasitology, v. 12, p. 581-7, 2005.

EBELING, P.; KOIVISTO, V.A. Physiological importance of dehydroepiandrosterone. Lancet, v.343, p.1479-81, 1994.

ELENKOV, I.J.; CHROUSOS, G.P. Stress hormones, proinflammatory and antiinflammatory cytokines, and autoimmunity. Ann. NY. Acad. Sci, v.966, p.290-303, 2002. 
FALLON, P.G.; RICHARDSON, E.J.; JONES, F.M.; DUNNE, D.W. Dehydroepiandrosterone sulfate treatment of mice modulates infection with Schistosoma mansoni. Clin. Diagn. Lab. Immunol, v.5, p.251-253, 1998.

FEDERICI, M.; LAURO, R. Review article: diabetes and atherosclerosis-running on a common road. Aliment Pharcol Ther, v.22, p.11-5, 2005.

FERNANDES, M.I.M.; ZUCOLOTO, S.; COLLARES, E.F.; FERRIOLI FILHO, F. Morphometric investigations of the colon mucosa in chronic Trypanosoma cruzi infected rat. Virchows. Arch. B. Cell. Pathol, v.60, p. 119-122, 1991.

FILIPIN, M.DEL.V.; BRAZÃO, V.; CAETANO, L.C.; SANTELLO, F.H.; TOLDO, M.P.A.; CAETANO, L.N.; DO PRADO JR, J.C. Trypanosoma cruzi: orchiectomy and dehidroepiandrosterone therapy in infected rats. Experimental Parasitology, v.120, p.249254, 2008.

FLORA FILHO, R.; ZILBERSTEIN, B. Óxido Nítrico: o simples mensageiro percorrendo a complexidade. Metabolismo, síntese e funções. Revista Associação Médica Brasileira. v.46, p.265-71, 2000.

FUKUI, Y.; SUDO, N.; YU, X.N.; NUKINA, H.; SOGAWA, H.; KUBO, C. The restraint stress-induced reduction in lymphocyte cell number in lymphoid organs correlates with the suppression of in vivo antibody production. Journal of Neuroimmunology, v.79, p.211$217,1997$.

GALVÃO, F.H.; WAITZBERG，D.L.; BACCHELLA，T.; GAMA-RODRIGUES，J.; MACHADO, M.C. Small intestine transplantation. Arq. Gastroenterol. v.40, p.118-125, 2003.

GAZZINELLI, R.T.; OSWALD, I.P.; HIENYS, S. The microbicidal activity of interferongamma-treated macrophages against Trypanosoma cruzi involves na L-arginine-dependent, 
nitrogen oxide mediated mechanism inhabitable by interleukin-10 and transforming grow factor-beta. European Journal of Immunology, v.22, p.2501-2506, 1992.

GIDRON, Y.; RUSS, K.; TISSARCHONDOU, H.; Warner, J. The relation between psychological factors and DNA-damage: A critical review. Biol Psychol, v.72, p.291-304, 2006.

GONÇALVES-DA-COSTA, S.C.; LAGRANGE, P.H.; HURTREL, B.; KERR, I.; ALENCAR, A. Role of $\mathrm{T}$ lymphocytes in the resistance and immunopathology of experimental Chagas'disease. I. Histopathological studies. Ann. Immunol. Inst. Pasteur, v.135, p.317-332,1984.

HADZIJAHIC, N.; RENEHAN, W.R.; MA, C.K.; ZHANG, X.; FOGEL, R. Myenteric plexus destruction alters morphology of rat intestine. Gastroenterology, v.105, p.10171028, 1993.

HANSEN, M.B.; NIELSEN, S.E.; Berg, K. Re-examination and further development of a precise and rapid dye method for measuring cell growth and kill. Journal of Immunology Methods, v.119, p.203-210, 1989.

HINSON, J.P.; RAVEN, P.W. DHEA deficiency syndrome: a new term for old age? The Journal of Endocrinology, v.163, p.1-5, 1999.

HOFT, D.F.; LYNCH, R.G.; KIRCHHOFF, L.V. Kinetic analysis of antigen-specific immune responses in resistant and susceptible mice during infection with Trypanosoma cruzi. Journal of Immunology, v.151, p.7038, 1993.

HÖLSCHER, C.; KÖHLER, G.; MÜLLER, U.; MOSSMANN, H.; SCHAUB, G.A.; BROMBACHER, F. Defective nitric oxide effector functions lead to extreme susceptibility of Trypanosoma cruzi-infected mice deficient in gamma interferon receptor or inducible nitric oxide synthase. Infection Immunology, v.66, p.1208-15, 1998. 
HUNTER, C.A.; SLIFER, T.; ARAUJO, F. Interleukin-12-mediated resistance to Trypanosoma cruzi is dependent on tumor necrosis factor and interferon. Infection Immunity, v.64, p.2381, 1996.

HUNTER, C.A.; ELLIS-NEYES, L.A.; SLIFER, T.; KANALY, S.; GRUNIG, G.; FORT, M.; RENNICK, D.; ARAUJO, F.G. IL-10 is required to prevent immune hyperactivity during infection with Trypanosoma cruzi. Journal of Immunology, v.158, p.3311-3316, 1997.

HRUBY, K.; ANZENBACHEROVA, E.; ANZENBACHER, P.; NOBILIS, M. Potential cancerostatic benfluron is metabolized by peroxidase:in vitro biotransformation of benfluron by horseradish peroxidase. Gen. Physiol. Biophys, v.16(4), p.321-7, 1997.

IWAKABE, K.; SHIMADA, M.; OHTA, A.; YAHATA, T.; OHMI, Y.; HABU, S.; NISHIMURA, T. The restraint stress drives a shift in Th1/Th2 balance toward Th2dominant immunity in mice. Immunol Lett, v. 62, p.39-43, 1998.

KHORRAM, O.; VU, L.; YEN, S.S. Activation of immune function by dehydroepiandrosterone (DHEA) in age-advanced men. J. Gerontol. A. Biol. Sci. Med. Sci, v.52(1), p.M1-7, 1997.

KIERSZENBAUM, F.; LOPEZ, H.M.; SZTEIN, M.B. Inhibition of Trypanosoma cruzispecific immune responses by a protein produced by $T$. cruzi in the course of Chagas' disease. Immunology, v.81, p.462-7, 1994.

KIOUKIA-FOUGIA, N.; ANTONIOU, K.; BEKRS, S.; LIAPI, C.; CHRISTOFIDIS, I.; PAPADOPOULOU-DAFOTI, Z. (2002) The effects of stress exposure on hypothalamicpituitary-adrenal axis, thymus, thyroid hormones and glucose levels. Prog Neuropharmacol Biol Psychiat, v.26, p.823-30, 2002. 
KIZAKI, T.; OH-ISHI, S.; OHNA, H. Acute cold stress induces suppressor macrophages in mice. J. Appl. Physiol, v.81, p.393-399, 1996.

KÖBERLE, F. Entoromegalia and cardiomegaly in Chagas Disease. Gut, v.41, p.399-405, 1963.

KÖBERLE, F. Chagas' disease and Chagas' syndromes: The pathology of American trypanosomiasis: Adv. Parasitol, v.6, p.63-116, 1968.

KOMORI, T.; FUJIWARA, R.; SHIZUYA, K.; MIYAHARA, S.; NOMURA, J. The influence of physical restraint or fasting on plaque-forming cell response in mice. Psychiatry Clin. Neurosci, v.50, p.295-298, 1996.

KRETTLI, A.U.; BRENER, Z. Protective effects of specific antibodies in Trypanosoma cruzi infection. Journal of Immunology, v.116, p.755-760, 1976.

KROBOTH, P.D.; SOLEK, F.S.; PITTENGER, A.L.; FABIAN, T.J.; FRYE, R.F. DHEA and DHEA-S: a review. J. Clin. Pharmacol, v.39(4), p.327-48, 1999.

KROBOTH, P.D.; AMICO, J.A.; STONE, R.A.; FOLAN, M.; FRYE, R.F.; KROBOTH, F.J.; BIGOS, K.L.; FABIAN, T.J.; LINARES, A.M.; POLLOCK, B.G.; HAKALA, C. Influence of DHEA administration on 24 hour cortisol concentrations. J. Clin. Psychopharmacol, v.23, p.96-9, 2003.

LABRIE, F.; BÉLANGER, A.; SIMARD, J.; VAN LUU-THE, LABRIE, C. DHEA and peripheral androgen and estrogen formation: intracinology. Annals of the New York Academy of Sciences, v.774, p.16-28, 1995.

LABRIE, F.; BÉLANGER, A.; LABRIE, C.; CANDAS, B.; CUSAN, L.; GOMEZ, J.L. Bioavailability and metabolism of oral and percutaneous dehydroepiandroterone in postmenopausal women. J. Steroid Biochem Mol Biol, v. 107, p.57-69, 2007.

LACHAT, J.J.; GONÇALVES, R.P. Influence of autonomic denervation upon the kinetics 
of the ileal epithelium of the rat. Cell. Tissue. Res, v.192, p.285-297, 1978.

LAMBERTS, S.W. Acromegaly and its treatment. Journal of Endocrinology, v.155, suppl 1: S49-51, 1997.

LAUCELLA, S.A.; POSTAN, M.; MARTIN, D. ; HUBBY FRALISH, B. ; ALBAREDA, M.C.; ALVAREZ, M.G.; LOCOCO, B.; BARBIERI, G.; VIOTTI, R.J.; TARLETON, R.L. Frequency of interferon-gamma-producing T cells specific for Trypanosoma cruzi inversely correlates with disease severity in chronic human Chagas disease. Journal Infection of Disease, v. 189, p.909-18, 2004.

LEITE-DE-MORAES, M.C.; HONTEBEYRIE-JOSKOWICZ, M.; DARDENNE, M.; SAVINO, W. Modulation of thymocyte subsets during acute and chronic phases of experimental Trypanosoma cruzi infection. Immunology, v.77, p.95-98,1992.

LI, T.; HARADA, M.; TAMADA, K.; ABE, K.; KOMOTO, K. Repeated restraint stress impairs the antitumor $\mathrm{T}$ cell response through its suppressive effect on Th1-type CD4+ T cells. Anticancer Research, v.17, p.4259-4268, 1997.

LYLE, D.T.; CUNNICK, J.E.; RABIN, B.S. Stressor-induced alteration of lymphocyte proliferation in mice: evidence for enhancement of mitogenic responsiveness. Annals of the New York Academy of Sciences, v.4, p.269-77, 1990.

LONGCOPE, C. Metabolism of dehydroepiandrosterone. Annals of the New York Academy of Sciences, v. 774, p.143-8, 1995.

LORIA, R.M.; PADGETT, D.A.; HUYNH, P.N. Regulation of the immune response by dehydroepiandrosterone and its metabolites. Journal of Endocrinology, v.150, p.209-220, 1996. 
LU, Z.W.; SONG, C.; RAVINDRAN, A.V.; MERALI, Z.; ANISMAN, H. Influence of a psychogenic and neurogenic stressor on several indices of immune function in different strains of mice. Brain Behav Immun, v.12, p.7-22, 1998.

MAIFRINO, L.B.; LIBERTI, E.A.; WATANABE, I.; DE-SOUZA, R.R. Morphometry and acetylcholinesterase activity of the myenteric neurons of the mouse colon in the chronic phase of experimental Trypanosoma cruzi infection. Am. J. Trop. Med. Hyg, v.60, p.721$5,1999$.

MANABE, A.; HATA, T.; YANAGIHARA, T.; HASHIMOTO, M.; YAMADA, Y.; IRIKOMO, S. Nitric oxide synthesis is increased after dehydroepiandrosterone sulfate administration in term human pregnancy. Hum. Reprod, v.8, p.2116-2119, 1999.

MARTINEZ-TABOADA, V.; BARTOLONE, M.J.; AMADO, J.A.; BLANCO, R.; GARCIA-UNZUETA， M.T.; RODRIGUES-VALVERDE， V.; LOPEZ-HOYOS， M. Changes in peripherical blood lymphocyte subsets in elderly subjects are associated with na impaired function of the lypothalamic-pituitary-adrenal axis. Mech. Aging. Dev, v.123(11), p.1477-86, 2002.

MARTINS, G.A.; VIEIRA, L.Q.; CUNHA, F.Q.; SILVA, J.S. Gamma interferon modulates CD95 (Faz) and CD95 ligand (Faz-L) expression and nitric oxide-induced apoptosis during the acute phase of Trypanosoma cruzi infection: a possible role in immune response control. Infection Immunity, p.3864-71, 1999.

McCABE, R.; MEAGHER, S.; MULLINS, B. Gamma interferon suppresses cute and chronic Trypanosoma cruzi infection in cyclosporin-treated mice. Infection Immunity, v.59, p.1633-,1991. 
McEWEN, B.S.; BIRON, C.A.; BRUNSON, K.W. The role of adrenocorticoids as modulators of immune function in health and disease: neural, endocrine and immune interactions. Brain. Res. Brain. Res. Rev, v.23, p.79-113,1997

McEWEN, B.S. Protective and damaging effects of stress mediators: allostasis and allostatic load. N. Engl. J. Med, v.338, p.171-179, 1998.

MECKERT, P.M.C.; CHAMBO, J.G.; LAGUENS, R.P. Modification of the pattern of infection and evolution of cardiopathy in experimental Chagas' disease after treatment with immunosuppressive and trypanocidal drugs. Medicina (Buenos Aires). v.48, p.7-11, 1988. MEIKLE, A.W.; DORCHUCK, R.W.; ARANEO, BA. The presence of a dehydroepiandrosterone-specific receptor binding complex in murine T cells. J. Steroid. Biochem. Mol. Biol, v.42, p.293-304, 1992.

MELO, R.C.; BRENER, Z. Tissue tropism of different Trypanosoma cruzi strains. Journal of Parasitology, v.64, n.3, p.475-82, 1978.

MERCADO, A.M.; QUAN, N.; PADGETT, D.A.; SHERIDAN, J.F.; MARUCHA, P.T. Restraint stress alters the expression of interleukin-1 and keratinocyte growth factor at the wound site: an in situ hybridization study. Journal of Neuroimmunology, v.129(1-2), p.74-83, 2002.

MEYER, T.N.; SILVA, A.L. Resposta cellular ao estresse. Revista da Associação Médica Brasileira, v.45, 1999.

MILLER, W.L. Androgen biosynthesis from cholesterol to DHEA. Mol. Cell Endocrinol, v.198, p.714, 2002.

MILLER, W.L. Disorders of Androgen Synthesis - from Cholesterol to Dehydroepiandrosterone. Med. Princ. Pract, v.14, p.58-68, 2005.

MONCADA, S.; PALMER, R.M.J.; HIGGS, E.A. Nitric Oxide: physiology, pathology and 
pharmacology of Nitric Oxide. Pharmacological Reviews, v.43, p.109-242, 1991.

MONCAYO, A.; ORTIZ YANINE, M.I. An update on Chagas disease (human American trypanosomiasis). Ann Trop Med Parasitol, v.100, p.663-677, 2006.

MORALES-MONTOR, J.; MOHAMED, F.; GHALEB, A.M.; BAIG, S.; HALLALCALLEROS, C.; DAMIAN, R.T. In vitro effects of hypothalamic-pituitary-adrenal axis (HPA) hormones on Schisyosoma mansoni. Journal of Parasitology, v.87(5), p.1132-9, 2001.

MORASKA, A.; CAMPISI, J.; NGUYEN, K.T.; MAIER, S.F.; WATKINS, L.R.; FLESHNER, M. Elevated IL-1 beta contributes to antibody suppression produced by stress. J. Appl. Physiol, v.93(1), p.207-15, 2002.

MORFIN, R.; LAFAVE, P.; COTILLON, A.C.; NATO, F.; CHMIELEWSKI, V.; POMPON, D. 7 alpha-hydroxy-dehydroepiandrosterone and immune response. Ann. N.Y. Acad. Sci, v.917, p.971-82, 2000.

MOSSMAN, T. Rapid colorimetric assay for cellular growth and survival: application to proliferation and cytotoxic assay. Journal of Immunology Methods, v.65, p.55-63, 1983.

NAGIB, P.R.; DUTRA, W.O.; CHIARI, E.; MACHADO, C.R. Trypanosoma cruzi: populations bearing opposite virulence induce differential expansion of circulating CD3+ CD4- CD8- T cells and cytokines serum levels in young and adults rats. Experimental Parsitology, v.116, p.366-74, 2007.

NESTLER, J.E.; CLORE, J.N.; BLACKARD, W.G. Dehydroepiandrosterone: the "missing link" between hyperinsulinemia and atherosclerosis. FASEB J, 3073-3075, 1992.

OBERBECK, R.; DAHLWEID, M.; KOCH, R.; VAN GRIENSVEN, M.; EMMENDÖRFER, A.; TSCHERNE, H.; PAPE, H.C. Dehydroepiandrosterone decreases 
mortality and improves cellular immune function during polymicrobial sepsis. Crit. Care. Med, v.29, p.380-384, 2001.

OKABE, T.; HAJI, M.; TAKAYANAGI, R.; ADACHI, M.; IMASAKI, K.; KURIMOTO, F.; WATANABE, T.; NAWATA, H. Up-regulation of high-affinity dehydroepiandrosterone binding activity by dehydroepiandrosterone in activated human T lymphocytes. J. Clin. Endocrinol. Metab, v.80(10), p.2993-6, 1995.

OKIMURA, T.; OGAWA, M.; YAMAUCHI, T.; SASAKI, Y. Stress and immune responses IV. Adrenal involvement in the alteration of antibody responses in restraintstressed mice. Jpn. J. Pharmacol, v.41, p.237-245, 1986.

OLIVEIRA, J.S.M. A natural humen model of intrinsic heart nervous system denervation: Chagas' cardiopathy. Am. Heart. J, v.110, p.1092-1098, 1985.

OLIVEIRA, J.S.M.; LLORACH-VELLUDO, M.A.S.; SALES-NETO, V.N. Megacolon in rats. Digestion, v.45, p.166-171, 1990.

OLIVEIRA, L.C.; BORGES, M.M.; LEAL, R.C.; ASSREUY, J.; KLOETZEL, J.K. Nitric oxide involvement in experimental Trypanosoma cruzi infection in Calomys callosus and Swiss mice. Parasitol Research, v.83, p.762-70, 1997.

OSWALD, I.P.; WYNN, T.A.; SHER, A.; JAMES, S.L. Interleukin 10 inhibits macrophage microbicidal activity by blocking the endogenous production of tumor necrosis factor alpha required as a costimulatory factor for interferon gamma-induced activation. Proc Natl Acad Sci USA, v.15, p.8676-8680, 1992.

POLLI-LOPES, A.C.; ZUCOLOTO, S.; CUNHA, F.Q.; FIGUEIREDO, L.A.S.; GARCIA, S.B. Myenteric devervation reduces the incidence of gastric tumors in rats. Cancer Lett, v.190, p.45-50, 2003.

PRATA, A. Chagas' disease. Infect. Dis. Clin. of North America, v.8, p.61-75, 1994. 
PRATA, A. Evolution of the clinical and epidemiological knowledge about Chagas disease 90 years after its discovery. Memória do Instituto Oswaldo Cruz, 1999, 4(Suppl)

PRATA, A. Clinical and epidemiological aspects of Chagas disease. Lancet, v.1, p.92-100, 2004.

RACHID, M.; MATAR, C.; DUARTE, J.; PERDIGON, G. Effect of milk fermented with a Lactobacillus helveticus $\mathrm{R} 389(+)$ proteolytic strain on the immune system and on the growth of $4 \mathrm{~T} 1$ breast cancer cells in mice. FEMS immunology and medical microbiology, v.47, p.242-53, 2006.

RADOMSKI, E.W., PALMER, R.M., MONCADA, S. Glucocorticoids inhibit the expression of na inducible, but not the constitutive, nitric oxide synthase in vascular endothelial cells. Med Sci, v.87, p.10043-7, 1990.

RAMIREZ, F.; SILVA, A. Glucocorticoids enhance concanavalin A-induced mitogenic response through the inhibition of nitric oxide production. Immunology, v.90, p.66-73, 1997.

RAMIREZ, J.R.; AGUDELO, S.; MUSKUS, C.; ALZATE, J.F.; BERBERICH, C.; BARKER, D.; VELEZ, I.D. Diagnosis of cutaneous leishmaniasis in Colombia: the sampling site within lesions influences the sensitivity of parasitologic diagnosis. J.Clin. Microbiol. v. 38, p.3768-3773, 2000.

RASMUSSEN, K.R.; HEALY, M.C.; CHENG, L.; YANG, S. Effects of dehydroepiandrosterone in immunosupressed adult mice infected with Cryptosporidium parvum. J. Parasitol, v.81, p.429-433, 1995.

REED, S.G.; BROWENELL, C.E.; RUSSO, D.M.; SILVA, J.S.; GRABSTEIN, K.H.; MORRISSEY, P.J. IL-10 mediates susceptibility to Trypanossoma cruzi infection. Journal of Immunology, v.7, p. 3135-40, 1994. 
REED, S.G. Cytokine control of the macrophage parasites Leishmania and Trypanosoma cruzi. In: Molecular approaches to Parasitology. New York: Wiley-Liss, Inc, p.443-445, 1995.

REGELSON, W.; LORIA, R.; KALIMI, M. Dehydroepiandrosterone (DHEA)-the "mother steroid”.I. Imunologic action. Ann. N.Y. Acad. Sci, v.719, p.553-63, 1994.

REZENDE, J.M.; MOREIRA, H. Forma digestiva da doença de Chagas. In: Brener Z, Andrade ZA, Barral-Neto Ml, eds. Trypanossoma cruzi e doença de Chagas, 2nd ed. Rio de Janeiro, Guanabara Koogan, p 297-343, 2000

REYES, P.; VALLEJO, M.; REYES, P. Trypanocidal drugs for late stage, symptomatic Chagas disease (Trypanosoma cruzi infection). Cochrane Database Syst Rev, Oct 19;(4):CD004102, 2005.

RIBEIRO DOS SANTOS, R.; MARQUES, J.O.; VON GAL, C.C.F.; OLIVEIRA, J.C.R.; MARTINS, A.R.; KÖBERLE, F. Antibodies against neurons in chronic Chagas' disease. Tropenmed Parasitol, v.30, p.19-23, 1979.

RIBEIRO, B.M.; CREMA, E.; RODRIGUES, V JR. Analysis of the cellular immune response in patients with the digestive and indeterminate forms of Chagas' disease. Human immunology, v.69, p.484-9, 2008.

ROPERT, C.; CLOSEL, M.; CHAVES, A.C.; GAZZINELLI, R.T. Inhibition of a p38/stress-activated protein kinase-2-dependent phosphatase restores function of IL-1 receptor-associate kinase-1 and reverses Toll-like receptor 2- and 4-dependent tolerance of macrophages. Journal of Immunology, v.171, p. 1456-65, 2003.

ROSSI, M.A.; BESTETTI, R.B. The challenge of chagasic cardiomyopathy. The pathologic roles of autonomic abnormalities, autoimmune mechanisms and microvascular changes, and therapeutic implications. Cardiology, v.86, p.1-7, 1995. 
ROTTENBERG, M.E.; BAKHIET, M.; OLSSON, T.; KRISTENSSON, K.; MAK, T.; WIGZELL, H.; ORN, A. Differential susceptibilities of mice genomically deleted of CD4 and CD8 to infections with Trypanosoma cruzi or Trypanosoma brucei. Infection Immunity, v.61, p.5129-5133. 1993.

ROTTENBERG, M.E.; SPORRONG, L.; PERSSON, I.; WIGZELL, H.; ORN, A. Cytokine gene expression during infection of mice lacking CD4 and/or CD8 with Trypanosoma cruzi. Scand. J. Immunol, v.41, p.164, 1995.

RUSSOMANDO, G.; DE TOMASSONE, M.M.; DE GUILLEN, I.; ACOSTA, N.; VERA, N.; ALMIRON, M.; CANDIA, N.; CALCENA, M.F.; FIGUEREDO, A. Treatment of congenital Chagas' disease diagnosed and followed up by the polymerase chain reaction. Am. J. Trop. Med. Hyg. V.59, p.487-491, 1998.

SACCO, M.; VALENTI, G.; CORVI MORA, P.; WU, F.C.; RAY, D.W. DHEA, a selective glucocorticoid receptor antagonist: its role in immune sydtem regulation and metabolism. J. Endocrinol Invest, 25(10suppl), p.81-2, 2002.

SAKATA, K.; KUNIEDA, T.; FURUTA, T.; SATO, A. Selective destruction of intestinal nervous elements by local application of benzalkonium solution in the rat. Experientia, v.35, p.1611-1612, 1979.

SALEK, F.S.; BIGOS, K.L.; KROBOTH, P.D. The influence of hormones and pharmaceutical agents on DHEA and DHEA-S concentrations: a review of clinical studies.

J. Clin. Pharmacol, v.42, p.247-266, 2002.

SANTELlO, F.H.; FRARE, E.O.; CAETANO, L.C.; ALONSO TOLDO, M.P.; DO PRADO JR, J.C. Melatonin enhaces pro-inflammatory cytokine levels and protects against Chagas disease. Journal of Pineal Research, v. 45, p.79-85, 2008a. 
SANTELlO, F.H.; FRARE, E.O.; DOS SANTOS, C.D.; CAETANO, L.C.; ALONSO TOLDO, M.P.; DO PRADO JR, J.C. Suppresive action of melatonin on the TH-2 immune response in rats infected with Trypanosoma cruzi. Journal of Pineal Research, v. 45, p.291-296, 2008b.

SANTER, R.M.; BAKER, D.M. Enteric neuron numbers and sizes in Aurebach's plexus in the small and large intestine of adult and aged rats. J. Auton. Nerv. Syst, v.25, p.59-67, 1988.

SANTORO, E. The history of gastric cancer: legends and chronicles. Gastric Cancer, v. 8, p. 71-74, 2005.

SANTOS, G.C.; ZUCOLOTO, S.; GARCIA, S.B. Endocrine cells in the denervated intestine. Int. J. Exp. Path, v.81, p.265-270, 2000.

SANTOS, P.V.; ROFFE, E.; H.C.; SANTIAGO, R.A.; TORRES, A.P.; MARINO, C.N.; PAIVA, A.A.; SILVA, R.; GAZZINELLI, T.; LANNES-VIEIRA, J. Prevalence of CD8 ${ }^{+}$ alpha/beta T cells in Trypanosoma cruzi-elicited myocarditis is associated with acquisition of CD62LLow LFA-1High VLA-4High activation phenotype and expression of IFNgamma inducible adhesion and chemoattractant molecules. Microbes Infection, v.3, p.971$984,2001$.

SANTOS, C.D.; CALDEIRA, J.C.; TOLDO, M.P.A.; PRADO, J.C. Trypanosoma cruzi: Effects of repetitive stress during the development of experimental infection. Experimental Parasitology, v.110, p.96-101, 2005.

SANTOS, C.D.; TOLDO, M.P.; LEVY, A.M.; KAWASSE, L.M.; ZUCOLOTO, S.; DO PRADO JR, J.C. Dehydroepiandrosterone affects Trypanosoma cruzi tissue parasite burdens n rats. Acta Tropica, v.102, p.143-150, 2007. 
SANTOS, C.D.; PRADO JR, J.C.; TOLDO, M.P.; LEVY, A.M.; FRANCI, C.R.; CALDEIRA, J.C. Trypanosoma cruzi: Plasma corticosterone after repetitive stress during the acute phase of infection. Experimental Parasitology, v.117, p.405-410, 2007.

SAPERSTEIN, A.; BRAND, H.; AUDHYA, T.; NABRISKI, D.; HUTCHINSON, B.; ROSENZWEIG, S.; HOLLANDER, C.S. Interleukin $1 \beta$ mediates stressinduced immunosuppression via corticotropin-releasing factor. Endocrinology, v.130, p.152-158, 1992.

SAPOLSKY, R.M. Why Zebras Don't Get Ulcers: A Guide to Stress, Stress-Related Diseases, and Coping. San Francisco, CA: Freeman, 1998.

SATO, A.; YAMAMOTO, M.; INAMURA, K.; KASHIKI, Y.; KUNIEDA, T.; SAKATA, K. Pathophysiology of aganglionic colon and anorectum: an experimental study on aganglionosis produced by a new meted in the rat. J. Pediatr. Surg, v.13, p.395-399, 1978. SAVINO, W.; VILLA-VERDE, D.M.; MENDES-DA-CRUZ, D.A.; MONTEIRO, E.S.; PEREZ, A.R.; AOKI, M.D.P.; BOTTASSO, O.; GUINÃZÚ, N.; SILVA-BARBOSA, S.D.; GEA, S. Cytokines and cell adhesion receptors in the regulation of immunity to Trypanosoma cruzi. Cytokine \& Growth Factor Reviews, v. 18, p.107-124, 2007.

SCHWARTZ, M.Z., STOROZUK, R.B. The influence of gastrin on gastrointestinal function. J. Pediatr Surg, v.21, p.1123-1127, 1986.

SCORZA, C.; SCORZA, J.V. Acute myocarditis in rats inoculated with Trypanosoma cruzi: study of animals sacrified between the fourth and twenty-ninth day after inoculation. Revista do Instituto de Medicina Tropical de São Paulo, v.14, p.171-77, 1972.

SIEGEL, S. Estatística não-paramétrica para as ciências do comportamento. São Paulo, McGraw-Hill do Brasil, 1975. 
SILVA, L.H.P.; NUSSENZWEIG, V. Sobre uma cepa de Trypanosoma cruzi altamente virulenta para o camundongo branco. Folha Clínica Biologia de São Paulo, v.20, p.191$201,1953$.

SILVA, J.S.; VESPA, G.N.; CARDOSO, M.A.; ALIBERTI, J.C.; CUNHA, F.Q. Tumor necrosis factor alpha mediates resistance to Trypanosoma cruzi infection in mice by inducing nitric oxide production in infected gamma interferon-activated macrophages. Infection and Immunity, v.63, p.4862-4867, 1995.

SILVA, J.S., ALIBERT, J.C.S., MARTINS, M.A., SOUTO, J.T., PADUA, M.A. The role of IL-12 in experimental Trypanosoma cruzi infection. Brazil J Med Biol Res, v.31, p.111-5, 2005.

SOBREIRA, L.F.R.; ZUCOLOTO, S.; GARCIA, S.B.; TRONCON, L.E.A. Effects of myenteric denervation on gastric epitjelial cells and gastric emptying. Digestive Disease and Science. v.47, p.2493-99, 2001.

SOGAYAR, R.; KIPNIS, T.L.; CURI, P.R. Acritical evaluation of the expression of parasitemia in experimental Chagas' disease. Revista do Instituto de Medicina Tropical de São Paulo, v.35(5), p.395-398, 1993.

SOLERTE, S.B.; FIORAVENTI, M.; VIGNATI, G.; GIUSTINA, A.; CRAVELLO, L.; FERRARI, E. Dehydroepiandrosterone sulfate enhances natural killer cell cytotoxicity in humans via locally generated immunoreactive insulin-like growth factor I. J. Clin. Endocrinol. Metab, v.84, p. 3260-3267, 1999.

SOMEKH, E.; DAGAN, R.; HANUKOGLU, A. The effect of endogenous dehydroepiandrosterone sulfate on antibody response to hepatitis B vaccine in neonates. Isr. Med. Assoc. J, v.3, p.200-202, 2000. 
SOUZA, E.M.; HENRIQUES-PONS, A.; BAILLY, C.; LANSIAUX, A.; ARAÚJO-

JORGE, T.V.; SOEIRO, M.N. In vitro measurement of enzymatic markers as a tool to detect mouse cardiomyocytes injury. Memória do Instituto Oswaldo Cruz, v.99, p. 697$701,2005$.

SPENCER, N.F.; NORTAN, S.D.; HARRISON, L.L.; LI, G.Z.; DAYNES, R.A. Dysregulation of IL-10 production with aging: possible linkage to the age associated decline in DHEA and its sulfated derivative. Experimetal Gerontology, v.31(3), p.393408, 1996.

SUN, J.; TARLETON, R.L. Predominance of CD8 + T lymphocytes in the inflammatory lesions of mice acute Trypanosoma cruzi infection. Ann. J. Trop. Med. Hyg, v.48(2), p.161-9, 1993.

SUNDERLAND, T.; MERRIL, C.R.; HARRINGTON, M.G. Reduced plasma dehidroepiandrosterone concentrations in Alzheimer's disease. Lancet, v.2, p.570, 1989.

SUZUKI, H.; MENEGAZZI, M.; DE PRATI, A.C.; OGURA, T.; ESUMI, H.; MATSUKAGE, A.; LIBONATI, M. Induction of DNA polymerase beta during proliferation of mitogen-stimulated human lymphocytes. Biochemical and biophysical research communications, v.181, P.623-8, 1991.

TALIAFERRO, W.H.; PIZZI, T. Connective tissue reactions in normal and immunized mice to a reticulotropic strain of Trypanosoma cruzi. Journal of Infection Disease, v.96, p.199-226, 1955.

TANNENBAUM, B.; TANNENBAUM, G.S.; SUDOM, K.; ANISMAN, H. Neurochemical and brhavioral alterations elicited by a chronic intermittent stressor regimen: implications for allostatic load. Brain. Re, v.953(1-2), p.82-92, 2002. 
TARLETON, R.L. Tumor necrosis factor (cachetin) production during experimental Chagas’ disease. Clinical and Experimental Immunology, v.73, p. 186-190, 1988.

TARLETON, R.L.; KOLLER, B.H.; LATOUR, A.; POSTAN, M. Susceptibility of $\beta_{2^{-}}$ microglobulin-deficient mice to Trypanosoma cruzi infection. Nature, v.356, p.338340,1992 .

TARLETON, R.L.; GRUSBY, M.J.; POSTAN, M.; GLIMCHER, L.H. Trypanosoma cruzi infection in MHC-deficient mice: further evidence for the role of both class I- and class IIrestricted T cells in immune resistance and disease. Int. Immunol, v.8, p.13-22, 1996.

TARLETON, R.L.; GRUSBY, M.J.; ZHANG, L. Increased susceptibility of Stat4-deficient and enhanced resistance in Stat6-deficient mice to infection with Trypanosoma cruzi. Journal of Immunology, v.165, p.1520, 2000.

TEIXEIRA, M.A.; MEYER, M.A.; COSTA, M.C.; PAIM, J.S.; DA SILVA, L.M. [Mortality due to infectious and parasitic diseases in Salvador, Bahia: evolution and intraurban differences according to living conditions]. Revista da Sociedade Brasileira de Medicina Tropical, v.35, p.491-7, 2002.

TERENZI, F.; DIAZ-GUERRA, M.J.; CASADO, M.; HORTELANO, S.; LEONI, S.; BOSCA, L. Bacterial lipopeptides induce nitric oxide synthase and promote apoptosis through nitric oxide -independent pathways in rat macrophages. J. Biochem, v.270(11), p.6017-21, 1995.

THOMSON, L.; GADELHA, F.R.; PELUFFO, G.; VERCESI, A.E.; RADI, R. Peroxynitrite affects Ca2+ transport in Trypanosoma cruzi. Mol Biochem Parasitol, v.98, p.81-91, 1999. 
TORRICO, F.; HEREMANS, H.; RIVIERA, M.T.; VAN MARCK, E.; BILLIAU, A.; CARLIER, Y. Endogenous IFN-gamma is required for resistance to acute Trypanosoma cruzi infection in mice. Journal of Immunology, v. 146, p.3626-32, 1991.

TOSTES JR, S.; LOPES, E.R.; PEREIRA, F.E.; CHAPADEIRO, E. Miocardiopatia chagásica crônica humana: estudo quantitativo de linfócitos CD4+ e CD8+ nos exsudatos inflamatórios. Revista da Sociedade Brasileira de Medicina Tropical, v.7, p.127, 1994. TRISCHMANN, T.M. Role of celular immunity in protection against Trypanosoma cruzi in mice. Parasite Immunology, v.6, p.561-570, 1984.

TSENG, L.H.; WANG, A.C.; LIN, Y.H.; LI, S.J.; KO, Y.J. Randomized comparison of the suprapubic arc sling procedure vs tension-free vaginal taping for stress incontinent women. International urogynecology journal and pelvic floor dysfunction, v.16, P. 230-5, 2005. UYEMURA, S.A.; ALBUQUERQUE, S.; CURTI, C. Energetics of Heart Mitochondria during Acute Phase of Trypanosoma cruzi Infection in Rats. Inst. J. Biochem. Cell. Biol, v.27, n.11, p.1183-9, 1995.

VESPA, G.N.; CUNHA, F.Q.; SILVA, J.S. Nitric oxide is involved in control of Trypanosoma cruzi induced parsitemia and directly kills the parasite in vitro. Infection and Immunity, v.62, p.5177-5182, 1994.

WORLD HEALTH ORGANIZATION (2003). Report of the Expert Commitee on the Control of Chagas Disease. Technical Report Series n 811. Geneva: WHO.

WU, W.; YAMAURA, T.; MURAKAMI, K.; MURATA, J.; MATSUMOTO, K.; WATANABE, H.; SAIKI, I. Social isolation stress enhanced liver metastasis of murine colon 26-L5 carcinoma cells by suppressing immune responses in mice. Life Science, v. 66, p.1827-1838, 2000. 
WU, S.; RUAN, Y.; YIN, M.; LAI, W. Research on the age-related changes in the nitric oxide pathway in the arteries of rats and the intervention effect of dehydroepiandroeterone. Gerontology, v.53, p.234-237, 2007.

WURTMAN, R.J. Stress and the adrenocortical control of epinephrine synthesis. Metabolism, v.51(6suppl 1), p.11-4, 2002.

YANG, E.V.; GLASER, R. Stress-induced immunomodulation: Impact on immune defenses against infectious disease. Biomed Pharmacother, v.54, p.245-250, 2000.

YOUNG, D.G.; SKIBINSKI, G.; SKIBINSKA, A.; MASON, J.I.; JAME, K. Preliminary studies on the effect of dehydroepiandrosterone (DHEA) on both constitutive and phytohaemagglutinin (PHA)-inducible IL-6 and IL-2 mRNA expression and cytokine production in human spleen mononuclear cell suspensions in vitro. Clinical Experimental Immunology, v.123, p.28-35, 2001.

ZHANG, L.; TARLETON, R.L. Persistent production of inflammatory and antiinflammatory cytokines and associated MHC and adhesion molecule expression at the site of infection and disease in experimental Trypanosoma cruzi infections. Experimental. Parasitology, v.84, p.203,1996.

ZHANG, L.; TARLETON, R.L. Characterization of cytokine production in murine Trypanosoma cruzi infection by in situ immunocytochemistry: lack of association between susceptibility and type 2 cytokine production. Eur. J. Immunol, v.26, p.102, 1996 a. ZHANG, Z.; ARAGHI-NIKNAM, M.; LIANG, B.; INSERRA, P.; ARDESTANI, S.K.; JIANG, S.; CHOW, S.; WATSON, R.R. Prevention of immune dysfunction and vitamin E loss by dehydroepiandrosterone and melatonin supplementation during murine retrovirus infection. Immunology, v.96, p.291-297, 1999. 
ZWILlING, B.S.; DINKINS, M.; CHRISTNER, R.; FARIS, M.; GRIFFIN, A.; HILBURGER, M.; McPEEK, M.; PEARL, D. Restraint stress-induced suppression of major histocompatibility complex class II expression by murine peritoneal macrophages. Journal of Neuroimmunology, v.29, p.125-130, 1990.

ZWILLING, B.S.; BROWN, D.H.; PEARL, D. Induction of major histocompatibility complex class II glycoproteins by interferon- $\gamma$ : Attenuation of the effects of restraint stress. Journal of Neuroimmunology, v.37, p.115-122, 1992.

ZUCOLOTO, S.; DIAZ, J.A.; OLIVEIRA, J.S.; MUCCILO, G.; SALES NETO, V.N.; KAJIWARA, J.K. Effect of chemical ablation of myenteric neurones on intestinal cell proliferation. Cell. Tissue. Kinet, v.21, p.213-9, 1988.

ZUCOLOTO, S.; DE DEUS, D.A.; MARTINS, A.A.; MUGLIA, V.F.; KAJIWARA, J.K.; GARCIA, S.B. The relationship between myenteric neuronal denervation, smooth muscle thickening and epithelial cell proliferation in the rat colon. Res. Exp. Med.(Berl), v.197, p.117-24, 1997. 